
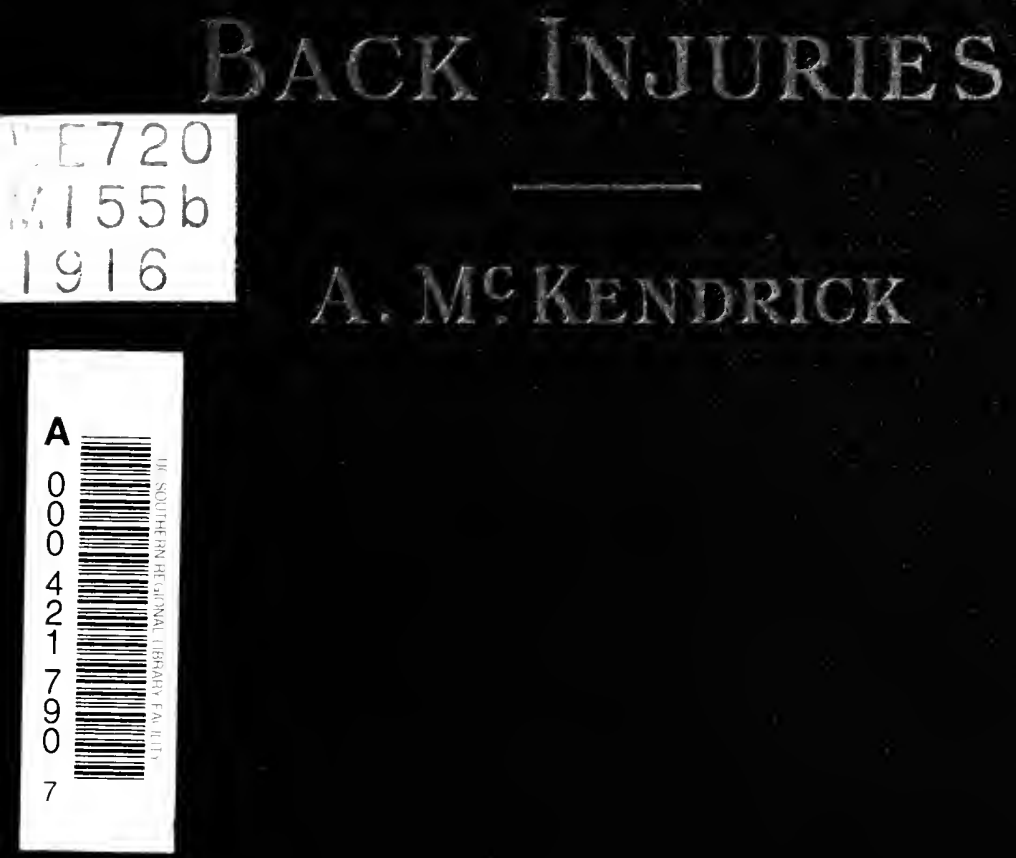


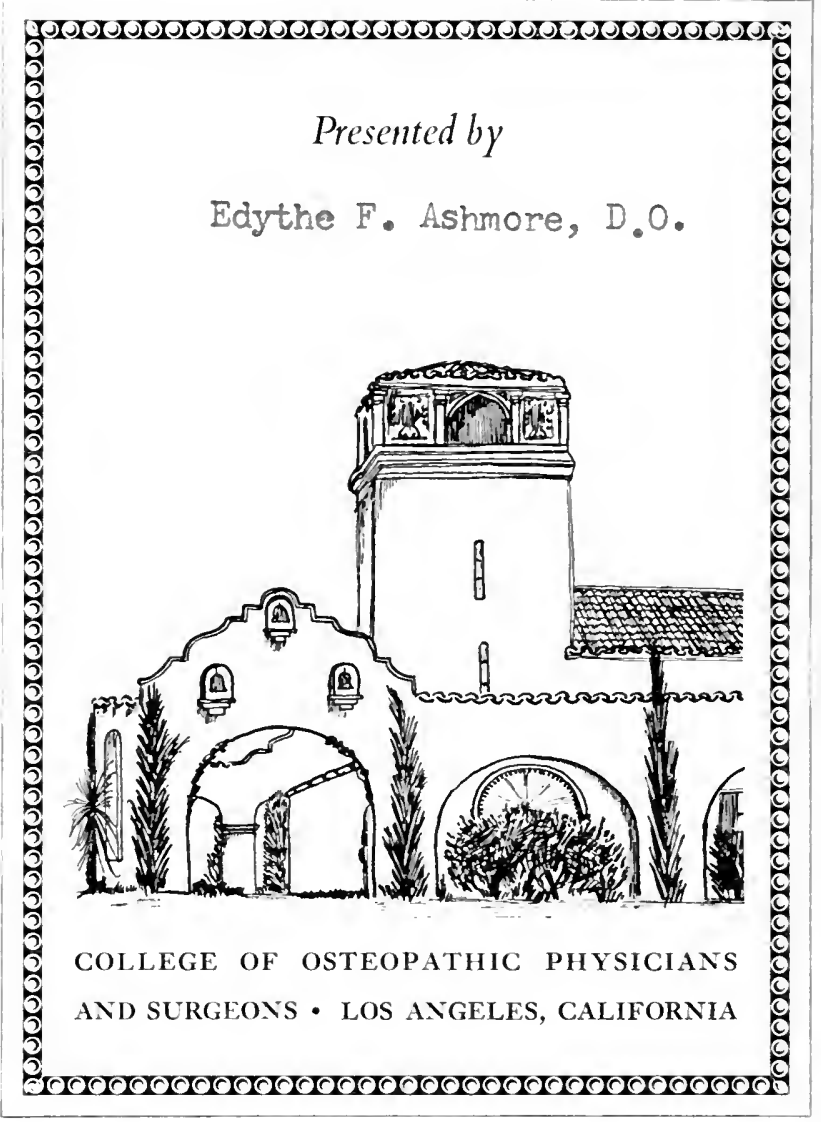


DI Edy he Aohmore

fuly, 1916.

rom M. r. H. 
Digitized by the Internet Archive in 2007 with funding from Microsoft Corporation 


\section{BACK INJURIES}





\section{BACK INJURIES ‥7}

AND 'THEIR SIGNIFICANCE

UNDER THE

WORKMEX'S COMPENSATION AND OTHER ACIS

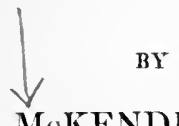

ARCHIBALD MoKENDRICK, F.R.C.S.E., \&r.

SURGEON IN CHARGE OF SURGICAL X-RAY DEPARTMENT, ROYAL INFIRMARY, EDINBURGH

\section{EDINBURGH}

F. \& S. Livingstone, 15-17 'Teviot Place 
WE 720

$M 155 \mathrm{~b}$

$19 / 6$ 


\section{PREFACE}

DBACK injuries have a bad reputation.

The workman looks upon them with apprehension, the insurance company with doubt, the

Note.-The Publishers beg to acknowledge their obligations to Messrs. W. \& A. K. Johxstox for kind permission to reproduce Figures 1, 2, and 3 from Cathcart and Caird's Atlas of the Bones and Ligaments.

enter on a long contest.

The medical examiner is faced with the diffieulty of estimating the true value of the subjective symptoms in the comparative absence of physical signs. His suspicion is born of the frequent disparity between these two. The degree of his suspicion will probably vary with the locality of his practice, for it is the writer's experience that in mining villages the workman

\section{$-22597$}


is longer off work after a baek injury, and is more likely to lapse into a. neurasthenie state than is the case in large industrial centres.

The lawyers are puzzled by the conflicting and often contradictory reports of the surgeons, and suffer from the lack of authoritative opinions in medieal literature.

This little book is offered to the medical and legal professions as an honest attempt to throw some light into the existing darkness, and to suggest some practical methods of testing. the genuineness or otherwise of the complaints made. $\mathrm{As}$ it is in the minor rather than the major injuries that difficulty as to diagnosis and doubt as to treatment chiefly arise, more attention has been devoted to the eommon and everyday cases than to the rarer and more severe forms of injury.

ARCHIBALD MCKENDRICK.

2 Coates Place,

Edinburgh, 1916. 


\section{CON'TENTS}

Structure of the Spinal Column-VertebreBodies - Intervertebral Dises - Neural Arches - Processes - Spinal Column as a Whole-Strength of the Spinal Column . 1-12

Muscles of the Spine-Fascie of the BackMnscular Tissne in General-Strain of Muscle-Contusion of Muscle-Healing of Muscle-Surface Anatomy . . . 13-47

Examination-History-Complaint-Pain and Tenderness - Strain - Mechanical Hindrance-Toxic Factors-Pain in Ligament-

Pain in Bone-Stiffness-Weakness-Inspection-Palpation . . . . 48-103

Movemerits and Measurements-X-ray Examination - Screen Examination - Electrical Testing-Physics of Back Injuries-Points of Weakness-Dynamics-Extrinsic Violence-Intrinsic Violence . . . 104-160 APPENDIX . . . . . . . 161-168 INDEX . . . . . . . . 169-173 


\section{LIST OF ILLUSTRATIONS}

FIG.

P'AGE:

1. Vertebra in different segments of the spinal column . . . . . Facing 8

2. Lateral view of the spinal column showing line of gravity . . . . . . , , 8

3. Anterior view of the spinal column a , " 9

4. Diagram showing constrictions in thick$\begin{array}{llllll}\text { ness of spinal column } & \text {. } & \text {. } & \text {. } & 9\end{array}$

5. Showing supine position; note angle of pelvis line. . . . . . . . 16

6. Showing back partially raised; purely spinal movement . . . . . . " , 16

7. Showing further elevation; hip joints coming into play . . . . . . , 16

8. Showing right angular position . . " , 16

9. Showing measurement of spine in upright position . . . . . . . . . , , 108

10. Showing same after bending forward . " 108

11. Showing parallel lines drawn at various levels; upright position . . . . , 109

12. Showing same after lateral flexion of

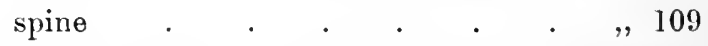

13. Discharge curves of condensers in electrical



14. Frequency of fractures in different regions of the spine $\quad$ viii $\quad \cdot \quad$. 


\section{BACK INJURIES}

\section{S'IRUC'IURE OF THE SPINAL COLUMN}

\section{THE SPINAL COLUMN}

SPINE.-The spine, vertebral column, or backbone may be looked upon as a flexible pedestal whose base is the pelvis, and on whose apex the head is supported. It forms the only connection between the upper and lower segments of the body, and acts as a bony tunnel for the reception of the spinal cord. The cord does not become pressed upon during movements of the spine, because the range of movement between the individual vertebræ is slight, and because the cord does not completely fill the neural canal. The individual vertebre comprising the spine differ slightly in the various regions of the spine, but the general characters of a vertebra are as follows (see Fig. 1):

Each vertebra is composed of two essential parts, a body in front and a neural arch behind. 
The body of the vertebra is of the best possible shape and strueture for the performanee of its functions of supporting weight, and resisting any "jar" to which it may be subjected. The neural areh, as the name implies, forms the bony protection for the spinal cord.

Bodies.-The bodies of the vertebræ are composed of spongy bone. They are more or less oval in shape, flattened from above downwards, and narrower in the middle than at the edges. The internal arehitectural arrangement of the lamelle of bone comprising the body of the rertebra is such that the principal lamella lie in a plane parallel to that of the lines of greatest stress. The upper and lower surfaces are slightly coneave for the reception of the intervertebral discs, and roughened at the edges for the attachment of ligaments. So rough are these edges that they form a prominent, strong, and roughened ring around the eircumference. This forms a secure bed for the dises.

Interyertebral Discs.-These are like pieces of india-rubber situated between the bodies of the individual vertebre. They act as shock absorbers or buffer's, and at the same time permit of movement between the vertebræ. In fact, all the movements of the spinal eolumn occur through the medium of this rubber-like substance. The so-called joints between the bodies of the vertebre 
are not like most other joints of the body, in which a sliding movement of the joint surfaces occurs. In the intervertebral joints, movement is only permitted to the extent of the flexibility of the rubber-like intervertebral discs. This is a mechanically perfect arrangement, and the structure of the discs themselves is no less so.

A disc is composed of fibro-cartilage at its periphery, and a soft pulpy substance in the centre. The fibrous tissue and fibro-cartilage are arranged in concentric rings. These rings are not absolutely cylindrical, nor are they exactly at right angles to the adjacent vertebræ, but are bulged out from the pulpy mass in the centre. This pulpy mass is really under pressure. It will be seen that the structure of the discs is admirably adapted to minimise "jarring" of the vertebræ, and at the same time to allow a degree of relative sliding movement between them. It will be seen that sprain of such a joint would be an unlikely injury. The so-called sprain of spinal joints is most frequently met with in the cervical and in the lumbar regions of the spine, where the discs are thickest, and the movement therefore most free. It stands to reason, that any sprain which might occur would damage the inelastic or unyielding fibrous tissue in the vicinity of the joints. Such a lesion would therefore extend over several spinal joints. 
Neural Arches.-Each neural arch springs from its corresponding body by two legs or pedicles. These are short flattened bony processes, and with two other flattened bony processes go to complete the arch. At the junction of the pedicles and laminæ the articular processes are situated for articulation with the vertebra above and below. At the junction of the lamine is situated the spinous process, a rough thickened process of bone which affords attachment for muscles and ligaments. It is the free extremities of these spinous processes which can be seen and felt in the middle line of the back.

Each neural arch is joined to the arch of the vertebra above and below it by ligaments (ligamenta subflava), and so a hollow cylinder or tunnel is formed for the transmission of the spinal cord. These ligamenta subflava are not of unyielding fibrous tissue like the ligaments about an ordinary joint, but are composed of yellow elastic tissue. The mechanical arrangement of the neural arches and their ligamenta subflava is therefore beautifully adapted for allowing movement of the spine, and at the same time protecting the enclosed spinal cord.

The articular processes, which spring from about the junction of the pedicles and laminæ, serve the double purpose of allowing movement and at the same time interlocking the bones. 
The spinous processes, already mentioned as springing from the junction of the laminæ, are directed backwards, and their tips can be felt just beneath the skin. Direct violence applied to the back may be transmitted through the spinous process to the neural arch, and so fracture the arch.

\section{Spinal Column as a Whole}

If the bones comprising the spine be taken and divested of all ligaments and intervertebral discs, and then articulated together, a curved chain of bones with its convexity directed backwards will be the result. At birth, the spinal column is more or less of this shape, but as age advances, and the child begins to hold up its head, the intervertebral discs grow in such a manner that a curve is developed in the cervical region with its convexity directed forwards. As the child sits up and begins to walk, a curve is developed in the same way in the lumbar region of the spine, with its convexity forwards. The movements of the spine, occurring as they do through the medium of the intervertebral discs, are naturally most free in the cervical and lumbar regions. The intervertebral discs in the dorsal region do not alter the curve of this region, and so this is called a fixed curve. It is really more or less 
fixed so far as antero-posterior movement is concerned, but this will be discussed later on.

After adult life, and as age advances, the intervertebral discs gradually become more and more fibrous and tend to disappear. The spine gradually loses its lumbar curve, and to some extent its cervical curve; in fact, it goes back to the original condition of one big curve with its convexity backwards. The centre of gravity being thus altered, the old man must stand with his knees and hips bent, in order to maintain his balance. So great may this curvature of old age become, that, in order to maintain the balance, two walking-sticks must be used to support the upper part of the body. In rheumatoid affections of the spine, and after a compression fracture in the lumbar region of the spine, a similar condition obtains in a minor degree.

In the lateral view of the spine (Fig. 2), these eurves are well seen. It will be seen that forward bending of the spine will have the effect of compressing the anterior portions of the intervertebral discs and relaxing their posterior portions.

The presence of the curves adds to the resiliency of the spinal column. In other words, if the spine were straight, and the vertebre were not separated from one another by intervertebral discs, the "jar" from every step would be transmitted directly to the head. 


\section{SPINAL COLUMN AS A WHOLE 7}

The anterior view of the spinal column (Fig. 3) shows the relative size of the individual vertebre. It will be noticed that the base of the pedestal, where it rests on the sacrum, is the broadest part. It gradually becomes narrower till a little above the mid-dorsal region is reached. From here it gradually broadens out till the seventh cervical is reached. It then becomes narrower up to the first, cervical vertebra. In the mid-dorsal region, where the spine is narrow, very little movement is possible, and the vertebre do not require the same strength as elsewhere, because of the support of the ribs. (See Diagram, Fig. 4.)

The movements of the spine are very complicated, and must be studied from two points of view. One, the clinical point of view, as enabling us to measure the amount of movement possible in a patient's back (page 104 et seq.), and the other from the anatomical or rather mechanical point of view, as enabling us to foretell the likely nature of the lesion produced by different kinds of violence applied to the back-in other words, the relative strength of the back at its various levels. This in turn leads us to a study of the strength of the bones themselves, but for our purpose a study of the resistance of the spinal column to different kinds of violence will suffice. 


\section{Strength of the Spinal Column}

The movable portion of the spine extends from the pelvis to the head. It is situated in the middle line of the back, where the spinous processes can be felt just beneath the skin. Meehanically, the architecture of the spine is perfect, combining as it does the greatest possible strength and mobility compatible with lightness.

The strength of the spine is its ability to withstand violence applied to it, so that in studying this branch of anatomy, we must have, not only a knowledge of the structure of the spine, but of the different forms of violence to which it may be subjected. This is fully discussed on page 139 et seq.

The bony processes projecting from the spinal column have what might be called an extrinsic value in strengthening the column as a whole. The spinous and transverse processes are the means whereby the column is anchored in position as a whole by the surrounding muscles, and a means whereby the individual vertebre are held together by ligaments. The articular processes guide the normal movements of one vertebra on another, and in virtue of the ligaments surrounding these articulations (capsular ligaments), they restrict the range of such movements. The articular facets are situated about the junction of the 

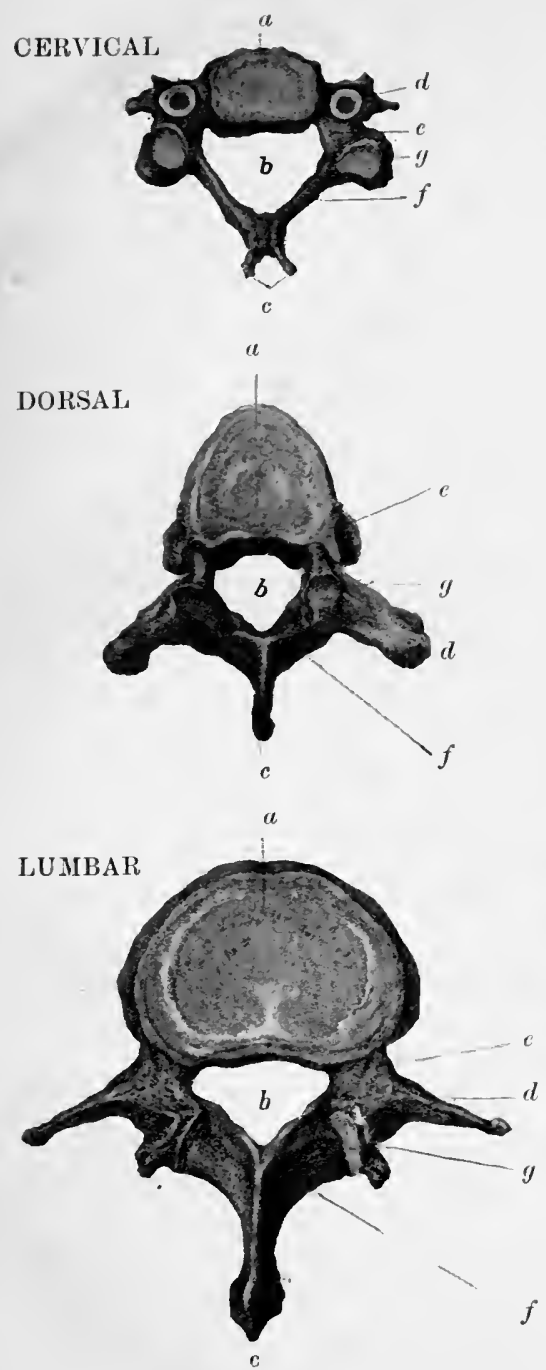

FIG. 1.-Vertebra in different segments of Spinal Column.

$a=$ Pody. $\quad d=$ Transverze process.

$b=$ Teural canal. $\quad e=$ Pedicle.

$c=$ Spinous process. $f=$ Lamina. $g=$ Superior articular facets.

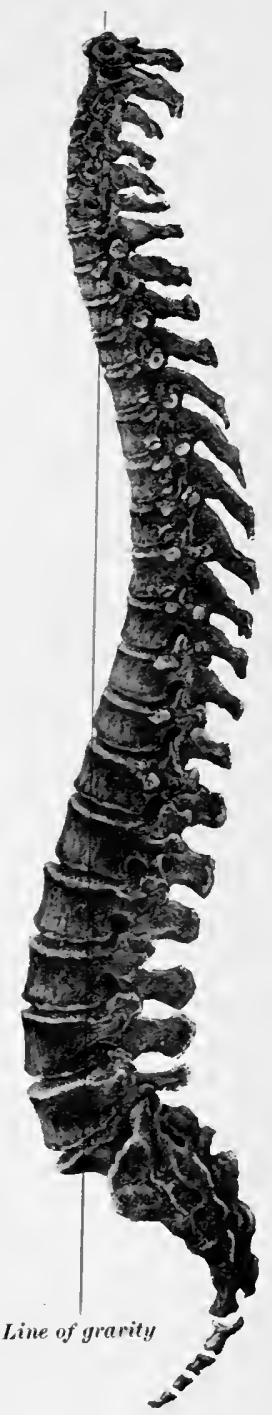

F1G. 2. - Lateral view of Spinal Column showing line of gravity. 


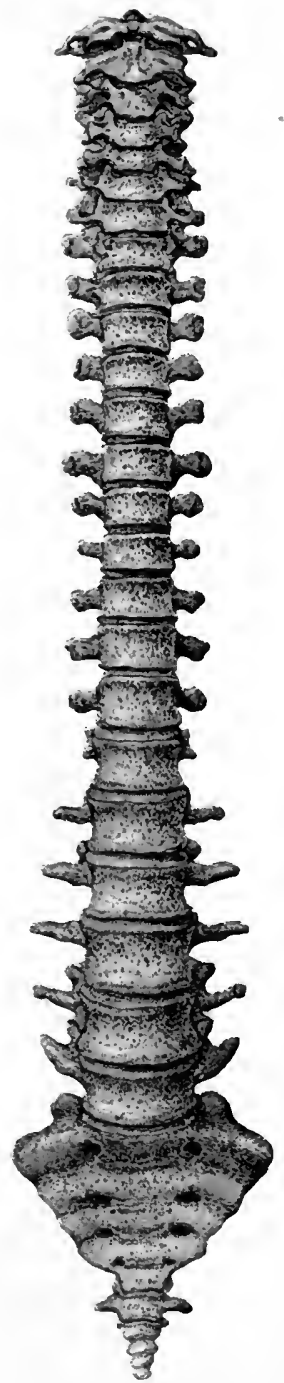

Fig. 3.-Anterior view of Spinal Column.

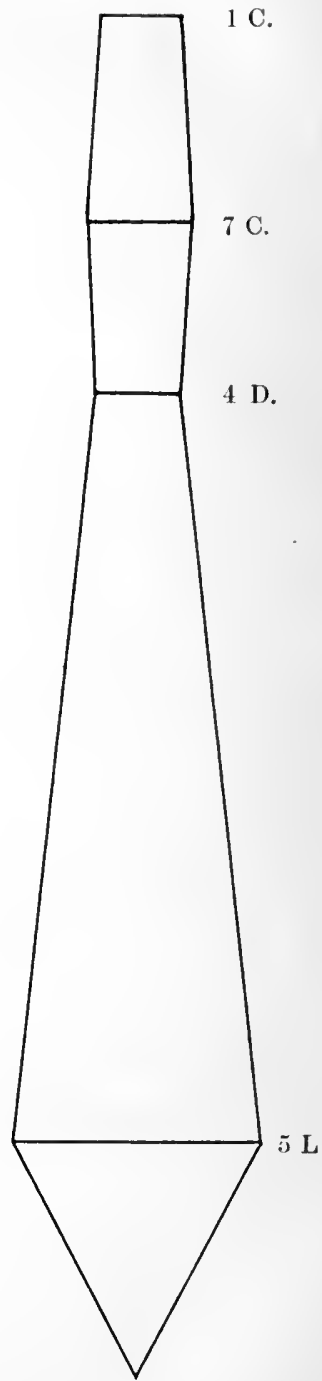

Fic. 4.-Diagram showing constrictions in thickness of Spinal Column. 
pedicles with the laminæ, and are four in number on each vertebra, two superior and two inferior. With the exception of the first and second cervical vertebre the superior facets all look more or less backwards, while the inferior all look correspondingly forwards. It will be seen that the spine as a whole is, therefore, more able to resist violence applied from behind. That is to say, any vertebra may be displaced baekwards on the vertebra below it, but before it can be displaced forwards, one or both of the articular processes must be broken or the joints dislocated. The articular processes, therefore, add considerably to the strength of the spine against by far the commonest direction of impressed foree.

In the cervical region, the upper articular facets are directed more upwards than backwards. This arrangement allows of greater rotation of the cervical vertebrie, but on the other hand it makes it easier for a dislocation forwards to occur, even without a fracture of the articular processes themselves. In order to produee such a dislocation, the cervical spine must be subjected to a form of violence which would forcibly bend it beyond due limits before the rest of the spine could be bent. Such a combination of eireumstances would obtain, for example, where forcible overbending occurred, and where the line of the violence fell in a plane posterior to the lumbar vertebræ. 
The writer has recently seen three cases of dislocation of the cervical region of the spine, and in no case were there any symptoms to indicate that the spinal cord had been damaged. In all three cases the dislocation occurred between the second and third cervical vertebræ. In two of these cases the injury was produced by a sack of grain falling on to the back of the head while the person was standing with the head bent forwards. The other case was peculiar in so far as the dislocation occurred in a most natural way. The patient was standing, and a friend tapped him on the shoulder from behind. He suddenly turned round his head to see his friend, and it has been ever since fixed in its dislocated position. The $\mathrm{X}$-ray examination in each case showed the dislocation, but did not reveal any fracture of the articular processes.

It is easy to see how it is possible for a pure dislocation to occur here, although it is generally taught that dislocation without fracture is impossible. The articular facets of the two vertebræ in this region are opposed to one another, just as two coins might lie one on the top of the other. In the normal position of the cervical region, the facets are flat together, with their edges coinciding. As the neck is bent, the facets slide over one another, so that there is less of their surfaces in contact. $\Lambda$ point is reached wherc the capsular 
ligaments which extend between the circumferences of the facets are overstretched. Usually the violence is not absolutely in the anteroposterior plane, and if the violence continues to act, the capsular ligament gives way on one side, and the facets slide past one another just as two coins might do.

There are several reasons why the articulations between the second and third cervical vertebre should be the commonest site of dislocation in the neck. (1) The intervertebral disc is shallower than any of the other cervical discs. (2) The movements in the upper cervical region are peculiar. Between the skull and the first cervical vertebra flexion and extension are the principal movements; between the first and second, rotation only occurs; between the second and third, the movement is limited in all directions; between all the other cervical joints, movement is free in all directions. (3) The forward flexion between the second and third is checked by the long projecting anterior lip of the inferior surface of the second cervical vertebra. It should be noted that when the neck is moved in any but an absolutely antero-posterior direction, the articular surfaces slide on one another in an oblique fashion. The upper facet on one side goes upwards and forwards, while the upper facet on the other goes downwards and backwards. Very. Cittle? 
It will be shown that any object is mechanically weak if it contains the junction of an inelastic with an elastic portion. There are three such junctions in the spinal column. (1) The freely movable cervical region with the much less movable dorsal region (see page 135); (2) the freely movable lumbar region with the dorsal; (3) the movable lumbar with the sacrum.

\section{Muscles of the Spine}

It must be borne in mind that, however complicated in their harmonious action, the muscles moving the spinal column bchave exactly like muscles elsewhere in the body, viz. as an elastic band stretched between origin and insertion.

That is to say, all muscles in front of the spine, when they contract, produce forward bending of the spine. All muscles behind the spine raise it from the bent position. Muscles on either side of the spine pull the spine over to their own side when acting separately; when acting together, they serve to steady the spine. Rotation of the spine is effected by the harmonious action of some or all of the foregoing muscles, aided by a complicated set of muscles, the musculi rotatores.

The minute attachments of all these muscles are given in any anatomical text-book. What 
concerns us most in the study of back injuries, is their actions and the forms of violence which can "strain" any one or any set of them.

A list of the muscles, grouped according to their actions, will be found on page 15 et seq.

The function of muscle is to perform mechanical work. If there happens "to be a disproportion between the work to be done and the power to do it, excessive stress of muscle will be the result. This may result in strain. The power exerted may be too great for the work to be done, or the power may not be sufficient to do the work it is called on to perform. That is to say, excessive energy may be exerted in performing a light action, as in a missed shot at golf, or when a person is lifting a heavy weight on the end of a rope, and the rope breaks unexpectedly. On the other hand, a person may over-exert himself in lifting a very heavy weight. The incidence of strain is different in either case.

Muscles which have the same action have the same nerve supply. Thus a group of muscles can act harmoniously together, to produce bending of a joint. When a group of flexor muscles act together to bend a joint, the extensor group on the other side of the joint are also in action. This may not be an accurate physiological statement, but it is borne out clinically, because in any case where there is 
paralysis of extensors, as in the wrist, the power of grasping is very weak.

Physiologically, the muscles are all in a state of "tone" unless during unconsciousness. When a message is sent along the nerve supplying a certain group of, say, flexors, to produce contraction of these, a message is simultaneously sent to the opposing group of extensors inhibiting their action. There is some imperfection in the mechanism somewhere, because when any forcible movement is stopped, the reaction is always greater than the action itself.

This can be well demonstrated by sharply flexing the elbow and attempting to stop the movement suddenly just before the hand touches the chest. The flexors (which are supplied by a certain nerve) cease to act at the end of the movement, and the extensors (which are supplied by a different nerve) are suddenly called into play. The strength of the nerve impulse should be just sufficient to overcome the momentum of the forearm. The impulse, however, is apparently too strong, because, instead of the hand coming to a dead stop, it is withdrawn from the chest, and the flexors again draw it back, perhaps to a standstill, or there may be several to and fro movements before rest is attained. (It should be pointed out that a single muscle is practically never used in the produc- 
tion of even the simplest movement of any joint, but that groups of muscles act together.)

In examination of cases of alleged strain of muscle, one must bear in mind the fact that, if a certain group of muscles is being used to lift a weight, or otherwise to overcome resistance, and the resistance is suddenly and unexpectedly removed, the result will probably be that the opposing group of muscles will be strained from the sudden and excessive call into action (disproportion between the work to be done and the power to do it).

The part of the back subjected to the heaviest stress is the lumbar region. This, in common language, is the part of the back which bends. The dorsal region does not bend, and is therefore seldom strained. The muscles are, therefore, better developed and more massive in the lumbar region than elsewhere about the spinal column.

The Flexors.-Flexion of the spine is produced by the contraction of pairs of muscles which are situated in front of the spine. These pairs of muscles are:-Rectus Abdominis, Sternohyoid, Sterno-thyroid, Thyro-hyoid, Mylo-hyoid, Digastric, Sterno-mastoid, External Oblique, Internal Oblique, Intercostals, Scalenus Anterior, Psoas Magnus, Psoas Parvus, Longus Colli, Longus Capitis (Rectus Capitis Anticus Major).

The flexors of the spine are practically never 
strained unless as the result of sudden removal of the resistance in lifting weights. These muscles all act simultaneously and successively in raising the body from the recumbent position.

If a person be lying flat on the back and make the attempt to rise to the sitting posture, the pelvis is first fixed by the action of the thigh muscles, the spine from the pelvis to the shoulders is fixed by the abdominal muscles, intercostals, and by the museles about the spine. In the ordinary movement, the head is lifted first from the ground by the action of all the different pairs of muscles in front of the neck. The dorsal spine is then raised almost en masse by the rectus abdominis and the obliquus muscles, the intercostals keeping the chest wall more or less fixed. The normal lumbar curve has disappeared, and the whole lumbar region, which previously was arched, may now be lying flat on the ground. The rectus and the oblique muscles continue to act, and fully flex the lumbar spine. The psoas muscles (which, it should be noted, have their main attachments to the intervertebral discs), along with the muscles in front of the thighs, tilt the pelvis round the axis of the hip joints, till the sitting posture is reached. The lumbar curve now reappears to a very slight extent. Further bending forwards of the spine is al- 



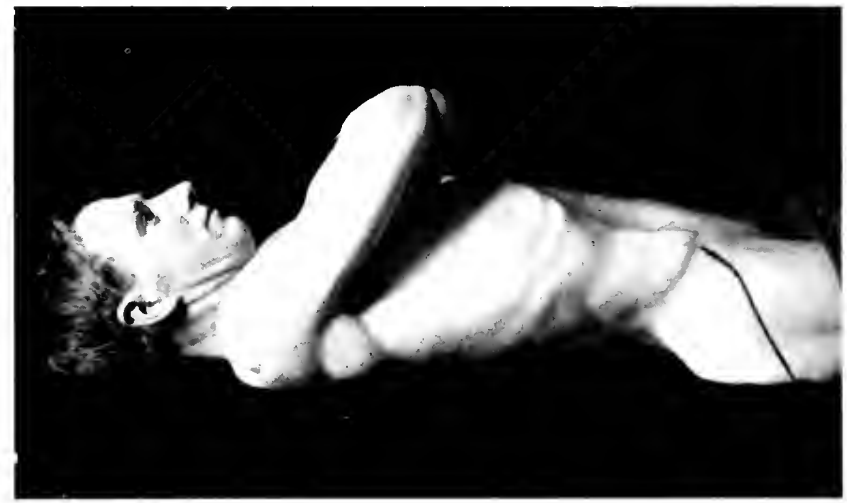

Fit. 5.-Showing suphe position. Note angle of pelvis line.

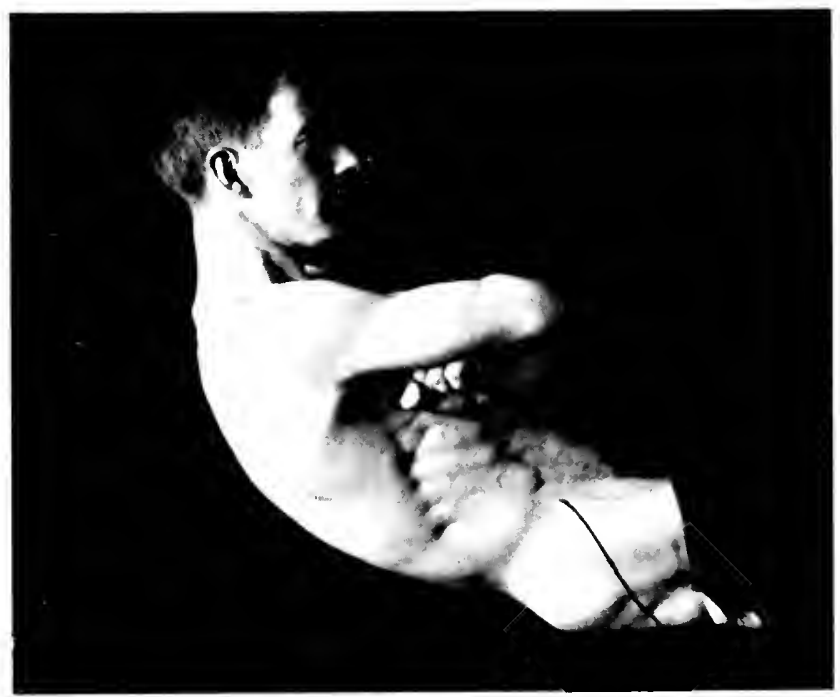

Fig. 6. Showing baek partly raised; purely spinal movenent. 


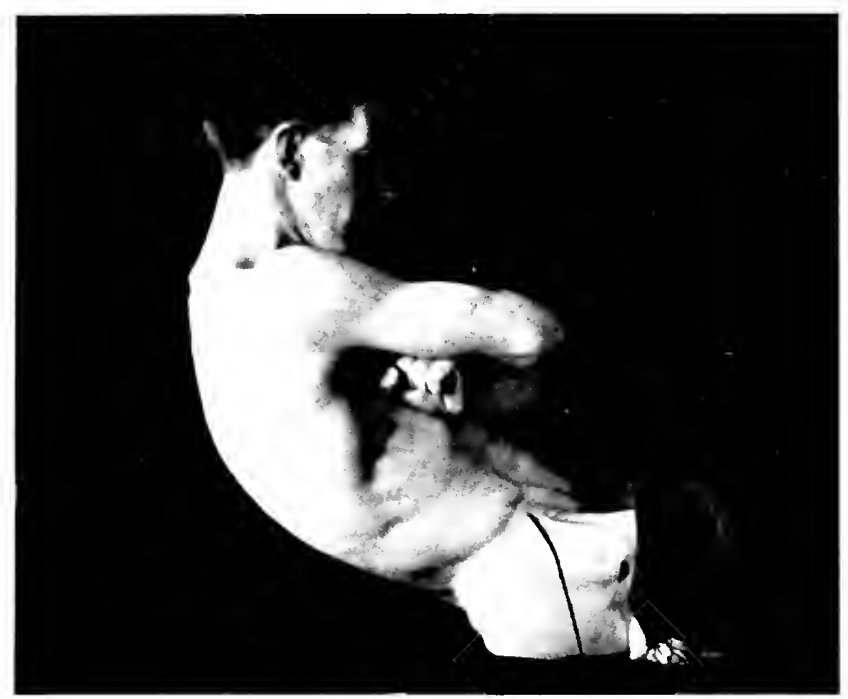

Fur. 7.-. Showing further elevation; hip joints coming into play.

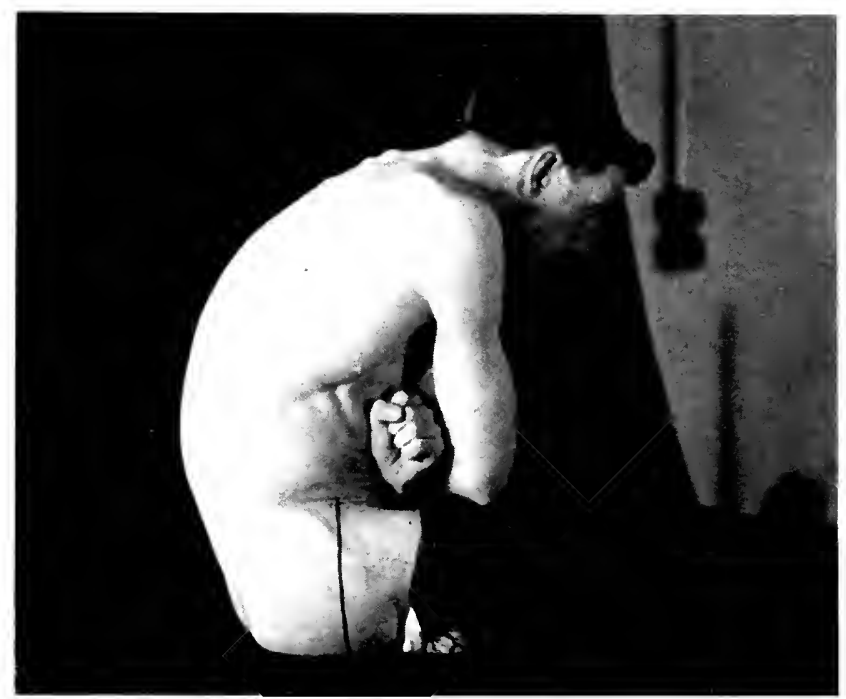

Fig. ....-Showing right angular po-ition. 

most entirely attained by further rotation of the pelvis round the axis of the hip joints. This extreme movement is restricted by the hamstring muscles which are now fully stretched. If the knees are now bent (to relax the hamstrings), further bending forwards of the spine can apparently be, obtained. The bending of the spine, however, is only apparent, for the movement really occurs entirely at the hip joints, and not in the spine at all.

The accompanying photographs were taken to show the amount of bending which occurs in the spine. A line was drawn on the patient's body, from the anterior superior iliac spine, over the tip of the great trochanter, to the tuber ischii. In the recumbent position, this line will be seen to fall at an angle with the table (Fig. 5). As he rises to the position shown in Fig. 6, it will be seen that the angle of the line to the table has remained practically the same. The curve of the back should be noted in this picture. As he rises to the position shown in Fig. 7, the curve of the back scarcely alters, but the pelvis begins to tilt, as shown by the line becoming more perpendicular, and as the back is fully bent as in Fig. 8 the curve of the back will still be seen to be very similar to that shown in Fig. 7, but the pelvis line is now perfectly perpendicular. 
It will be noted also that the slight angle, which in the previous positions was seen at the lumbosacral junction, is now obliterated, so that the extreme forward bending of the spine takes place at this point.

The important facts to be noted as the result of the foregoing observations are these: (1) The total movement possible is through a little more than a quarter of a circle. ${ }^{1}$ (2) That of this quarter of a circle, about half of it is obtained by tilting the pelvis through about 45 degrees. (3) That the dorsal spine does not take part in the flexion. (This will be demonstrated later; see page 104 et seq.)

Perhaps the most important point, however, is that in the "right angular position" the lumbar spine is fully flexed. That is to say, when the knees are kept straight, and the patient sits a little beyond the upright, the spine is fully bent. The malingerer who alleges inability to bend his back can often be got to sit in this position without complaint.

The Extensors.-Extension of the spine is produced by the equal and combined action of pairs of muscles situated on either side of the spinal column, and in a plane posterior to the axis of

1 These photographs are taken of an expert in physical culture, and the movements are therefore about as full as it is possible to obtain. 
movement of the spine. If the muscles on one side contract more powerfully than those on the other side, lateral bending of the body or bending with rotation is produced. The following list of extensors must therefore be taken as acting equally in pairs. Erector Spinæ (Sacrospinalis), Quadratus Lumborum, Semispinalis, Multifidus Spinæ, Rotatores Spinæ, Interspinalis, Serrati Posteriores, Splenius, and when the Scapula is fixed, the Levator Anguli Scapulæ, and the upper fibres of the Trapezius.

Erector Spinæ (Sacro-spinalis).-This is the largest and most powerful muscle of the back. Acting with its fellow, it performs nearly the whole of the work done in weight lifting. The other extensors may be looked upon as merely helpers in the performance. When acting on one side only, it produces lateral bending of the spine towards its own side (acting along with the quadratus lumborum of the same side). It is therefore the back muscle which is most frequently strained, and, as such, must be studied rather minutely. It is so complicated that anatomists have specialised its various portions, and named them according to their anatomical position and attachments. Its origin is roughly from the back of the pelvis. Here it is narrow and tendinous. As it ascends to the lumbar region it becomes a large fleshy mass 
the prominence of which is seen just at the side of the spinal column. It is here beginning to split into two portions, the iliocostalis or rib portion, and the longissimus or rib and spinal portion.

In the dorsal region, where it occupies the costo-vertebral groove, another portion is differentiated, the spinalis dorsi (a purely spinal portion). In the cervical region it is still more highly differentiated, into the special muscles at the back of the neck. The fleshy origin of the muscle is from the back of the sacrum and posterior third of iliac crest. The aponeurotic origin is from the last three dorsal spines, all the lumbar and all the sacral spines, from the dorsal one-fifth of the iliac erest and lateral margin of the sacrum. In the lumbar region the muscle begins to divide into the three more or less distinct bundles already mentioned. Each of these will be followed up to its ultimate attachment.

Iliocostalis Lumborum (Sarro-Lumbalis).-Origin. -Chiefly from the back of the sacro-spinal aponeurosis and from the iliac crest directly.

Insertion.-From the muscle mass tendinous slips are inserted into (1) the tips of the transverse processes of all the lumbar vertebræ, (2) into the dorsolumbar fascia through fibrous bands which pass from the tips of the transverse processes to that fascia, and 
(3) into the inferior margin of the last six or seven ribs near their angles. (Note that the upper margin of the ribs here gives origin to the next portionthe iliocostalis dorsi.)

Iliocostalis Dorsi (Musculus Accessorius).-Origin. -From the upper margin of the lower six or seven ribs medial to their angles (note that these slips pass medially to the slips of insertion of the previous (lumbar) portion.

Insertion.-Into the upper six or seven ribs and into the transverse processes of the seventh cervical vertebra.

Iliocostalis Cervicis (Cervicalis Ascendens).-Origin.-From the seventh to the third ribs near their angles.

Insertion.-Into the backs of the transverse processes of the fourth, fifth, and sixth cervical vertebræ.

Action.-The iliocostalis lumborum, dorsi and cervicis, lies lateral to and closely connected with the longissimus dorsi. From its lateral position, it has more power to bend the spine laterally than the longissimus. When in action with its fellow, it is an extensor of the spine, not so powerful however as the longissimus. Its mode of attachment to the ribs is interesting. The dorsal and the cervical portions cannot act as extensors unless the lumbar portion is in action. If the lumbar portion is paralysed, the other two may act as extraordinary muscles of respiration. The greatest power can be got out of the erector spinæ muscles when the ribs are fixed, as when a deep breath is taken and held, preparatory to a heavy lift.

Longissimus Dorsi.-Origin.--(1) From the deep surface of the sacrospinal aponeurosis, (2) from the 
rough area on the medial surface of the ilium, and from the lateral portion of the dorsal surface of the upper part of the sacrum, and (3) through accessory slips which arise from the transverse processes of the first two lumbar and the last five or six dorsal vertebræ.

Insertion.-From the muscle mass arise fasciculi which are inserted partly by means of tendons into (1) the lower border of the transverse processes of the lumbar vertebre and the inferior margin of all the ribs lateral to the tubercles; (2) into the accessory tubercles of the lumbar vertebræ; and (3) into the tips and inferiol margin of the transverse processes of the dorsal vertebre.

Longissimus Cervicis (Transversalis Cervicis).Origin.-By tendinous slips from the upper dorsal vertebræ.

Insertion.-Into the posterior tubercles of the transverse processes of the middle cervical vertebræ.

Longissimus Capitis (Trachelo-mastoid)-Origin.By tendinous slips from the transverse processes of the first three or four dorsal, and the articular processes of the last three or four cervical vertebræ.

Insertion.--Into the mastoid process.

The longissimus portion of the erector spinæ really forms the main mass of the muscle, and is the portion concerned most in a direct upward lift. Acting singly, it is a powerful flexor of the spine to its own side, and an equally powerful extensor when the spine is laterally flexed to the opposite side.

Spinalis Dorsi.-This portion of the erector spinæ is purely spinal. It extends between the tips of the spinous processes of the two upper lumbar and the two lower dorsal vertebræ. 
Spinalis Cervicis.-(This muscle is inconstant.) When present it extends between the spines of the two upper dorsal and the two lower cervical vertebræ. This cervical portion is a pure extensor of the spine, but with little power.

Quadratus Lumborum.-Origin.-(1) From the inner lip of iliac crest near the junction of the middle and dorsal thirds, and the ilio-lumbar ligament, which extends from the fourth and fifth lumbar vertebræ to the ilium; (2) from the three or four lower lumbar transverse processes; (3) from the dorso-lumbar fascia, which extends from the twelfth rib to the ilio-lumbar ligament.

Insertion.-(1) Into the transverse processes of the upper three or four lumbar vertebræ; (2) into the medial part of lower border of the twelfth rib; (3) into the bands from the transverse processes which run in the lumbar fascia.

Action.-Singly, it acts as a powerful lateral flexor of the spine. With its fellow, it acts as an extensor of the spinal column.

Semispinalis, Multifidus, and Rotatores Spinæ. -These muscles, although included in the group of extensors, are really more concerned with rotation than extension. All the muscles acting together on both sides of the spine will certainly aid in extending the spine. They are here classified together, as they are seldom if ever strained, and because they are so closely allied anatomically. All are composed of fasciculi which are oblique in direction from the transverse processes to the spinous processes farther up the spinal column. The semispinalis is the most superficial. Its fasciculi therefore extend over four to six vertebre. 
This muscle is only present in the cervical and in the dorsal regions. The multifidus is best developed in the lumbar region, and least in the dorsal. It is inserted into all the spinous processes, lumbar, dorsal, and cervical. Its bundles pass over three or four vertebræ. The rotatores extend from the sacrum to the second cervical vertebra. The bundles of the rotatores breves pass between each vertebra. The rotatores longi pass between alternate vertebræ.

Interspinalis. - These muscles are only found in the cervical and in the lumbar regions, not in the dorsal. They extend between the spinous processes.

\section{LATERAL FLEXORS OF THE SPINE}

The lateral flexors of the spine are those muscles which help to incline the spinal column to their own side, or help to restore it to its upright position when bent to the other side. They are as follows :

Erector Spinæ. Quadratus Lumborum. Semispinalis. Multifidus. Rotatores. Intercostals. External Oblique. Internal Oblique. Levatores Costarum. Serrati Posteriores. The Scalene muscles. Splenius Cervicis. Longus Colli. Intertransversarii. Psoas, and when the scapula is fixed, the Levator Anguli Scapulæ and Trapezius. The more important of these have already been described on the previous pages.

Intercostals. - These act on the spine almost entirely in virtue of their power of fixing the chest wall as a whole.

Serrati Posteriores.-These act when the chest wall is fixed, as lateral flexors of the spine. They act towards their own side. The superior extends from 
the ligamentum nuchæ and spines of the upper two or three dorsal vertebræ, to the second, third, fourth, and fifth ribs external to the ilio-costalis. The inferior extends from the lumbo-dorsal fascia, the spines of the last two or three dorsal, and first two or three lumbar vertebræ to the last four ribs external to the iliocostalis. The scalene muscles, the splenius cervicis, and the longus colli are neck muscles which are seldom strained.

The Intertransversarii.-These are short vertical bands of muscle passing between the transverse processes of the cervical and lumbar vertebræ. If they are present in the dorsal region at all, it is only in the lower dorsal.

\section{ROTATORS OF THE SPINE}

Rotators to their own sile:-Splenius Cervicis. Internal Oblique (the ribs being fixed). Serratus Posticus Inferior (ribs fixed). Lower fibres of Trapezius (the scapula being fixed).

Rotators to the opposite sile:-Multifidus. Semispinalis. Rotatores. External Oblique. Longus Colli (the lower oblique fibres). Latissimus Dorsi, and Trapezius (with scapula and humerus fixed).

Of the above two groups, only one muscle need be described, viz. the Latissimus Dorsi.

Latissimus Dorsi.-This muscle, acting as it does on the arm, on the shoulder girdle, and in a secondary fashion on the back, is frequently strained in workmen who have heavy lifting to perform.

Origin.-(1) From an aponeurosis attached to the spines and interspinous ligaments of the last six 
dorsal and the upper lumbar vertebra, the lumbodorsal fascia, the posterior third of the iliac crest (external lip); (2) from the external surface and upper margin of the last three or four ribs by muscular slips which interdigitate with those of the external oblique.

Insertion.-From this extensive area of origin the fibre bundles converge towards the tendon of insertion in the bicipital groove of the humerus. It is sometimes adherent to the inferior angle of the scapula.

Action.-With the trunk fixed, the latissimus dorsi draws the raised arm downwards and backwards, and rotates it inwards as in swimming. When the arm is hanging by the side, the muscle exerts its action on the scapula, depressing the glenoid and drawing it backwards. When the humerus is fixed, it serves to lift the trunk and pelvis forwards as in climbing. It also acts in forced inspiration. For surface marking of this muscle see page 47 .

\section{FLEXORS OF THE SPINE}

All the muscles of the trunk which are situated on a plane anterior to the spinal column act as flexors of the spine. These muscles may be strained, but as this is scarcely within the province of "back injuries," the student is referred to anatomical text books for minute information regarding their origin, insertion, and action.

It seems imperative, however, to mention the psoas muscle in connection with back injuries, not because of the likelihood of its being strained, but because it is so often wrongly stated to be the seat of strain.

The psoas muscle is not an active muscle during 
weight-lifting. Its action is to flex the thigh on the pelvis and the pelvis on the trunk.

The performance of weight-lifting is the reverse of this, viz. an attempt to extend the thigh on the pelvis, and extend the pelvis on the trunk. The psoas therefore cannot be strained during the performance of a lift.

There is another point regarding its attachment to the spine which is of interest and importance. It does not flex the vertebræ in the same way as the erector spinæ muscles produce extension. It tends to flex the trunk as a whole, and this is attained by its special method of attachment. Its attachment is to the intervertebral discs, rather than to the bodies of the vertebræ, where there is a fibrous arch extending from the upper and lower margin of the body. The muscle takes origin from this arch, and through the arch pass the lumbar arteries and sympathetic nerves. These latter structures are thus protected from pressure while the psoas muscle is in action. It will be seen that the psoas by its action cannot possibly dislocate a vertebra, nor tear the periosteum from the body of a vertebra, nor does it play an active part in the performance of weightlifting.

\section{FASCIE OF THE BACK}

A description of the principal back muscles (those most liable to strain) would be incomplete without mention being made of the various layers of fascia which serve the triple function of, (1) 
separating the various muscles from one another, (2) forming tunnels for the long muscles to run in, and so prevent their "bow-stringing," (3) affording attachment to various muscles.

Lumbo-Dorsal Fascia.-This fascia consists of two layers called respectively the anterior and the posterior layer. The erector spinæ muscle (sacrospinalis) runs between these two layers. The muscle acts almost like the wire of the Bowden brake, and the fascia as the covering. The fascia on the posterior aspect of the muscle acts like a tendon sheath.

The anterior layer of fascia lies in the vertebral furrow, and forms a floor for the muscle. In the dorsal region the floor is formed not only by vertebre, but by ribs. In the lumbar region the place of the ribs is taken by the anterior layer which extends from the last rib to the ilio-lumbar ligament. This is strengthened by the lumbocostal ligament which extends between the transverse processes of the first and second lumbar vertebre and the last rib. The anterior layer is also strengthened by fibrous bands which extend into it from the transverse processes of the lumbar vertebre. The anterior layer separates the intrinsic dorsal musculature (erector spinæ, \&c.) from the quadratus lumborum.

The anterior and posterior layers unite at the outer border of the erector spine (sacro-spinalis), 
thus enclosing the muscle. It will be recalled that the erector spinie is attached to the fibrous bands in the anterior layer.

The posterior layer (vertebral aponeurosis).Although the anterior layer stops short at the last rib, the posterior layer (roof of erector spina tunnel) continues upwards to the neck. Inferiorly, it is attached to the iliac crests, the distal and lateral margins of the sacrum and sacral spines. In the lumbar and dorsal regions it is attached medially to the spines of the vertebrie. Laterally, in the lumbar region it is reflected round the outer border of the erector spine to join with the anterior layer. In the dorsal region it is attached laterally to the ribs near their angles external to the erector spine. In the cervical region the fascia is continued into the intermuscular septa which surround the muscles of the neck.

Several muscles take origin from the posterior layer of lumbo-dorsal fascia. (1) The serratus posticus inferior opposite the lowest three dorsal vertebre and upper two lumbar. (2) Obliquus internus abdominis in its whole length between the last rib and middle of iliac crest. (3) Latissimus dorsi.

The importance from the present point of view of these layers of fascia is not so great from the anatomical as from the mechanical aspect. Muscles possess a certain degree of elasticity. 
Fibrous tissue (such as the fascie and tendons of the body) on the other hand, is almost devoid of this quality. As already mentioned, the junction of muscle with fibrous tissue is mechanically a weak spot. In the case of tendons of insertion and origin in "bellied" muscles, the junction between the muscular tissue and the fibrous tissue of the tendon is effected gradually. By this means the junction is strengthened.

In the erector spinie muscle, two forms of junction may be studied. At its origin, where great strength is necessary, we find that the aponeurosis of origin has its fibres directed in the line of action of the muscles, and that these fibres become gradually and completely embedded in the muscle fasciculi which take origin from such fibres. The incorporation is gradual, and it is not until the lower dorsal region is reached that the fibrous tissue becomes lost in the muscle substance. On the other hand, there is almost no gradual embedding of fibrous tissue into the muscular tissue where the muscle is attached to the transverse bands extending outwards from the transverse processes of the lumbar vertebre. Stress of muscle is therefore likely to result in strain at this point. 


\section{MUSCULAR TISSUE IN GENERAL}

The fleshy portion of the muscle is called its belly, and is composed of bundles of reddish fibres. The origin of a muscle is the name given to the more fixed part, and the insertion is the attachment to the more movable part. Muscles are usually composed of an origin, a belly, and an insertion. The intrinsic muscles of the back, however, differ from most other muscles in so far as they are composed of many fasciculi, many tendons of origin and insertion, all complexly inter-related. It has already been stated that the junction of fibrous to muscular tissue is a mechanically weak spot, and, as a natural consequence, this is the usual seat of any tear which may occur as the result of excessive stress being thrown upon any muscle.

No attempt will be made to describe the minute microscopic appearance of muscle tissue, but some of the more general features of its histological structure may be mentioned. The contractile cells of which muscle is composed are long multinucleated masses of protoplasm called "muscle fibres." These are surrounded by a specially differentiated sheath called the sarcolemma, and outside of this is a layer of delicate connective tissue called the endomysium. The fibres of the endomysium are inserted into the sarco- 
lemma, and at the ends of the fibres it increases in amount, and acts to the fibre almost exactly as the tendon acts to the muscle as a whole. A collection of muscle fibres is called a "muscle fibre bundle." A group of muscle fibre bundles is called a fasciculus. A muscle is composed of many fasciculi enclosed in connective tissue (the epimysium) which is continuous with the endomysium of the muscle fibre. The connective tissue surrounding a muscle forms practically an inelastic sheath. When a muscle contracts, the effect is that of approximating the point of insertion to the point of origin of the muscle, which thus becomes shorter and thicker.

There is a historical story told of the erection of the pillars at the entrance to the old Edinburgh University buildings. The pillars are not of the usual blocks of stone placed one on the top of the other, but are hewn from one piece. When these were being erected in the position which they now occupy, one was found to be considerably off the perpendicular, and in danger of falling forwards. The contractor was in a dilemma, as the guy rope at the back could not be pulled any tighter in order to draw the pillar into an upright position. An old sailor, who was one of the numerous onlookers, shouted out, "Weet yer backmost guy rope." Pails of water were poured upon the rope bchind the pillar with the desired effect that it 
shortened sufficiently to pull the pillar into the perpendicular position. It is said that the contractor presented the old salt with five pounds for his timely suggestion.

The contraction of muscle, although it occurs much more rapidly, is explained in much the same way as the shortening of the guy rope. An ordinary muscle is composed of countless fibres, each of which has the power of becoming shorter and thicker, and these fibres run in the long axis of the muscle. When a muscle is thrown into action, each fibre contracts, and so the muscle as a whole becomes shorter and thicker, drawing the origin and insertion nearer to one another. It. may seem superfluous to state that there is an equal amount of pull on either end of a muscle, but the fact must not be lost sight of.

Muscles are always in a state of "tone" except during complete relaxation. If, for example, the middle of the belly of the biceps is cut through, one half of the muscle will be pulled up, and the other half down the arm. The width of the gap left will be a measure of the amount of tonic contraction of the muscle. The middle of the belly of the muscle is the area of greatest stress or tension when the muscle is in action; but if the muscle ruptures during action, this is not usually the site of the rupture. The weak portion is at the junction of the tendon with the muscle fibres, 
or of the tendon to bone, and it is usually at one or the other of these points that the tear occurs.

\section{STRAIN OF MUSCLE}

The word strain, although it conveys to the mind a fairly definite impression, is not of itself a definitive term. The multiplicity of meanings of the term is not to be wondered at when we consider its double origin. From the Latin root, it means "to stretch"; from the Anglo-Saxon it means "to compress," as in straining wine. The English word embraces not only the properties of elasticity and compressibility, but the overtasking of these.

From the medico-legal point of view the expression "Strain" may be taken to mean an overtasking of any tissue of the human body beyond the physiological limit. It is an axiom in mechanies, that strain is proportional to stress. In this sense, strain is the deformation produced in any substance, and stress is the force which produces that deformation. Here the force is external to the body acted upon. In medicolegal work, the large majority of cases of strain are of muscle. Now, in strain of muscle the force is exerted by the muscle itself, so that in this connection the term strain has even a wider significance than it has in ordinary use. This is perhaps un- 
fortunate, for we find the term used as a cloak for our ignorance to designate any condition the result of violence as a "strain" when the exact diagnosis is uncertain.

As applied to joints, the terms strain and sprain are used indiscriminately to denote an injury produced by a twisting form of violence, although there is a tendency to restrict the term "sprain" to a condition where damage to ligaments can be diagnosed; but where, as the result of a twist, mild synovitis is set up in the joint, the condition is spoken of as a strain. (Here also ligaments are likely to have been damaged, and a strain might be considered as a mild sprain.)

Strain of fibrous tissue (ligaments, \&c.) is easy to understand. It is purely a question of the tissue being stretched beyond its physiological limits. Strain of muscle, on the other hand, is a much more complicated problem. Every golfer is familiar with the muscular strain associated with a missed tee shot. On the other hand, a muscle may be strained in the attempt to lift an excessive load. It has already been said that where there is a disproportion between the work to be done, and the power to do it, there is excessive stress on the muscles involved.

There is another form of strain of muscle which may be mentioned, and that is strain produced by a prolonged stress, as in the case of miners 
nystagmus or of dilated heart. By prolonged stress is meant that which extends over a period of weeks, or months, or years. In connection with the subject of "strained backs," there is still another factor which must be taken into account. A tissue which is subjected to prolonged intermittent stress may hypertrophy, if the periods of rest between the times of stress are of sufficient duration. If, however, no rest be given for the tissue to rebuild, such stress may result in actual strain, as in the case of "marching fracture," a fracture of one or more of the metatarsals from no obvious mechanical injury. I have known this occur in an officer who was considered one of the best marching men of his company, after two days' marching.

Even inanimate objects appear to suffer from "tiredness" after prolonged use, as is seen in the case of some parts of machinery which give way for no obvious reason. In the case of muscle this factor of "tiredness" is of importance, because a muscle which is fatigued is very much more liable to strain, or even rupture, than a fresh muscle. Recently I was consulted by a doctor with the view to administering to him salicylate of soda by means of ionization, as he had almost ruined his digestion by taking it in the ordinary way. He was under the impression that he had a rheumatic nodule in his tendo-Achilles. This was causing 
him considerable pain and incapacity. His description of how it commenced was rather characteristic. His car was undergoing repairs, and after a hard day's work, in which he had done a considerable amount of walking and stair-climbing, he was walking along the level street on the pavement when he felt " just as if some one had struck him over the back of the leg with a stick." He looked around, but no one was near him. On $\mathrm{X}$-ray examination, a tear was visible in his tendoAchilles, just below its junction with the belly of the muscle. He had made no sudden effort, and apparently the tissue had just become "tired," and given way.

Another case, a dock-labourer on this occasion, who had been working overtime, alleged that he had been struck over the back of the leg when he was walking along a plank towards a ship, but still on the pier. There was no one near enough whom he could see, but he was positive some one had hit him. In his case there was found on examination a large gap in his calf muscles. Here, again, rupture had occurred, presumedly because of fatigue of the muscles.

Rupture of a muscle is an extremely complex subject. It usually occurs during the sudden and violent contraction of a muscle. It might be said to occur most frequently when the contraction is of the nature of a reflex action, as, for example, 
when, in attempting to recover one's balance and avoid falling backwards, the quadriceps is ruptured or the patella fractured. It is usually taught that fracture of the patella from this cause is like breaking a piece of stick across the knee, but it is difficult to conceive that sufficient leverage could be obtained by applying a force to either pole and a counter force at its centre. On the other hand, it is really only a portion of the quadriceps tendon, and the weakest part of it, at that, to withstand a "traction" form of violence. The olecranon at the elbow sometimes gives way during such acts as throwing a cricket ball. Here the olecranon may be fractured from muscular action, and the ball has to be dropped instead of thrown.

Instead of the muscle which is actively engaged in performing a special movement, the opposing group of muscles may be the site of injury to the muscular tissue. This seems to have been the state of affairs in a recorded case of an athlete, who, while sitting at table, ruptured his biceps in the attempt to save a falling glass. (Disproportion between the work to be done and the power to do it.) The action of the opposing group of muscles may be demonstrated experimentally, as described on page 14. It appears as if the opposing group overdid its work, and that the flexors had to pull the forearm a second time. A person 
attempting to lift a heavy weight may strain the anterior abdominal muscles (this is the opposing group), if the weight is suddenly removed as by the handles or rope supporting the weight giving way.

Actual rupture of muscle is, however, comparatively rare. Rupture of muscle practically never occurs as the result of a prolonged stress, such as weight-lifting, that is to say, when the muscles concerned are fully governed by the will of the individual. What may occur in such circumstances is the so-called strain of muscle. The designation "strain," although it indicates the manner in which a muscle has probably been injured, gives no indication as to the nature of the damage done to the muscle. The condition never calls for operative interference, so that the surgeon gets no chance of actually examining the site of injury, and as the sufferer does not die from it, the pathologist never investigates it. We are, therefore, driven to deduce what the actual damage must be in a case of strained muscle from what we know of the structure of muscle, its physiology and its physics. Physiologically, when a muscle is stimulated, each part of the muscle does not contract absolutely simultaneously. The contraction begins at the end plates (nerve), and spreads in both directions through the muscle. It should be noted here 
that the erector spinæ muscle has many nerves supplying it, and that there must therefore be many "meetings of messages" from the brain when it is called into action.

A muscle will not go on contracting indefinitely. If it be repeatedly stimulated, or if it be kept continuously in action, it becomes tired out; it becomes slower in response to a stimulus, and the maximum work of which it is capable diminishes. At the same time, the muscle does not return to the same length as it was before the contraction began. The shortening which remains is spoken of as the "contraction remainder." Anyone who has had occasion to work for a long time in a stooping position is conscious of the difficulty in straightening the back thereafter. A fresh muscle is therefore able to withstand a greater stress than a muscle which has been doing work, and it is my experience, from the examination of many miners who have "strained" their backs, that such strain usually occurs towards the end of their shift.

We will have occasion to study two kinds of violence (page 139) which may be applied to any of the body tissues from without. In dealing with contractile tissue, another factor comes into play, viz. violence applied from within, in virtue of the inherent power of contractility. This power may be considered as violence when it does 
damage to the muscle, or its connections. This form of violence may also be subdivided into sudden and prolonged. This is fully discussed on page 150 et seq. Strain of muscle may be looked upon as a minor degree of rupture. In weakened or degenerated muscle, it is conceivable that the lesion might be amongst the muscle fibres. In health, the probability is that any lesion which occurs in muscle as the result of undue stress is situated at the weak spot, viz. the junction of fibrous tissue and muscle fibre, or in the fibrous tissue alone.

\section{CONTUSION OF MUSCLE}

This results from direct violence applied to the muscle from without, and so differs from rupture or strain. The actual change in the muscle substance is, however, perhaps very similar. Rupture may occur from direct external violence if the muscle is in action at the time of infliction. When a muscle is contused, there is effusion of blood into its substance. This effusion may be little or great according to the degree of violence.

Great violence may produce a temporary paralysis. As the result of a blow, the muscle contracts. This is followed by fibrillary twitchings, after which the muscle relaxes. The power may not be recovered for several days. When per- 
manent paralysis occurs after a blow, it is usually due to damage to its nerve supply, rather than injury to the muscular fibres themselves.

\section{HEALING OF MUSCLE}

When, as the result of an injury, blood is effused into the muscle, several things may happen to this blood.

(1) It may be absorbed, and leave practically no trace.

(2) It may partially organise, and lead to adhesions between the muscular fibres themselves or between the muscle and its sheath. Such adhesions may be only temporary.

(3) It may organise into fully formed fibrous tissue, strangling the muscle fibres and replacing them with a scar of fibrous tissue.

(4) The fibrous tissue so formed may undergo fatty or calcareous degeneration. It may even undergo true ossification (traumatic myositis ossificans).

(5) Occasionally the effused blood is neither totally absorbed nor totally organised, but forms a blood cyst in the substance of the muscle. This becomes organised at its periphery, and sometimes the walls of the blood cyst ossify, and fine strands of bone are found crossing its interior. This condition is usually classified 
along with myositis ossificans, as that condition is usually associated with it.

Perhaps the most important question, medicolegally, in connection with the healing of muscle, is, "How long should a strain of muscles of the back incapacitate a man from work?" This question is a vexed one, which in Court usually resolves itself into a question of, "Is the man fit to return to work?" Of course there are two sides represented, and necessarily two opposed medical opinions. This is unfortunate, but it appears as if such a state of affairs will continue to obtain until the nature of back injuries is better understood. It is impossible to treat a strained back scientifically if the nature of the lesion is obscure, and although it is not the purpose of this volume to advise any special form of treatment, it is hoped that by setting forth an association of the clinical signs with the pathological condition which is accountable for these signs, at least an indication as to rational treatment may be established.

\section{SURFACE ANATOMY}

The bony landmarks of the back vary in accessibility, according to the musculature and according to the stoutness of the patient.

In the middle line of the back are the spinous 
processes of the vertebre. These are quite palpable, and their prominence may be visible in certain regions, but not so in others. Looking directly from the back, the spinous processes should form a straight line, but when viewed from one side, the various normal curves are seen. On either side of the middle line, the prominence caused by the erector spinie nuscles is visible, being very distinctly so in the lumbar region, and gradually becoming lost as they ascend into the lower dorsal region. In very muscular subjects, the outlines of the muscles may be followed up to the upper dorsal region.

The spinous process of the seventh cervical vertebra can almost always be seen, and can always be palpated. A word of warning is here necessary, however, because there are two prominent spines at the base of the neck-the seventh cervical and the first dorsal spine. Very commonly the first dorsal is the more prominent of the two. The cervical spines cannot be palpated as a rule; the upper dorsal spines can be made out easily; but, on account of the difficulty of knowing whether or not the prominent spine happens to be that of the last cervical or of the first dorsal, it is not advisable to rely upon a count of the spines from above downwards alone. The third dorsal spine is approximately on a level with the medial end of the spine of the scapula. 
The seventh spine is on a level with the lower angle of the scapula. The dorsal spines below this level, though not so easily palpable, can usually be made out.

It should be remembered, however, that the level of the spines does not correspond with the level of the bodies of the same vertebre. This is due to the obliquity and overlapping of the spinous processes in the dorsal region. Neither do the ribs correspond with the spines. The spine of the second dorsal vertebra corresponds with the head of the third rib. The lumbar spines are easily palpated, and, although they correspond more with their own bodies in level, it is very difficult to be sure which spine is being palpated. The posterior superior spine of the ilium is usually represented on the surface of the back by a distinct dimple. A line joining the dimple on either side very nearly corresponds with the level of the second sacral spine. The first prominent spine above the level of the dimples is that of the last lumbar vertebra. The fourth lumbar spine can always be located by drawing a line horizontally round the body on a level with the highest points of the iliac crests. This line is on a level with the fourth lumbar spine. It is easy to palpate the spines from this level upwards to the last dorsal, which is often wanted for measurements in back injuries.

It has already been stated that the ribs do not 
tally in level with the corresponding vertebra. The eleventh and the twelfth ribs do tally, but this is of no value in localisation of the last dorsal vertebra, because the twelfth rib is often not palpable, and the eleventh might be mistaken for it. The twelfth rib is sometimes quite rudimentary, and does not even reach the outer margin of the erector spine muscle. The second lumbar spine corresponds roughly with the termination of the spinal cord. It should be noted that the lumbar spines are roughly on the same level as their corresponding bodies.

There is a median furrow in the middle line of the back, extending from the occiput to the sacrum. This is more or less marked according to the muscular development of the individual.

The trapezius muscle can be mapped out as follows: Raise the arm so that it makes a right angle with the spine. Mark the external occipital protuberance, and the last dorsal spine. Mark the outer third of the clavicle, and the commencement of the spine of the scapula. Draw a line joining the occipital protuberance and the last dorsal spine; this gives the medial outline. Draw a line joining the occipital protuberance and the outer third of the clavicle; this gives the upper extent. Draw a line joining the last dorsal spine, and the root of the spine of the scapula; this gives the lower and outer extent of the muscle. 
The latissimus dorsi muscle can be mapped out as follows: Raise the arm above the right angle. Mark the crest of the ilium, the lower two or three ribs, the posterior fold of the axilla, and the bicipital groove. Draw a line joining the sixth dorsal spine and the third sacral spine; this gives the spinal origin of the muscle. A line from the third sacral spine to the posterior third of the iliac crest will give the origin of the muscle from the sheath of the sacro-spinalis (erector spinæ) and from the ilium. A line from the sixth dorsal spine, upwards over the lower angle of the scapula to the bicipital groove in the humerus, will give the upper margin of the muscle. A line from the posterior third of the iliac crest, obliquely upwards towards the posterior folds of the axilla, will give the lower border of the muscle. The lateral border of the sacro-spinalis muscle (erector spinæ) and the quadratus lumborum may be indicated on the surface thus:-(Stiles.) "That of the sacrospinalis by drawing a line from a point on the iliac crest $3 \frac{1}{2}$ inches from the middle line upward and slightly laterally to the angles of the ribs. That of the quadratus passing upwards and slightly medially lies a little lateral to that of the sacro-spinalis at the crest, and a little medial to it at the twelfth rib." 


\section{EXAMINA'IION}

There is no doubt that the examination of an injured back is one of the most difficult tasks a medical examiner is ever called upon to perform. On account of the doubt which usually surrounds the signs and symptoms associated with an injury to the back, there is a tendency on the part of the examiner to rely almost wholly upon the history given by the injured workman since the date of his accident (in regard to which his own account is frequently the only information available), and his demeanour during the medical examination. How he dresses and undresses, how he spends his time, and how he behaves and moves about when he thinks he is unobserved, are certainly important facts to be noted in a report, but these facts alone are insufficient, and form far too indefinite a basis on which to found a scientific opinion.

The medical examiner's task is certainly difficult, but he is only asked to express an opinion. This is nothing to the unenviable task of the Judge, who has to give, not an opinion, but an actual decision. He has always to decide be- 
tween two diametrically opposed opinions, and it is little wonder that he too will be influenced more by the general aspect of the case than by anything else.

Strained or "racked" back is the commonest form of back injury, and at the same time the most difficult of accurate diagnosis, on account of the scarcity of physical signs. In this, as in all forms of injury to the back, every available means of diagnosis must be adopted by the medical examiner, lest he be confronted in Court with some form of evidence which he has never thought of.

It has been the writer's experience in Court, on several occasions, to see a certain part of the spine alleged to be damaged, although such part of the spine could not possibly have been damaged by the violence to which it had been subjected. On this account, it seems unfortunately necessary to issue a word of warning to all medical examiners who examine back injuries on behalf of either employer or em-ployee: beware of the fifth lumbar vertebra!

The full meaning of this will be better appreciated if $I$ quote the adaptation of a whist maxim, used by a legal friend of my own who yearly passes a large number of accident cases through his hands, when commenting on the frequency with which, especially of late, an injury to this 
particular bone has been alleged in cases of back injury, "When in doubt, play the fifth lumbar vertebra."

$\mathrm{X}$-ray examination is a comparatively recent acquisition, and $\mathrm{X}$-ray diagnosis is accordingly difficult. Along with my colleague in the X-ray department of the Royal Infirmary, Edinburgh, I must have seen hundreds of radiographs of the region of the fifth lumbar vertebra, without having noticed that the shadow cast by this bone was very irregular. Sometimes there is practically no shadow cast by the body at all, sometimes it appears crushed up. The angle at which the radiograph is taken alters the relationship of the bony processes of this vertebra with the surrounding bones. If the patient is not lying absolutely flat on the plate, or if the spine is laterally flexed in the least degree, the apparent alteration of bony relationship is markedly increased.

All this is seen in radiographs of persons who have sustained no injury whatsoever.

When there was a history of accident, and when we were looking for bone damage instead of for urinary stones (a radiograph of this region is always made in such cases), we diagnosed damage to the fifth lumbar vertebra. Such diagnosis we know must have been in error, for now that our attention has been called 
to the bone in question we have systematically noted the appearance of it in 'cases apart from injury, and are now familiar with its vagaries. With our experience now extending over thousands, instead of hundreds, of examinations in this region, we can say with confidence, that we have practically never seen a well-defined shadow of the fifth lumbar vertebra.

There is a very definite reason for this. The fifth lumbar vertebra, on account of its body being wedge-shaped, and on account of the distance it is from the $\mathrm{X}$-ray plate during examination, cannot possibly cast a definite shadow. Its outline is always obscure, and I am safe to say that ninety-nine medical men out of a hundred would diagnose damage to this vertebra in a normal case. A fuller account of this subject will be found in the chapter dealing with X-ray examination of the spine as a whole (page 112), but from what has been said, it will be clear that the perfectly normal fifth lumbar vertebra, on account of the obscure shadow which it casts on the plate, may be a stumbling-block, and give rise to no end of trouble to the medical examiner.

It must not be judged from this that X-ray examination of the spine is useless. Other regions of the spine are shown quite clearly, and I have frequently seen cases of fracture of the 
spine, where no fracture was suspected on account of almost entire absence of symptoms. In such cases, the violence applied to the spine has been of such nature as to be capable of producing fracture. It should be added that, in these cases, the violence has always been indirect, and the fracture has occurred at the weakest part of the spine (viz. near the dorso-lumbar junction).

It is too often the case that medical reports upon back injuries, arising under the Workmen's Compensation Act, are nothing more nor less than an expression of opinion as to the reality or otherwise of the claimant's pain or disability, based almost entirely upon the claimant's demeanour during the examination. It must be admitted that his general behaviour tells its own tale, and is often extremely important, but it is far too indefinite a basis on which to form an opinion.

In the back, as elsewhere in the body, the first step in diagnosis is the determination of the tissue which has been injured-skin-fibrous tissue-muscle-bone-joint-or the spinal cord in addition.

A lesion in muscle gives rise to pain when that muscle is thrown into action, a lesion in fibrous tissue when the fibrous tissue is put upon the stretch, a lesion in bone or joint on all movements of the spine.

The most complicated cases to diagnose cor- 
rectly are those in which there is some derangement of the spinal cord. These cases are, however, comparatively uncommon. The class of case which gives rise to most trouble from the medicolegal standpoint is the "strained" or "racked" back. These cases are by far the commonest, and frequently the most prolonged, so no excuse is made for going more fully into what might be called the minor forms of back injuries.

In writing a report there are several headings which may be conveniently adopted-history of accident - subsequent history - complaint_facts on examinations-opinion.

\section{HISTORY}

The history of the accident itself, and the subsequent statement of the man, may often with advantage be written down as a complete story.

Great pains should be taken to record as minutely as possible the physics or mechanics of the accident. There is always an unlimited supply of circumlocution regarding this history, and it is not sufficient that the examiner should have only a general idea of how the accident happened. He must sift the gold from the dross, and if possible get the man to rehearse the details of the accident. If the case be one of alleged strain of muscle, the man should be asked to put himself into the 
exact attitude he was in at the time of the accident. This will almost certainly cause him pain. The examiner must then study the posture carefully, and determine which muscles were in action at the moment of the alleged strain.

If the case be one of violence applied to the back from without, the examiner must inquire into the exact nature and direction of the violence, whether it was a sharp blow, or a force which continued to act after the back had been struck. Here again, the exact attitude of the man at the time of the accident has a direct bearing upon whether or not the violence would continue to act after he had been struck,

The hour at which any alleged strain of muscle occurred should be noted. It will be found as a rule, in straightforward cases, that the strain occurred towards the end of a "shift." (The reason for this is given on page 40.)

It must be borne in mind that every back injury is the result of some definite mechanical violence applied to the back intrinsically or extrinsically, and that the result of such violence must necessarily have some definite mechanical result. In other words, given the nature of the violence, and knowing the mechanical architecture of the structure on which the violence falls (the back in this case), the mechanical result can be foretold. It will be seen from this, that it may be possible to 
prove the history, as related by the man, to be incorrect. In fact it may prove, after the nature of the injury is ascertained, that the story has been a concoction in order to cover up what would be considered contributory negligence, as the following case will show.

A miner, who had sustained injury to his spine two years previously, gave me a description of the site of his accident, and rehearsed his own position at the time. His description was minute, but it should be related that the case had been through the Court, and that the man was well up in his description on that account. On examination, I found that he had sustained a compression fracture of his spine, the first and second lumbar vertebræ being compressed together. (This was the first discovery that his spine had actually been fractured.) Obviously such an injury could only have been sustained by some form of violence which would bend the spine in this region beyond its physiological or mechanical limit.

In my report, I pointed out the very marked dis. crepancy between the man's description of the physics of the accident and the conditions found on examination. I added to my report a description of the form of violence which could produce the injury from which the man suffered.

Several weeks after I had sent in the report, I happened to be visiting the mine in which the accident occurred, and was told by one of the accident inspectors that this man's case had been in Court before my examination, and that the insurance company had tried to prove that the man had been riding on the top 
of a hutch (which would have amounted to contributory negligence).

My description of how the injury might lave been produced corresponded with what the company had tried to prove but, for want of sufficient evidence, conld not be brought home to the man.

In a straightforward case, the history of the accident will be in keeping, not only with the facts found on examination, but also with the symptoms and complaint of the injured man.

The subsequent history is, as a rule, only the reflection of the man's view of his own case. It is one-sided, and may or may not furnish valuable evidence. Every symptom must have a corresponding pathological cause, and a chronological record may be of value in enabling the examiner to arrive at a just estimate of the progress towards recovery, or the development of complications.

An illustrative example of the importance of the subsequent history came under my notice some time ago.

A warehouseman (C. S.) sustained an injury to his back in November 1911. He was struck over the lower ribs by a bag of empty bottles. He was standing at the time, and was knocked forwards, but the bag did not fall on the top of him. He was sent to my department in the Infirmary for treatment several months after the accident, as he did not seem to improve beyond a certain point. After some electrical treatment, he seemed to improve somewhat. 
He seemed to enjoy it, but when examined he always said that his pain was pretty bad. The pain and the associated tenderness were said to be situated over the region where he had received the blow, viz. over the back in the region of the lower ribs. Gradually his complaints became more general, and, as time went on, indefinite. He was being treated at the Infirmary, and had therefore a sort of official stamp of invalidism. Whether or not this made him more introspective, I cannot say; but, in order to relieve myself of the responsibility of his becoming a confirmed valetudinarian, I examined him very carefully, and took an $\mathrm{X}$-ray plate of his spine in case there might be some insidious disease present. The spine was normal. I was firmly convinced that his condition was mental and not physical. I discharged him.

To my surprise, about a year later, I was asked to examine him on behalf of an insurance company, as litigation was pending. Again I was convinced that he was the possessor of no physical defect in his spine, and that he could work if he tried.

In this case, the region of the fifth lumbar vertebra was said to be damaged, and $\mathrm{X}$-ray plates were produced in Court to prove the point. Here, then, is a case which illustrates several points. The man had a direct blow over his lower ribs and corresponding region of the spine. His spine was not forcibly bent, so that a compression fracture could not occur. If the spine had been damaged, 
the injury would have been at the site of impact of the blow, and might possibly have been of the nature of fracture of the neural arches. There was no such damage as shown by $\mathrm{X}$-ray examination. The pain and tenderness alleged were at the same point, indicating that the site of damage was localised to the part struck. In Court, evidence was led to show that damage had been sustained to the region of the fifth lumbar vertebra, a distance of six or seven inches away from the part struck and the part complained of, and, it may be added, the strongest part of the spinal column. The physical impossibility of the fifth lumbar being damaged by such violence as the claimant sustained need not be reiterated. The want of correspondence between the site of tenderness and the seat of alleged damage need only be mentioned to be appreciated. In addition, the subsequent history of the man-that is, the history between the time of accident and the time of litigationwould go to show that the man's incapacity was due to mental and not to physical causes.

\section{COMPLAINT}

The injured party's complaint at the time of examination is of importance even in eases where litigation is not pending. It should always be written down in the report; it is not sufficient to state "sore back." The exact site of pain should 
always be noted. On subsequent examinations this may be found to have shifted in position-new pains may be said to have come on. The complaints may be so numerous or indefinite, that they might well be written down as Mr. Punch puts it: "When I sees a job of work-there, I'm all of a tremble."

Even the foregoing case shows the importance of noting down the actual complaint. If the complaint (which is practically synonymous with what keeps the workman off his work) is about one region of his body, it is only fair to assume that he cannot go into Court, and try to prove that it is another region which has been damaged.

In the foregoing case, it should be mentioned that one of the medical examiners, who examined him after the X-ray plate had been taken of his fifth lumbar vertebra, stated that the claimant only complained of pain over the region of the fifth lumbar vertebra. It is a well-recognised fact that if a person has, as the result of some slight injury, his attention focussed on any definite part of his body, he may feel pain in that part, long after the injury has healed, and the longer the attention is directed to the spot, the more firmly does it become riveted, and naturally, the more definite in his appreciation becomes the pain. It eventually may become an obsession.

A unique and most interesting case illustrating 
this point came under my observation some time ago.

A window cleaner fell from a distance of about ten feet and landed on his buttocks. He walked home, and lay in bed for a few days because his buttocks were sore. When he got up, he found that he got easily tired, and that tiredness gave way to pain in the buttocks after he had walked a short distance. Even standing on his feet for a short time produced the same tiredness, and then pain in the buttocks. When his own doctor examined him, he was of opinion that the buttocks seemed smaller than they should be, and the man was accordingly sent to my department at the Infirmary to have some form of stimulation applied to the injured region. On examination of the buttocks, they were certainly atrophied and flabby. There was no reaction to faradism, and to galvanism both glutei showed R.D. On testing with the condenser discharge, there was very marked diminution in electrical excitability. It took something like 1.5 microfarads to produce contraction. He was treated by the condenser testing apparatus, and improved slightly. I advised him to have massage in addition, but one application of massage was enough; his buttocks were black and blue on the following morning. After about four months of electrical treatment he was able to walk half a mile without pain, but 
afterwards the tiredness and pain recommenced. His glutei now reacted to faradism, there was no actual R.D., and on condenser testing they reacted to $0 \cdot 126 \mathrm{Mf}$.

Obviously he was not cured, but he remained the same for several months, and I had to refer him to his own doctor, stating that several methods of stimulation at our disposal had been tried, but that the muscles would not improve beyond a certain point. To my surprise, about fifteen months after the accident, this man was referred to me by an accident insurance company for a medical report. He was still complaining of tiredness and pain in the buttocks, and I learned a useful lesson from his visit. On the former occasion I was asked to treat the condition. This I did to the best of my ability. There was no doubt as to the wasting of the buttocks, and I must admit the guilt of taking it for granted that the injury was due to direct violence applied to the buttocks. On this occasion he was referred to me for examination, and it shows how the attitude with which one approaches a case may make a big difference in the procedure.

The history was given me by the man. The first question to be decided was, What tissue has been damaged? Sudden shocks to the buttocks with the violence continuing to act after the buttocks had been struck-this is the picture as it presents 
itself from the purely physical or mechanical aspect. Such violence must have produced compression of the bodies of all the vertebre. Did this exceed the physiological limit? There were no signs of damage to the spine. If the spine were damaged, where would the damage be? Almost certainly in the region of the dorso-lumbar junction. As a fact, an X-ray plate was taken of this region, and showed an unmistakable compression fracture between the first and second lumbar vertebræ.

I did not tell him that his spine was damaged, and I am not aware how he got his information, but after this date he always complained of his back. He was subjected to no manipulation which could cause pain in his spine. I have recently examined him. He still complains of pain in his back towards the end of his day's work. $\mathrm{He}$ is doing the same work as before his accident, and it is only after his day's work is tinished that his pain is in evidence.

$\mathrm{X}$-ray examination shows the fracture healed. It is now several year's since the accident. His buttocks give him no trouble whatsoever, and it is interesting to note that it is only after his day's work that his pain and tiredness begin.

A whole volume might be written on the subject of "Complaints" in cases of back injury, for these range from a simple stiffness to nearly 


\section{PAIN AND TENDERNESS}

every other symptom that human flesh is heir to. We will concern ourselves more especially with those symptoms which are more or less directly attributable to the actual lesion-the symptoms which will act as sign-posts for us in our search for the site of any damage which may be present. These may be limited to three-pain, stiffness, and weakness.

\section{Pain and Tenderness}

Pain is without doubt the symptom which is almost invariably given as a reason of incapacity for work. It seems almost unnecessary to state that symptoms are what the patient feels or is aware of, and that signs are what the medical examiner finds out as the result of his examination. Pain, on account of its subjective nature, and the difficulty there is in assessing its actual severity, is the bone of contention in nearly all the "back" cases which find their way into our Law Courts.

Besides guiding the cxaminer to the seat of injury, it should form a sort of scaffolding around which all the facts elicited on examination will hang together. Pain is the outward expression of the pathological condition within, and as such should be proportional to it. It should be relieved or intensified according as the pathological condition is altered during examination. This is exhibited in the elicitation of tenderness or pain 
on movement. 'To put the matter shortly, pain is due to pressure upon nerve structure. If the pressure is increased by overstretching, or by the application of pressure from without, the pain is increased. If the existing pressure is relaxed, the pain is relieved.

A whole series of facts regarding the pain in any one case may be written down, and should be supplied in every medico-legal report on a case of back injury. It too often happens, however, that the subject of pain and tenderness forms an indefinite mist, amongst which the medical witnesses on either side ar'c made to play "hide and seek." The Judge, who is placed in the unenviable position of sifting the golden facts from the opinionative dross, is practically called upon to decide whether or not the man is fit for no work, light work, or for his ordinary duties. It is, of course, impossible for human intelligence to disprove absolutely the presence of an alleged pain, or even to estimate its degree, if present, with any mathematical accuracy. This is not, however, an excuse for the common but erroneous expression, "The man says he has pain, and who can say he leas not?"

We can only estimate pain by its concomitants, but fortunately these are numerous. Even the lay person can see in a sufferer's face and demeanour, evidence of severe or long-continued 
pain. It has many other effects obvious only to the medical examiner. A pain which is slight, or which has become an obsession, exhibits none of these effects; and there is no condition known to medical science which can compete with back injuries so far as obsession pain is concerned.

However this may be, we must first of all take the man's own description of his pain-what it feels like to him, and then we can set about finding out what intensifies or diminishes the pain. When the pain is intensified, we can examine for the presence of concomitants. The pain will vary in character according to the stage, site, and severity of any inflammatory lesion. The patient's description is often of value.

A constant pain which is not severe, and which is associated with only slight tenderness, usually indicates a chronic inflammatory or hyperæmic lesion.

A dull pain, described as "boring" in character, is commonly complained of when there is any increased intramedullary pressure, such as occurs in abscess or tumour of bone.

A severe constant pain suggests an acute inflammatory or hyperamic condition, or a rapidly growing tumour in fairly dense tissue, or a strangulation of nerves by constricting fibrous tissue.

A throbbing pain is indicative of pus forma- 
tion, and a lancinating pain of an abseess pointing.

A burning pain signifies that skin is involved.

These varieties of pain, although not absolutely pathognomonic, are, when taken in association with other signs and symptoms, of great value. If the pain is long continued or acute, we will find many concomitants.

In the investigation of any pain, the first point which must be decided is: Does the seat of the pain correspond with the site of the lesion? or, Is the situation of the pain due to a misinterpretation on the part of the patient's brain as to the actual position of the lesion? In other words, are we dealing with a local or with a referred pain? 'This can usually be determined by eliciting tenderness, which when present points to a local origin of the pain.

We will discuss pain therefore under two heads-(1) pain associated with tenderness, and (2) pain not associated with tenderness. These are spoken of as (i.) local, and (ii.) referred pain; and, although not absolutely accurate, the terms are clinically deseriptive. Generally speaking, referred pain is unusual in the minor forms of back injury. A knowledge of it is essential, however, for the better appreciation of local pain.

Referred Pain.-If the painful area is not 


\section{PAIN AND TENDERNESS}

tender to light or to deep pressure, the pain may be described as "referred." In every case of referred pain, the nerve, in the course of which the pain occurs, must be traced from its origin to its peripheral distribution; and not only so, but all other branches of that nerve must be scrutinised for some lesion which will account for the pain.

There are several situations in which referred pain is commonly found-(1) at the peripheral distribution (commonest), (2) where the nerve passes through a bony or fibrous foramen (common), (3) along the whole course of the nerve (common in injuries to the spinal cord-the pain in this case being bilateral), (4) at the site of an old lesion somewhere else in the course or distribution of the nerve.

Examples.-When the posterior division of a lumbar nerve is injured, pain is frequently complained of in the region of its peripheral distribution towards the front of the abdomen.

The girdle pains (bilateral) going horizontally round the trunk are characteristic of transverse lesions of the spinal cord. It should be noted that when there has been damage only to the nerve trunks issuing from the spinal column, the pain does not go horizontally round, but radiates diagonally downwards and forwards along the course of the nerve trunks. 
Where the external branches of the posterior divisions of the lumbar nerves go through a fibrous foramen like the aponeurosis of the latissimus dorsi, pain is often complained of.

It might be mentioned in quoting this as an example of pain being referred to the exit from a bony, canal or fibrous foramen, that the nerve is quite likely to be actually damaged at this site, and that it is possible for such injury to be followed by pain referred down to the buttocks as far as the great trochanter.

Local Pain.-All pain is due to irritation of nerve structure, and in nearly every case this irritation is of the nature of pressure. It follows, then, that pain will be most severe in those tissues which are most favourable to the localisation of pressure, and that pain will be increased as the pressure is increased. If we temporarily increase the pressure by means of the tip of the finger, or any blunt instrument, and the pain is thereby increased, we speak of the presence of tenderness. The existing pressure may not be sufficient to make the patient aware of pain, but extra pressure will make it evident.

There are other means by which we can attain the same object, viz. by mechanically stretching the painful tissue or by moving it. The facts we have to record in such cases are not spoken of as "tenderness," but as pain on some special move- 
ment : the production or increase of pain, however, is the same in either case.

Concomitants of Pain.-As a rule, all pain of even moderate severity, if long continued, produces changes in the part which may be demonstrable. Severe pain produces more marked changes, and, in addition, even although the pain is of short duration, general changes are produced. The severity of a pain, or the severity of any alleged tenderness, may be roughly estimated by the degree of the general changes which accompany it. 'The patient's own description of the pain, depending as it does on his descriptive ability, does not help us in an estimation of its severity.

Local changes are most evident when the pain has been long continued. These are of the nature of trophic changes, vaso-motor changes, and partial loss of function.

The general changes associated with severe pain or tenderness are increase in the pulse rate, rising of the blood-pressure, dilatation of the pupil, alteration in facial expression, attitudes adopted by the patient, and protective gestures which he may make to guard the painful part against injury. The dilatation of the pupil is due to irritation of the sympathetic nervous system; and it should be noted that, even in the absence of pain or tenderness, it is possible to produce dilatation of the pupil by applying deep pressure over 
the splanchnic area, or by pinching the tissues in the region of the neck.

A profuse perspiration, or even a sweating about the nose and upper lip, is often seen to accompany the presence of a severe pain. 'This, however, cannot be relied upon, as such sweating may be due to other causes. If it does occur, we must not be satisfied that it is due to pain, unless it happens on subsequent occasions when the painful area is pressed upon, or unless it accompanies the other concomitants of pain.

We have, therefore, several means by which we can at least approximately determine the severity of a pain, or the degree of tenderness which accompanies it. If a person has severe pain in a certain area, he will unconsciously assume a characteristic attitude, in which the tissues in that area are relaxed. He will be apprehensive lest the painful area be tonched or otherwise subjected to an increase of pressure. That is to say, his gestures will be protective; and not only will his voluntary movements be protective, but if the lesion is deep seated, the overlying muscles will be constantly on guard. The muscles will go into spasm on the application of the slightest stimulus, if they are not already firmly contracted or "boarded." If we increase the pain by the external application of pressure (eliciting tenderness), there will be a change in blood-pressure, 
pulse rate, and pupils. If he complains of severe pain, and exhibits none of these phenomena, we may safely discount his statements regarding the pain. There is one pitfall, which from our point of view is happily not a serious one, viz. the case of a highly strung neurotic individual. To him a stimulus, which would only cause discomfort in an ordinary individual, might cause pain. This pain may be sufficiently severe even to evoke the usual concomitants of pain. We can, to a certain extent, estimate his susceptibility to pain by pinching up the loose skin at some distance from the site of his injury, noting his complaint, and noting at the same time his pulse, pupils, \&c.

Pain in Muscle.-If a muscle has been injured, pain will be produced when the muscle is thrown into action, because it will then be under increased tension. For a long time it was not known that sensory nerve receptors existed in muscular tissue. To Sherrington is due the discovery of these, and to Head the elucidation of their clinical importance. The skin over an injured muscle, if the injury is of the nature of a strain, is not hypersensitive on pinching it between the fingers, but when the muscle itself is grasped pain is produced.

As the "strained back" is the commonest, and at the same time the most difficult, con- 
dition to diagnose, to treat, and to give a prognosis upon, a short discussion on muscle in general in its relationship to pain may not be amiss.

Strain of muscle is a localised lesion, and is definitcly circumscribed. It usually occurs at the junction of muscle fibre with fibrous tissue. The pain complained of is usually localised to the site of the lesion, but may extend for some distance beyond it. The tenderness, however, is distinctly localised. This is not so with "infections" of muscular tissue, where the pain and tenderness are more generalised. Most people are familiar with the muscular soreness associated with influenza. This is often confined to the back muscles, but it is generalised in these. The unfortunate sufferer from lumbago knows, to his cost, that the whole of the lower part of his back is painful and tender. The excruciatingly painful back of small-pox, which, by the way, may be of very sudden onset, is characteristic.

After a long experience in the examination of miners' backs, the writer is of opinion that a great many of the so-called "racks" are complicated by infection from some part of the alimentary canal. Some of them are even cases of pure and simple lumbago; but how are we to get over the difficulty of accident as a cause? The 
infective affections may be as sudden in their onset as the traumatic. In fact, lumbago usually commences so suddenly, during the performance of some simple movement, that it has been questioned whether it could possibly be due to a pure infection.

Bacterial or toxic invasion, and suddenness of onset of pain, however, are not incompatible. Most of the acute infectious diseases commence suddenly, just after the incubation stage of the causative organism has passed, and the toxins are being liberated. The pain associated with any acute infective process is fairly sudden in its onset, and, if the tissue involved happens to be voluntary muscle, it is easy to understand why the incidence should be abrupt.

Take an extreme case, where a portion of the body has been constricted, and the circulation in the part beyond impeded or stopped thereby. On relief of the constriction, and with the re-establishment of the circulation, discomfort amounting to pain may be experienced.

The supply of blood to any muscle during its action is fully provided; at rest it is lessened, and when it is stretched or overstretched the muscle is less fully supplied still. When muscle is overstretched for a prolonged period, there is a physiological factor to be considered which may be due to the vascular change, viz. exhaustion or 
loss of full contractile power. Most people have experienced this after working even for a short time with the back fully bent; it is almost impossible to straighten it immediately thereafter.

The voluntary muscles more than any other tissues in the body exhibit this temporary devitalisation. It is reasonable to suppose, therefore, that if the blood is deficient in quality, owing to the presence of toxins, as well as in quantity, the onset of any pain in muscle may be sudden.

Evidence is gradually accumulating to show that toxins are constantly present to a varying degree within our musculature. Devitalisation of muscle from overwork or from overstretching will allow such toxins to become operative, and as the vascular and physiological changes within the muscle may be abrupt, any pain may be accordingly sudden, however small the part played by trauma.

So far as the legal responsibility of the employer is concerned, we cannot relieve him of it. In every purely traumatic case, the employer is justly liable. In the more or less purely toxic cases, there is always some muscular action which can be blamed (however fairly or unfairly) for the onset of the condition, and so here also the employer is usually held responsible. 
There seems no doubt that this toxic element is a potent factor in prolonging the convalescence from the majority of these minor back injuries. The relative part played by trauma and by toxins is often evidenced in the history of the case. When a muscle is mechanically strained the pain is sudden, and the loss of power correspondingly immediate. When a muscle is "pathologically" or "toxically" strained, if we might use this term, the pain may be sudden, but it is not usually so severe. It is not necessarily incapacitating at first, although it may become so later.

In a large number of so-called strained backs, the history points to toxicity as the exciting cause, and to strain as only a possible predisposing factor.

A miner, who has habitually lifted derailed hutches, may one day have sudden pain during the performance of this ordinary task. He rests for a little, and often finishes the shift he is engaged in. He states that his back did not trouble him much till after he cooled down in the evening. This is a very common history, and one which is more compatible with a toxic than with a traumatic origin of the condition.

I am not trying to deny that there is muscular strain, but rather pointing out the small part which mechanical strain plays in the production of the lesion in some cases of ordinary muscular action, when the muscles are perhaps a little tired, 
as they are bound to be towards the end of a shift. To the medical examiner such a history will alter his prognosis. To the doctor who is attending the patient, it should modify his treatment.

A simple strain of muscle, with its sudden pain and disability, is mechanically produced, and only requires mechanical treatment, viz. rest. Recovery should be complete in two or three weeks. If, on the other hand, the history is suggestive of the presence of toxins, the prognosis and treatment are markedly different.

The medical examiner is here placed in a very difficult position. The prognosis is totally dependent upon the treatment adopted by the man's own doctor, and in order to safeguard himself, the medical examiner should investigate as thoroughly as he can all possible sources of sepsis. The source of infection may be a septic mouth, a stagnant bowel, a running ear, gonorrhœa, or, in fact, a septic focus in any region of the body. If the man is the possessor of any such septic cesspool, even a simple strain of muscle may become complicated thereby. The healing of muscle, instead of being a simple physiological reparative process, becomes hindered or perhaps even defeated by the action of the toxins generated in the cesspool, and carried in the blood to the injured region. The repair is not so good as it should 
be, and if the man does just a little exercise, he again suffers pain, and his convalescence drags on.

In nearly every such case the history is forthcoming that the weather has a marked influence on the pain-an influence which, it must be agreed, could not possibly have any effect on a simple strain. The pain is probably real. Its persistence rather than its degree is what makes the man apprehensive, and accordingly he remains off work, although possibly physically fit. $\mathrm{He}$ often wears a blue flannel belt for some reason. He says he cannot walk a hundred yards without it. He gradually develops additional pains which have no anatomical or other relationship with the injured tissues. It is interesting to note that he becomes a moral, mental, or psychological wreck long before his tissues have become physically weak. If we study his pain during the process, we will find that its character is influenced by the relative part played by toxin or trauma.

In simple strain the onset of pain is sudden, as if a blow had been struck across the back with a stick. It is sharp in character for a few minutes, and becomes more or less constant. This pain is due to the subcutaneous wound. Movement augments the pain, and so the patient usually keeps quiet during this stage. As re- 
pair progresses, the constant pain liminishes, and by the end of a week or so has gradually disappeared, though pain may still be produced on throwing the muscle into action. This pain also gradually disappears, and by the end of a fortnight or three weeks should have totally disappeared.

\section{Strain Complicated by Mechanical Hindrance}

If the original strain has not been severe, if exercise is indulged in before a sound scar is produced in the muscle, the healing process is interfered with. As in simple strain, the pain tends gradually to disappear, but before all the effusion has been dissipated or absorbed, the muscle is mechanically and physiologically weak. If now the muscle is used beyond its present physiological capacity, pain will be produced, and there will be an increase in the amount of effusion. The pain may be momentary, or only last for a few seconds, but each time it recurs there is a little more effusion added, and also during each interval this effusion must either be removed or organised. With many such small strains there is the over-production of scar tissue or adhesions, in exactly the same way as in a wound over the knuckles. Healing is delayed by movement of the part, and the effect of the summation 
of little movements is seen in the hard, raised, slow-healing scar so characteristic of any wound which has been mechanically irritated during the process of healing. This type of case does not result in the production of a continuous pain, but the area of the pain tends to increase in extent, and the accompanying tenderness to become less localised. It is not characteristic of this type that any weather influence is manifested.

It is a common state of affairs. The injury is just sufficient to keep the man off work, but not bad enough to keep him in bed. He hangs about street corners, or even indoors, and does little odd jobs. He is constantly adding little aggravations to the original injury, and thereby piling up the fibrous tissue about his wound, and, as time goes on, it may require less and less muscular action to produce the pain. This is perhaps the most difficult case to express a satisfactory opinion upon. Absolute rest is essential for recovery, and after a sound scar has been produced, graduated exercises. These will certainly cause pain, but here the pain is totally different in character from the previous pains. It is now produced on passive as well as active movement. It has not the beneficent property of nearly all other pains. Pain as a rule is protective. It is Nature's way of calling out for rest.

Here, however, where adhesions have formed, 
and are mechanically tending to limit the normal range of movement, pain must be disregarded. The movements which cause pain in this special case are the movements which will be most beneficial, and which should be most practised and persisted in even in spite of pain.

\section{Strain Complicated by Toxic Factors}

This category is meant to include only such cases as have definite evidence of some traumatic origin, but in which toxins play the more important part.

In these eases the pain of onset is usually sudden. It may or may not be severe. The man may finish his day's work, or even work for several days after the strain.

The pain, only lasting a few minutes at the onset, comes on again perhaps in the evening, when he cools down, or on the following morning. He may attempt to work, but the pain becomes more and more persistent, and he has to lie up. With rest the pain tends to diminish, but a little exereise brings it on again.

The pain and tenderness are usually over a fairly large area, and, unlike the pain of a simple strain, that due to toxic conditions tends to be more or less constant. The slightest exposure to cold, a change in the weather, or 
an error in diet are sufficient to augment the pain.

It is probable that, in the majority of such cases, the cesspool is in the alimentary canal. The bowels may have been fairly regular in their action while the man was at work, having his regular exercise and regular hours. When off work, the bowel, along with the rest of his bodily tissues, becomes more sluggish, and a more fertile source of toxins, and so a vicious circle is set up.

These types gradually merge into one another, and it is impossible to draw a hard and fast line. The character of the pain, however, guides us as to whether toxæmia or trauma is the more potent factor. It might be said that with pure strain the pain is sudden, severe, and probably immediately incapacitating. It is distinctly localised, as also is the tendemess accompanying it.

Where toxæmia plays the major part, the pain may or may not be sudden or severe, it may or may not be localised at first. It tends to be generalised, even if by any chance it was localised at the start, and it is more or less constant in character. The prolonged incapacity of the "strained back" is well known. If the rôle of toxæmia were more generally appreciated, and its mitigation attempted during treatment, the average period of incapacity would be markedly diminished thereby. 
It is not the intention of the present volume to deal with the treatment of back injuries, but a few indications may not be amiss, considering that so little has been written on this subject. The injury is produced mechanically, and must therefore be treated by mechanical means. As with all mechanically injured tissues, rest is the first indication in treatment. The more absolute the rest, the more rapid the healing in the case of muscle.

Pain is our guiding post, just as the pulse and temperature are in other conditions. Avoid causing pain, and for this reason avoid unskilled massage.

Massage is employed with the view to the removal of effusion. If skilfully performed, it relieves most pain, but here we are dealing with a contractile tissue for which we wish to give rest as nearly absolute as possible. All but the very lightest massage will cause the injured muscle to go into spasm, and pain will be produced. It is usually impossible in industrial practice to obtain the services of a highly skilled masseur. Better leave massage alone in the early stages than have it done roughly.

When the pain of the subcutaneous wound has disappeared, and is only brought into existence by the performance of certain movements, the patient should have graduated exercises which stop short 
of the production of pain. Do not force active movement if it causes much pain.

If in doubt as to the genuineness of such pain, electrical testing by the condenser discharge will show if the muscle is really hypersensitive. In every case, no matter how apparently purely traumatic in origin, look for a possible septic cesspool, and combat its evil effects by every means available. Avoid the blue flannel belt"once worn, always worn." After being fully satisfied that it is a case of strained muscle, impress firmly upon the man that it is a minor injury, but that he must obey instructions regarding absolute rest if he wishes to get well quickly.

To Recapitulate.--The effort which strained the muscle is the effort which will be productive of pain during the examination. That is to say, when the injured muscle is thrown into action, then, and then only, will pain be produced. This is associated with localised tenderness. Passive movement does not cause pain unless the injured muscle is thereby very much overstretched. Pain is produced even in the absence of movement if the muscle is thrown into action. Pain is produced when the muscle is made to contract electrically,

Pain in Ligament.-In ligament pain is only produced or augmented when the injured tissue is 
subjected to increased pressure, either by digital pressure or by mechanically moving the joint actively or passively. Here, again, the movement which has produced the injury is the movement which will produce pain on examination. It must always be remembered that ligament is not a contractile tissue, and that it cannot therefore be damaged by its own action. Damage to ligament is due to the overtaxing of a joint whose range of movement is limited by ligament. The ligament on the convexity of the bend is mechanically torn or overstretched; this is followed by an effusion of blood into the tissues surrounding the joint, and probably into the joint itself.

Ligament is composed of dense unyielding fibrous tissue, and consequently the pain is severe and totally different in eharacter from that associated with injury to muscle. Let us suppose, for example, that an ankle joint has been sprained by the foot slipping off the pavement, and that the ankle has been bent so that the foot was turned inwards; the outer ligament will have been overstretehed or torn, there will be effusion of blood into the joint and into the tissues surrounding the ligament at its outer side.

The same lesion may occur in the vertebral joints, and the same process of effusion and repair also, so that the two lesions only differ in so far as they occur in different parts of the body. The 
pain of the tear is sudden and severe. It is immediately incapacitating, but after a few minutes it gets a little easier, and the person may even be able to walk home. The effusion of blood into the joint cavity continues, and, in the course of an hour or two, the cavity becomes over-distended. This gives rise to a constant pain, which increases in severity with the degree of distension. All movements of the joint are painful, whether active or passive. The joint is tender all over so long as the increased pressure exists. As the effusion clears up, the pain and tenderness diminish, and the pain caused by movement is not so severe. Eventually, pain is not present while the joint is at rest. It will, however, be produced on bending the foot inwards (the movement which produced the injury). This pain will be felt at the outer side of the foot, and will be accompanied by tenderness on pressure over the outer ligament. It will be relieved by bending the foot outwards, but there will still be tenderness on the outer ligament. The tenderness over the remainder of the joint disappears along with the constant pain.

This is exactly what happens in the case of sprain of a spinal joint. The clinical findings, however, are modified by the anatomical arrangement of the parts. The spinal joints are a long way from the surface of the body; the pain is therefore deep seated, and the tenderness on 
pressure almost impossible to elicit; there is no visible swelling, and practically no discolouration.

As our first step in diagnosis is to discover which tissue has been injured, it will repay us if we briefly compare the pain in muscle with that in ligament. Active and passive movements give exactly the same results when the injured tissue is ligament or fibrous tissue, but active and passive movements give totally different results where the injured tissue is muscle. This is easily understood when we consider that muscle is an elastic structure capable of voluntary contractile movement, and therefore liable to intrinsic as well as to extrinsic influence, whereas ligament and fibrous tissue are devoid of elasticity, incapable of voluntary contractile movement, and are only liable to extrinsic influence.

It is of prime importance that an exact diagnosis be made in the early stages as to whether muscle or ligament has been injured, because the treatment of the two conditions is diametrically opposite. Rest is essential in muscle injuries, whereas movement is strongly indicated in the case of damage to ligament. In sprain, forcible movement should be persisted in, in spite of the pain which will be produced thereby. This will produce a more rapid removal of effused blood, and there will be less chance of ultimate stiffness 
if this treatment is adopted. In the case of muscle, on the other hand, there is not the same amount of clot: there is not the involvement of a joint which might become stiff, and muscle being a contractile tissue will reflexly contract when attempts at movement are made. These act like a series of similar but slighter injuries to the already damaged muscle.

Pain in Bone.- It may be taken as a general rule that the pain associated with bone disease or tumour is continuous in character. Syphilitic and tuberculous bone diseases are, as a rule, worst at night. We are now only concerned, however, with injury.

In fracture, pain may be entirely absent if impaction has occurred, as is common in spinal cases, or if the fragments are separated by a considerable interval. It might be stated generally that the pain associated with a simple fracture is caused by any movement which tends to produce rubbing of the fractured ends together (pressure upon nerves in the vicinity). The same may be said about joint injuries, and joint diseases in which the articular cartilages are involved.

Where the injury has been to the bones or joints of the spine, "jarring" of the spinal column will be productive of pain. A word of warning is here necessary on the manner in which this test is to be applied. Do not rely upon the results 
obtained by placing the hands upon the patient's shoulders, and suddenly applying a jarring pressure. This procedure may give rise to pain, when the vertebræe and intervertebral joints are perfectly healthy, if the museles about the chest wall are tender. The best method is to get the patient to rise on his tiptoes and suddenly to come down on his heels. This will give rise to pain if the lesion is about the vertebræ or intervertebral joints.

Percussion with the ulnar portion of the closed hand is at best a rough and ready method of eliciting tenderness of the spine. Most patients complain of pain when they are hammered over any alleged painful area. I do not mean that the complaint of pain may not be genuine, but that this direct percussion method does not help us to localise the tissue which has been injured. Even when a muscle in the region of the spine has been strained, pain will be elicited by this method. We can say, however, that if percussion over the spinous processes does not eause pain, there is no gross damage to the neural arches.

\section{STIFFNESS}

This is a nondescript term, used by the patient to signify that he has some difficulty in bending his back. The mechanical disability may be any- 
thing from a lack of agility to an actual rigidity. The range of movement may be restricted by pain, by reflex muscular spasm, or by an actual structural change. Although nondescript, it is a convenient term medically; convenient in writing a report in order to convey an impression rather than to state a fact.

As a complaint or symptom, we must investigate its cause in order to record any facts regarding it. If it is due to pain, we must differentiate between muscle, ligament, and bone pain, as already discussed (page 71 et seq.). If it is due to muscular spasm or to actual structural change, we can, by palpating the back during movement, differentiate the several causative factors as already described under the subject of palpation (page 100). For purposes of recording any degree of limitation, actual measurements should be made as described on page 106 et seq.

\section{WEAKNESS}

This is purely a subjective symptom so far as back injuries are concerned. Apart from its degree, the presence or absence of weakness cannot per se be proved or disproved. There is no test which we can apply, and we are accordingly forced to rely upon a combination of all the other evidence afforded in the case. The neurasthenic patient 
almost invariably complains of an aching tiredness or a weakness in the small of the back. Even apart from injury this is a common complaint.

The sexual neurasthenic is seldom without it. The woman deprived of her corsets feels unablc to maintain the upright posture for any length of time. The injured miner, who adopts the usual blue flannel abdominal bandage, will tell you that he cannot walk one hundred yards without its support, and consequently he seldom gives it up after he has adopted it. What does it all mean?

How much of the weakness complained of is really due to actual though partial inability of the muscles to perform their full function, and how much due to the mentality of the patient? The medical examiner is called on to decide this question, or rather to express an opinion thereupon.

We know, for example, that there is no actual muscular weakness in the back of the sexual neurasthenic after a nocturnal emission, although he complains bitterly of this, often the one and only symptom. We know, on the other hand, that disuse will produce very decided weakness of muscle, and that in a surprisingly short time. Disuse for even a fow weeks may produce an atrophy of bone which is apparently out of all proportion to the desuetude of the limb.

It is exceedingly difficult to give a satisfactory 
reason for atrophy of bone in the neighbourhood of an injury. Although it is the usual accompaniment of immobilisation, it does not follow that if a limb is kept at rest, a marked osteoporosis will be the result. We occasionally see fractures which have been kept at rest for a month or six weeks with little or no sign of atrophy of bone.

On the other hand, it is common to find a bone injury result in marked atrophy of the bones in the vicinity where splints have not been employed.

Chronic poisoning, especially alcoholic, seems to predispose to osteo-porosis after injury.

In back injuries, where the pain is severe or the "weakness" is marked, it is quite common to have great difficulty in obtaining a satisfactory $\mathrm{X}$-ray plate of the spinal column. The vertebre are composed of cancellous tissue, and the incidence of atrophy is seen to be confined to the cancellous tissue in all other parts of the body.

I have seen this osteo-porotic condition of the vertebræ remain for over two years after an injury. The picture presented on X-ray examination is rather like the atrophy of bone associated with tuberculosis, but lacks the characteristic eggshell appearance of tuberculous osteo-porosis.

Weakness of the back sometimes is evidenced by myotatic irritability in the back muscles. 
This also is due to a nutritional cause, and in fact it might be concluded quite logically that, if there is an actual weakness present, it is bound to be associated with some local nutritional disturbance. In the absence of any such accompanying disturbance, it is fair to assume that the degree of weakness is not great, and that exercise in the form of light work will more likely be beneficial than hurtful.

Facts on Examination.-If the facts elicited on examination of the patient are not written down at the time, it is impossible to compare them with any degree of accuracy with those of any future examination. This is the most important part of a medico-legal report, and it is surprising how often it is omitted from such documents. The difference between what is fact and what opinion cannot be emphasized too strongly. Great care must therefore be taken that no opinionative statements are made under this heading. Although a definite routine cannot be followed in the examination of every case of back injury, it is well to have general lines to go upon. Negative, or what might be more correctly called eliminative, evidence should be recorded as well as positive facts. General remarks should be left to the last, and stated just before the opinion on the case is expressed. 


\section{INSPECTION}

The patient should be stripped, and examined from in front, and from behind, as well as laterally. Any asymmetry of the two sides should be noted, but care should be taken to discriminate between apparent and real asymmetry. By apparent is meant that due to posture, or to throwing certain muscles into action; by real is meant any more or less permanent anatomical change. This latter can only be determined by examining the patient in various attitudes. If the spine has a slight lateral curve (apparent or real), one erector spinx muscle is more prominent than the other. The patient should be asked to fold his arms across the chest and to bend forwards while the examiner looks along the back from behind. If the prominence disappears, it has been due to posture. A plumb line dropped from between the shoulders to the fold between the buttocks will show the direction of the curve, if present.

In so-called adolescent scoliosis (lateral curvature), the first change is a rotation of the bodies of the vertebræ upon the more securely anchored neural arches. A person may therefore have scoliosis, and the spinous processes still remain in a straight line. When the patient bends forwards, however, a rib-hump is distinctly visible. This is due to the ribs being thrown out of 
symmetry by the alteration in the distance between the transverse process and the body. In other words, the body is nearer one transverse process on one side than on the other. In postural lateral eurvature there is no such altered relationship, and accordingly no rib-hump is visible. It frequently happens that while the patient is standing up before the medical examiner for inspection, he unconsciously throws one erector spinæ muscle into action, produeing a prominence on that side of the spine. This, of course, disappears when the patient bends forward.

Cases of suspected hysterical curvature may present some difficulties. Examination of the skin affords useful information here. It is a pathological axiom that tissues which are absolutely and continuously relaxed, undergo nutritive shortening, while tissues which are eontinuously on the stretch, lengthen. The posture of organic, or real scoliosis is absolutely continuous, while that of apparent or postural scoliosis is not. It disappears, for example, when the patient is asleep. The skin undergoes nutritive shortening in the concavity of the curve when the scoliosis is organic, and undergoes no such change in the postural variety. The skin folds are therefore more numerous, and the skin loose in the concavity of the curve, in a case of hysterical spine.

The lower angles of the scapula should always 
be observed during an examination, and the relative position of these to the spine noted, lest a winged scapula be missed. The condition is uncommon, no doubt, but it may be met with in any workman whose daily occupation entails the carrying of weights on the shoulder-a mason's labourer, for example, as the result of carrying the hod. If the serratus magnus is the only muscle paralysed, the condition is likely to be missed, because, while at rest, there is no deformity visible except slight approximation of the lower angle of the affected scapula to the spinal column. To test these muscles, the patient should be asked to raise the arms in front of the body, and to push against resistance (Sherren). If the lower trapezius alone is paralysed, there is slight winging of the scapula, which disappears as soon as the serratus is thrown into action, but on pushing below the level of the right angle, the winging is increased. If the serratus is alone paralysed, winging is scarcely noticeable, but becomes marked when the arm is raised to a right angle, and more marked still on attempting pushing movements.

During the inspection of the patient, any characteristic attitude should be noted and its cause considered. Nature always demands "rest" in the presence of pain. She also demands protection, and the human body is so 
beautifully constructed that she can usually attain her object. The attitude of the patient is the result of Nature's attempt to protect and give rest to the painful part. The nerves which supply a joint, supply also the museles moving that joint. If the joint is inflamed, the nerves are irritated, and the muscles moving the joint are so kept in a state of constant watchfulness that the joint is held stiff.

If there is disease of the bodies of the vertebra, or of the intervertebral joints, this is exhibited in the phenomenon called "boarding." The muscles of the back are held so rigid, that on palpation they feel like a board. (For a list of conditions in the spine which may give rise to boarding, see page 102.) It is interesting to note in passing how boarding is exhibited in the abdomen when the appendix is inflamed, and how the boarding spreads over the rest of the abdomen as the inflammation spreads within, and finally, if the appendix becomes gangrenous, and its nerve supply therefore cut off, how the boarding may disappear just over the region of the appendix, while it remains over the rest of the abdomen. The characteristic attitude of appendicitis need not be recalled, but the attitude is the result of Nature's attempt to give rest and protection to the inflamed area.

If a joint is inflamed, it is held in a character- 
istic position, which depends to a great extent upon the relative strength of the muscles on either side of it. The muscles which bend a joint are, with a few exceptions, stronger than those which straighten it. Most joints when inflamed are therefore held in a bent position. The wrist, the forefinger, and the thumb joints are held straight, however, beeause the muscles on either side of these joints are of about equal power.

The spine is made up of a series of complicated joinț, and the characteristic attitudes associated with spinal injuries are correspondingly complicated. In this, our first step in diagnosis, we are not coneerned with the differentiation of attitude from deformity. By attitude is meant a posture assumed by the patient, natural or acquired, but which may be made to disappear on manipulation, or which does of itself disappear during sleep, or under an anesthetic. By deformity is meant an abnormal posture which is permanent, more or less fixed, and which does not disappear with unconsciousness. An attitude may become a deformity if the cause of the attitude is continuously at work-that is, during the sleeping as well as the waking hours. Without at present differentiating as to the temporary or permanent nature of these two groups, we may classify the whole as posture, position, attitude, or appearance, 
and merely state the altered anatonical relationships of the various parts of the spine.

(1) Disappearance of Normal Curves.- We know the development of the spine (page 5), and to what the normal eurves of the spine are due. A retrogression to the infantile curve, or more correctly a progression to the eurve of old age, due to the atrophy or fibrosis of the intervertebral dises, may be deseribed as a "disappearance of the normal eurves." This is a slow change, and is, as a rule, progressive. It does not come on until some considerable time has elapsed since the injury. It is probably of the nature of a so-called rheumatoid change in the intervertebral dises. I have seen it in the case of soldiers who have been buried under sandbags after an explosion, and it appears as if a prolonged bending of the spine were necessary for its production, as, in each case in which this developed, the man had been buried for a considerable time before he was relieved. The same oecurs in miners who have been similarily buried by a fall of coal from the roof. Pathologically, it is of course possible for a gross injury to any of the spinal joints to cause this rheumatoid change, but it is the writer's experienee that it more frequently follows such forms of injury as have resulted from the application of a prolonged form of violence. 'This is a real deformity. It does not disappear when the patient is laid on 
his face upon a table, as the postural variety does.

(2) Exaggeration of Normal Curves.-We have seen that the flexors of joints are as a rule stronger than the extensors. In the spine this rule does not hold good. To prove this for ourselves, it is only necessary for us to lie flat on our back with the hands above the head, and, even although the feet are fixed, we will find how difficult it is for us to rise up into the sitting posture. The extensors of the spine are the muscles employed in weight-lifting. If the joints of the spine are inflamed or injured, the erector spinie muscles, on account of their greater strength, should pull on and exaggerate the lumbar curve. It will be remembered, of course, that the dorsal curve is practically fixed normally. This exaggeration of the lumbar curve is generally spoken of as lordosis. Its degree is difficult to estimate, as the lumbar curve differs in different individuals. If exact figures are wanted for the purposes of a report, or for future reference, the patient should be laid on his back on a flat table, with the heels, buttocks, shoulders, and knees touching the table. The distance of the limit of the lumbar curve from the table can then be quoted in exact figures. If the lordosis is not fixed, it will disappear as the knees are flexed up on the abdomen.

(3) Riginity.-For want of a better expression, 
this term may be used to denote a condition in which the patient keeps his spine as motionless as possible. This is a common condition to note in the examination of back injuries. The erector spina muscles are usually seen to be in action during the whole examination, and when the patient is in the upright position, it is difficult to get him to undo this fixation of his lumbar curve. Several methods may be adopted to prove that this is purely an assumed position. (See page 93.)

(4) Lateral Curvature.-This is usually recorded by a tracing of the spinous processes. A method whereby it may be measured in terms of an angle is shown on page 109.

(5) Rotation.-The degree of this is best estimated by getting the patient to fold the arms across the chest, and to bend forwards while the examiner looks along the spinal furrow from behind. The rotation, which is usually in the dorsal region, causes the ribs to bulge on one side, viz. the side to which the bodies of the vertebrie are rotated.

\section{Palpation}

Palpation should be performed, (1) while the spine is at rest, and (2) while it is undergoing movement. At rest, it enables us to localise the spinous processes, and to estimate the condition of the back muscles. Usually, the erector spinæ 
muscles will be found to be in action, even al though the patient is lying down. Sometimes it is possible to detect fibrous nodules within the muscle, but there is no special position in which one can be sure of finding the muscle relaxed, and 'so these are difficult of detection. If the patient is thin, the lumbar vertebre may be palpated through the abdomen. This method of palpation is useful when examining the spine during movement. The patient should be laid on his belly on a couch. The hand of the examiner on the abdomen is used to lift up the patient off the couch. During this procedure, the other hand may be employed in palpating the lumbar spines and estimating their range of movement.

Boarding of the spinal muscles has already been mentioned under "inspection" (page 96). Palpation of the spine during movcment will give us further information. It is not sufficient to place the hand on the patient's back, and to ask him to bend forwards, and to note that there is boarding; this is only a half truth. The test is incomplete unless the examiner's hand is kept for at least a full minute on the patient's back when he (the patient) has bent it as far as possible. Three things may happen when boarding is present.

(1) The spine may remain absolutely stiff in the region under observation. This may indi- 
ante the presence of-(a) tuberculous disease, (b) congenital deformity (fairly common), (c) osteo-arthritis (common), (d) senile rigidity, (e) old fracture (uncommon, unless the fracture has been very extensive), $(f)$ malignant disease of the spine (uncommon), $(g)$ traumatic myositis ossificans (uncommon). It will be seen from this list that "boarding of the spine," although one of the classical signs of tuberculous disease of the spine, is by no means necessarily due to this disease.

(2) The erector spince muscles beneath the examining hand may begin to twitch. This is followed by a "giving" of the spine. The manner in which this "give" takes place is of importance. If there is a short "give," then a slightly longer one, and so on until the spine is fully bent, it indicates that the erector spinse muscles have been voluntarily kept in action. They have gradually become more and more tired out, and have finally become exhausted. This indicates that the boarding has been nerrous in origin. It is found in hysteria. It is often found in the case of a malingerer, but is never found (in my experience at least) in cases of traumatic neurasthenia. In this last mentioned condition, the true traumatic neurasthenia is meant ( $a$-sthenos=strengthless).

(3) There is another series of "gives" possible. 
This occurs as a more or less gradual "give" followed by a shorter one, then a shorter, and so on, till the back is fully bent. The rigidity or boarding in this case has probably been due to, $(a)$ rheumatism, (b) to some strain or wrench of the spinal joints.

While dealing with palpation, and not being aware of any literature on the subject, the author would like to record having met with two cases in which small subcutaneous lipomata were said by their possessors to have been developed after receipt of an injury. These tumours had the characteristic dimpling on digital pressure associated with lipomata. In one case there was a fracture of the spine, and in the skin supplied by the corresponding spinal segment there were many of these small tumours (bilateral), the largest being no bigger than a hazel nut. In the other case, there was the history of the workman having been jammed in such a position that his spine was bent towards the right side by a fall of stone in a pit. Here there were fewer tumours, localised to the right side in the region supplied by the last dorsal segment. No actual bone damage could be seen on $\mathrm{X}$-ray examination of this case. When I examined this man, it was eighteen months after the accident. He stated that the lumps came when he got up out of bed after his accident, and within two months of the date of it. 


\section{MOYEMENTS AND MEASUREMENTS}

The range of movement of the spinal column as a whole is by no means so extensive as is generally supposed. The figures referred to on page 17 may again be used to prove this. They are from photographs of an expert in physical culture during movement of his spine. A line was drawn on his body, extending from the anterior superior spine to the tuberosity of the ischium. This really represents the line of the pelvis, so that, when the pelvis moves, the line will correspondingly move. Fig. 5 shows the man lying flat on his back. The pelvis line is seen to be lying at an angle of about 60 degrees with the table. Fig. 6 shows the pelvis line at a similar angle, and the back lifted away from the table. The lumbar curve has disappeared; the dorsal curve has remained unchanged. The head has been raiserl, roughly, through 60 degrees. Fig. 7 shows that in order to raise the head farther from the table, the pelvis must rotate through the axis of the hip joints. This is indicated by the pelvis line becoming more perpendicular. It is now making an angle of 75 degrees with the table. It will be noticed also that the cervical spine has been bent. Fig. 8 shows him in what might be called a rightangular position. This is the fullest extent to 
which he can bend his spine. During all these photographs, the knees were kept in contact with the table. In Fig. 8 it will be seen that the pelvis line is now at right angles to the table.

Now let us analyse the extent of these movements. We may safely leave out of account the movements of the head upon the spine, and even those of the cervical vertebre, as they are seldom implicated in the ordinary back injuries.

The very great proportion of injuries to the spine are sustained in the lower dorsal and lumbar regions. This, of course, is on account of the stress to which this part of the spine is subjected in all forcible movements of the trunk. Nature has accordingly made this the strongest portion of the whole column. The muscles are strongest here, and the bones themselves are most massive.

The dorsal region will have been noticed to undergo practically no change in shape whatsoever. 'This point, if not sufficiently clear' on the photographs, will be proved on measurement. The dorsal region may be said to contribute absolutely nothing towards flexion of the spine as a whole, so far at least as flexion between the individual dorsal vertebrix themselves is concerned. Let us take, then, the upper limit of the dorsal spine, and see through what arc of a circle it has moved 
during full flexion of the spine below this level. In the straight position of the spine it is lying just below the level of a horizontal line drawn through the hip joint. When the spine is fully flexed, it comes to a point just beyond a perpendicular line drawn through the hip joint. It has moved through just a little more than a quarter of a circle-this, be it noted, in a man whose profession is physical eulture. Practically it has moved through a right angle, hence the above term "right-angular position." Of this right angle, a portion has been due to movement through the hip joints. That is to say, we must subtract from the right angle the portion which has been due to flexion of the hip. The pelvis line has changed, from an angle of 60 degrees with the table, to an angle of 90 degrees (right angle). The whole excursion was 90 degrees, so that the lumbar spine accounts for 60 degrees and the hip joints 30 degrees of the movement.

The practical point of all this for the medical examiner is that, if a man can sit in the rightangular position-that is, with both knees touching and with both knees on the table-he can bend his spine fully. Let us now see how much this amounts to on measurement. We can locate the first dorsal spine; we can also locate the posterior superior spines of the ilium. These may be marked on the patient's back. The last dorsal 
spine should be located, by counting upwards, and this should also be marked. If the commencement of a tape measure is laid over the first dorsal spine, the last dorsal spine will, as a rule, be found twelve inches farther down the spine, and the posterior superior spines will usually be found about eighteen or nineteen inches from the first dorsal. If we locate the fourth lumbar spine, we will learn even more with regard to the site of the movement which occurs.

The patient during these measurements should be standing in an upright position. If he is now asked to bend forwards as far as he can, it will be found that there is no change in the measurement of the dorsal surface. There has been no flexion of the dorsal vertebre, for the last dorsal spine still corresponds with the figure twelve inches. The distance between the last dorsal spine and that of the fourth lumbar will be found to have increased by about an inch and a half. The space between the last dorsal and the posterior superior spines will have increased by about two and a half inches. The space between the fourth lumbar' spine and the posterior superior spines will have increased by about an inch.

These are the average movements taken by actual measurement of a large number of normal backs. If the reproduction of the accompanying photographs shows the figures on the tape 
measure, it will be seen that the actual numbers are as follows :

(1) With back straight (Fig. 9)-

1 st dorsal, 0 inch.

12 th dorsal, 12 inches.

4th lumbar, $16 \frac{1}{2}$,

P.S.S. level, 181

(2) With back fully bent (Fig. 10)-

1st dorsal, 0 inch.

12 th dorsal, 12 inches.

4th lumbar, 18 ,

P.S.S. level, 21 ,

To put these measurements in a more striking light. There is a distance of $4 \frac{1}{2}$ inches between the last dorsal vertebra and the fourth lumbar when erect, and this increases by $1 \frac{1}{2}$ inches during full flexion. There is a distance of $1 \frac{3}{4}$ inches between the fourth lumbar vertebra and the P.S.S. line in the erect posture, and this increases by $2 \frac{1}{4}$ inches. This shows how much greater the range of movement is between the lower lumbar vertebre than between the upper. This is borne out in the writer's experience in many cases in which fracture has occurred in the upper lumbar region. A great many of these cases recover without any restriction in the movements of the spine.

It is easy enough to locate the various bony points, and to take measurements when the patient is in the upright position. It is difficult 

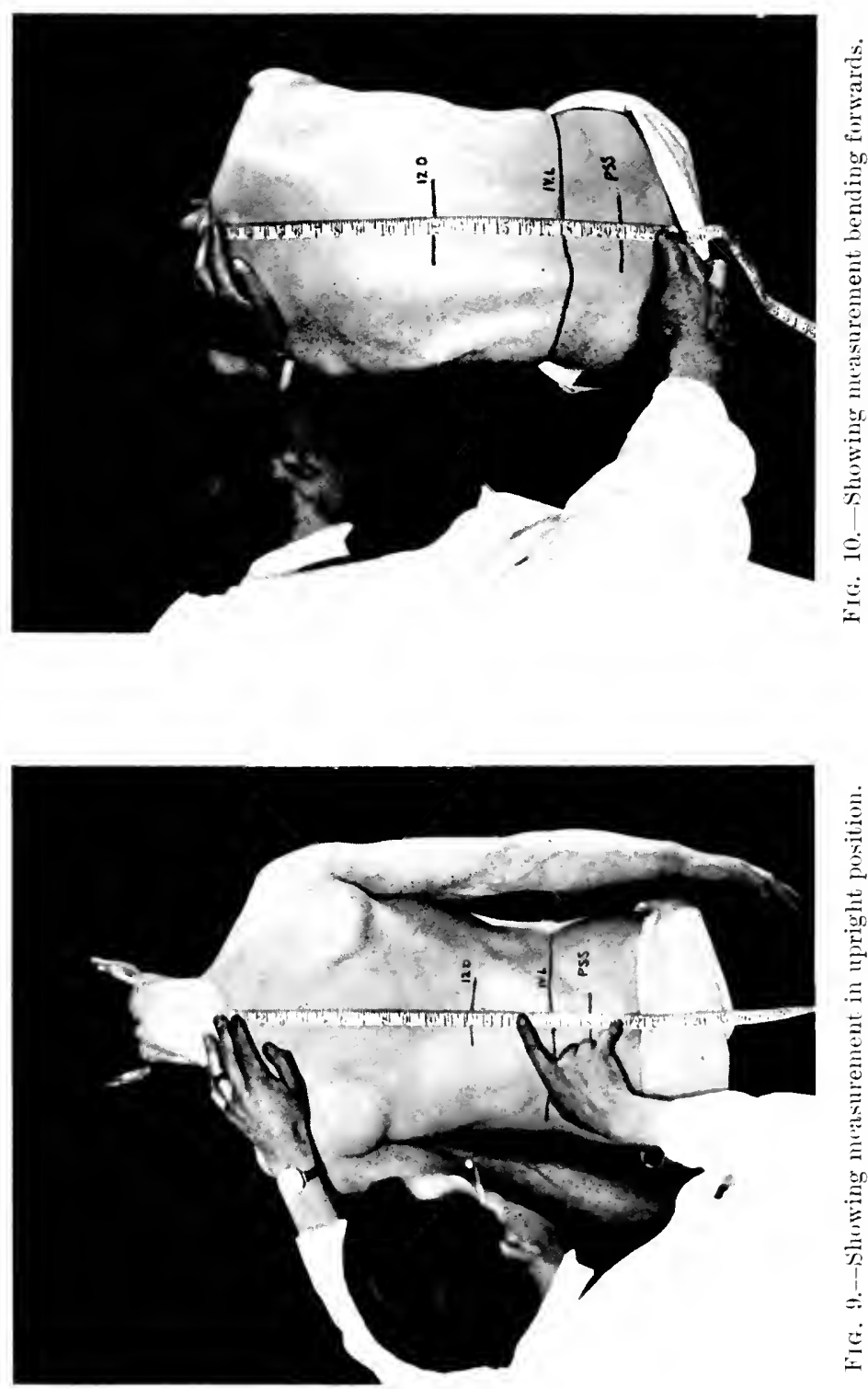

 


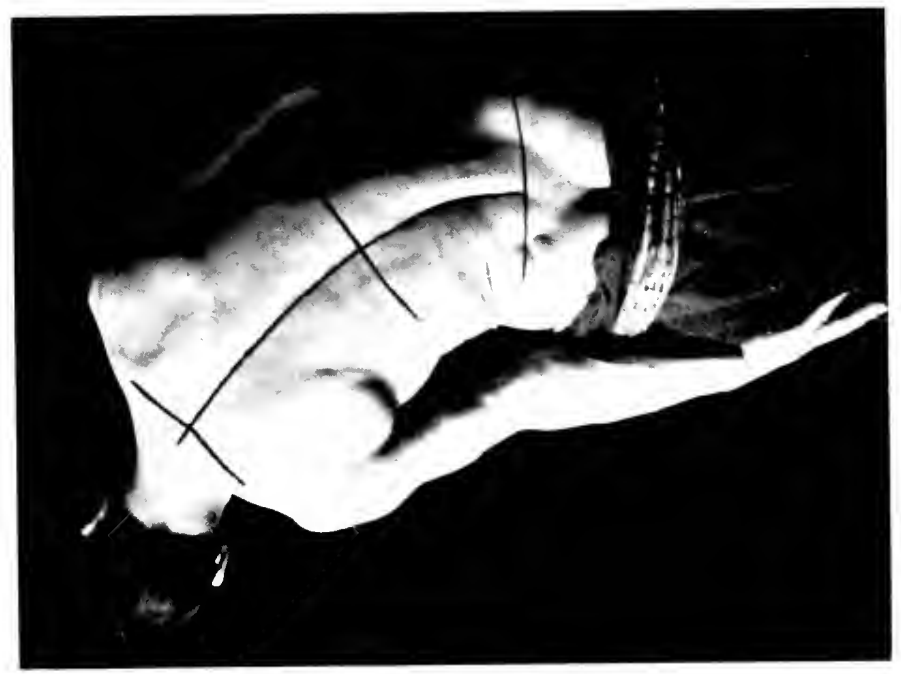

造
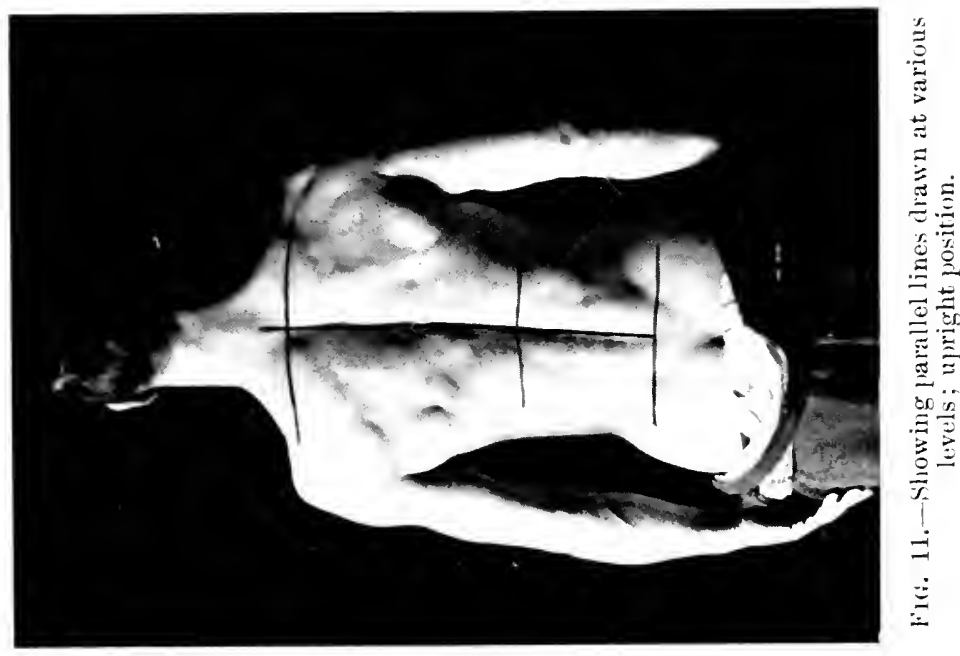


\section{MOVEMENTS AND MEASUREMENTS 109}

to get him to bend forwards as far as he can. I have done this repeatedly, and found that all the movement was taking place at the hips. On getting such a patient to sit in the right-angular position, it will often be found that the usual two or three inch elongation is obtained.

From the above it will be seen that flexion does not occur in the dorsal region. From the following it will be seen that the same may truly be said about lateral flexion. Fig. 11 shows the same athlete in the upright position. A line has been drawn down the centre of the back, corresponding to his spinous processes. At right angles to this line, three others have been drawn. One at the level of the first dorsal vertebra, another at the level of the last dorsal, and another across the posterior superior spine level. On lateral flexion of the trunk, it will be seen that the lines representing the limits of the dorsal vertebræ remain parallel to one another, while they makc a marked angle with the P.S.S. line. Lateral flexion is taking place entirely in the lumbar region. The photograph (Fig. 12) shows the extreme limit to which the athlete could laterally flex his spine. This was when the hips and shoulders were in the same plane. If even a slight degree of rotation were allowed, there was apparently a very much greater degree of lateral flexion visible.

While discussing rotation, it may be remarked 
that its degree is very difficult to estimate accurately in the different levels of the spinal column. It was with the greatest difficulty that the subject of these photographs could be got to keep from rotating his spine while showing the limits of lateral flexion. The same may be said in an increased degree of an attempt to get a photograph of him in the position of his fullest rotation. Allowing a little lateral flexion, he could get the arms in a plane at right angles to the plane of the hip joints. When the small degree of lateral flexion was disallowed, the range of rotation was markedly restricted. The difficulties in measuring the degree of limitation of the movements of rotation and lateral flexion of the spine need not preclude us from expressing an opinion thereupon. Different people can rotate their spines to a different degree, probably on account of the diverse occupations which they follow, so that any opinion expressed regarding any limitation of this movement is purely relative to a rough average.

Fortunately, an exact estimate of any limitation of rotation or lateral flexion is not. called for in the examination of injuries to the back. If flexion and extension are not restricted, it follows that rotation and lateral flexion will not be restricted either. This will be more easily appreciated if we recall the nature of the spinal joints. For the performance of full flexion and extension, 


\section{MOVEMENTS AND MEASUREMENTS 111}

the intervertebral discs must have retained their elasticity, and the interspinous joints their full capability of gliding upon one another. It follows from this, that the joints are functionally good, and that rotation and lateral flexion will be likewise unrestricted. It seems hardly necessary to point out that where there is a fixed deformity of the spine, such as is present after empyema, this rule does not hold good.

Slight lateral curvatures of the spine are very common. In fact, it may be said that nobody possesses an absolutely symmetrical body. The right and the left legs are seldom the same length. This cannot be detected by actual measurement, but is evidenced by the fact that a wanderer in the desert, when attempting to walk in a straight line, will describe a huge circle, and probably come back to the place from which he started. So slight is the inequality in the length of the limbs, that it cannot be detected or even measured. Nature compensates for this, and keeps the body erect by slight curving of the spine. When a curve is present which cannot be accounted for, there are various measurements which we can make, in order to find out the origin of the asymmetry. Tubby had suggested several measurements for the detection of asymmetry. From the supra-sternal notch to the anterior superior spines of the ilium. From the supra- 
sternat notch to the internal malleoli. From the anterior superior spines to the internal malleoli. By comparing the measurements on either side, the site of the asymmetry may be arrived at.

\section{X-RAY EXAMINATION}

X-ray examination plays an important part in exact diagnosis of injury to the back.

It falls to the lot of one seeing many thousands of radiographs per year to come across some interesting and unique cases, but the frequency with which fractures of the spine are seen, with little or no clinical evidence of such a lesion being present, is more than unique; it is eommon. Since taking a special interest in this region of the body, I have subjected many cases of injury to the back to an $\mathrm{X}$-ray examination. Even in cases where fracture of the spine was scarcely more than a remote possibility, in which there was no deformity detectable on ordinary clinical examination, and no symptom or sign to indicate that a fracture had occurred, it has been found, and this not in one, or even two, but in many instances. The fracture in such cases has been situated in the upper lumbar region. It is usually of the nature of a compression fracture, and has been produced by a form of violence which would 
cause longitudinal jarring of the spinal column, or forcible bending beyond its physiological limits.

It should be emphasized that the fracture always corresponds with the nature of the violence producing it, and that it may be due to a degree of violence surprisingly slight.

It is unnecessary that the medical examiner need be intimately familiar with the method of taking the radiograph, but he should know sufficient about it to be aware of the possibilities, limitations, and pitfalls in technique which may affect his interpretation of the radiograph when finished.

Cervical Region.-It is impossible to obtain a satisfactory antero-posterior (A.P.) view of the upper cervical vertebra, because the shadow cast by the lower jaw is superimposed upon the vertebral shadow so as to obliterate it.

If the lesion is definitely localised, it may be possible to show the first and second cervical vertebre through the open mouth, but this is a matter of chance, as these vertebric camnot be palpated and localised so as to show through the mouth.

A lateral view is easily obtained of the upper cervical vertebra. This shows the individual vertebra beautifully in profile. If it is wanted for any special reason to show the odontoid pro- 
cess of the axis, or the neural arches of the first and second, the tube should be centred not directly over those vertebre, but over the external auditory meatus, or even above this level if the neck is rigid. It is impossible to show more than from the first to the sixth cervical vertebrie in this lateral view, because the X-ray plate cannot be sunk down any deeper into the root of the neck. In this lateral view, note the large size of the lamine and spinous process of the second as compared with all the others, and the neural arch of the first with practically no spinous process. It also shows how these are widely separated from one another to allow of nodding movements of the head, and how all the others are directed downwards and backwards, parallel with one another and close together.

The spaces occupied by the intervertebral dises should be clearly seen. Do not be misled by the shadow of the hyoid bone, which is usually visible as a very irregular shadow lying in front of the spine, its shape depending upon the angle of incidence of the $\mathrm{X}$-rays during exposure. The thyroid cartilage casts a shadow which cannot be mistaken for anything else.

Cervico-dorsal Region.-This and all other regions of the spine, except the above, are best taken with the plate behind, and the X-ray tube 
in front of the body (A.P. view). This is a convenient view to take in any injury about the root of the neck, including from about the fourth dorsal vertebra. It may be taken with the head looking straight forward or looking to one side, the pictures of course differing from one another. Both should be taken. Note that the intervertebral spaces are all visible, that the seventh cervical has very large but not dense transverse processes, that if the head is in the direct A.P. position the spinous processes form a straight line. Do not be misled by the apparent fusion of the transverse processes of the lower cervical vertebræ; this is due to their normal imbrication.

Dorsal Region.-This is the most unsatisfactory portion of the spine to examine by means of X-rays. The shadows of the vertebræ have superimposed upon them the shadows of the heart and great vessels, as well as that of the liver.

It is fortunate for this reason that the dorsal region is comparatively seldom the site of a traumatic lesion.

Dorso-lumbar Region.-This is a convenient view to take, because it is by far the commonest seat of injury in the whole length of the spinal column. It includes the last three or four dorsal vertebræ and the first three or four lumbar. Note that the lower dorsal vertebræe are not so clearly defined as the lumbar on account of the superimposition of 
the liver shadow. Note also the meagreness of their intervertebral dises as compared with those of the lumbar. The outline of the psoas musele is usually visible. The transverse proeesses of the lumbar vertebre are well seen; but do not be misled by the line of erossing of these shadows, which may often be so marked as to simulate a fracture of the transverse process.

If there are any adventitions shadows present in the region of the lumbar spine, these must not be positively diagnosed as due to trauma or disease, unless they are constantly present in subsequent radiographs of the region. Such shadows are often due to frecal masses in the bowel. The presence of gas in the bowel may also mislead the unwary. There is another misleading shadow which is often seen apparently running through the body of a vertebra, and which is sometimes wrongly diagnosed as a fracture. This is the shadow east by the articular processes. These shadows may be demonstrated in most of the lumbar vertebræ, but it often happens that one is more distinctly seen than all the others, and, unless the observer is particularly familiar with its appearance, an erroneous interpretation is all too easy.

Lumbar Region.-This has already been discussed in the foregoing paragraph, and is now given because it is a common view to take, viz. from 
first to fifth lumbar vertebrie. It is in this view that apparent curvatures are so common. If any curvature is present, it is well to note (1) the shape of the bodies and of the discs; in temporary curves the discs alone present a very definite wedge-shape, the bodies being unaffected. (2) The relative position of the spinous processes. In temporary curves, these still retain their medial position in relationship to the shadows of the bodies. A localised deviation is pathological, whereas a generalised deviation of the spines to one side is probably the result of the X-ray tube not having been centred vertically over the middle line.

(3) The size and shape of the interlaminous spaces should also be noted: these may be markedly altered by the posture of the patient.

The normal lumbar spine presents a marked antero-posterior curve with its convexity directed forwards. The most prominent part of the curve is at the promontory in the region of the fifth lumbar vertebra. This portion of the spine then is removed a considerable distance from the $\mathrm{X}$-ray plate on which the patient is lying; the shadow cast is therefore not so distinct. When the patient is lying "flat on his back," the curve is so marked that the operator's hand can be easily inserted between the plate and the patient's back. If the X-ray plate is taken with the patient in this position, the interlaminous spaces are seen to be 
small. This is where most of the movement occurs in bending the back; and if there is any difficulty in getting the patient voluntarily to bring the back into contact with the $\mathrm{X}$-ray plate, he should be asked to draw up his knees. This will bring the back into contact with the plate, and a better result will be obtained.

It is sometimes necessary to have a permanent record of the fact that the patient is actually able to bend this portion of his spine. When he alleges that the back is "stiff," an X-ray plate taken in both postures will afford this evidence, and the amount of movement can be demonstrated by the difference in size of the interlaminous spaces. If further proof is needed, a measurement may be made of the distance between the shadows of the spinous processes on the two plates. When the back is arched forwards, the spinous processes which are situated in the concavity of the curve are crushed together, whereas in the straight position of the spine they are more widely separated from one another.

Lumbo-sacral Region.--To anyone who has not had an extensive experience in the interpretation of $\mathrm{X}$-ray plates in this region of the body, mistakes in diagnosis are bound to arise. This is due to the anatomical arrangement of the parts, as well as to the natural law that $\mathrm{X}$-rays, like light rays, travel in straight lines. Before this can be eluci- 


\section{X-RAY EXAMINATION}

dated, we must appreciate the fact that a radiograph is a shadow picture, and that the farther the opaque object is removed from the sereen on which it falls, the larger will be the shadow and the less distinet its outline. There is another point to be borne in mind, viz. that the rays are able to, and do penetrate the solid object, and therefore cast a shadow of the near as well as the far side of the object. The $\mathrm{X}$-ray shadow of any wedge-shaped object is aceordingly misleading. In the foot it is impossible from any point of view to get a well-defined radiograph of the wedge-shaped cuneiform bones. The lumbosacral region of the spine is a meeting-place of wedges, and is always far removed from the $\mathrm{X}$-ray plate. This twofold anatomical disadvantage cannot be overcome, and must be taken into consideration before a correct interpretation of the plate can be arrived at.

The body of the fifth lumbar vertebra is far removed from the $\mathrm{X}$-ray plate. It is not the same shape as are the other lumbar vertebre, but is wedge-shaped, with the narrow end of the wedge directed backwards. Not only so, but it is bound to lie at an angle with the X-ray plate, beeause its axis is directed backwards and upwards. The X-rays, therefore, fall obliquely upon it and through it, and the shadow cast upon the plate is ill defined. It should be noted that its lamine 
and spine are less massive than those of the other lumbar vertebrae.

The development of the fifth lumbar vertebra is peculiar. It has in addition to the separate epiphyses common to other vertebræ two epiphyses for the laminie also. These are frequently found in the adult to have remained ununited. This gives rise on $\mathrm{X}$-ray examination to a line which closely simulates a fracture. It is even fairly common to find that one of the lamine of the fifth lumbar vertebra has entirely failed to develop normally; a distinct gap is seen in such cases on $\mathrm{X}$-ray examination.

I have recently gone over nearly twenty thousand X-ray plates, and paid particular attention to those of the lumbo-sacral region. The majority of these were taken not for the condition of the spine, but for purposes of diagnosis in genito-urinary cases. It may therefore be assumed that the question of trauma did not arise in these. In practically every case the fifth lumbar vertebra presented the appearance of having been crushed. It did not cast a shadow anything like the other lumbar vertebrie. In the vast majority of cases the outline of the body either could not be seen, or was so ill-defined that its detection was hardly more than a guess.

The articular processes varied greatly, and very often presented an appearance which suggested 
diagonal crushing of the vertebra in question, and even sometimes a diagnosis of dislocation would have been excusable. The lamina were perhaps even more peculiar than any other portion of the vertebra-always narrow, but casting a very dense shadow. Usually the laminre were off the horizontal plane, giving the vertebra an appearance of having been tilted. In quite a number of cases a developmental malformation was apparent, and in some of these a fracture of the lamina was simulated. In some, the spinous process and adjacent portion of the neural areh were absent. In others a portion of the neural arch, just where the spinous process joins on to it, was absent. In all these malformations the free ends of bone were nicely rounded off. In those which simulated fracture there was apparent overlapping of the free ends, which could not accordingly be well outlined.

It is little wonder that damage is often diagnosed here when none exists. In order to avoid slipping into this error, think of three things: (1) Could the violence possibly have produced a fracture in this particularly strong region? (2) Do the symptoms and signs point to gross damage to the base of the spinal pedestal? (3) Is the diagnosis of damage here justifiable from X-ray examination alone?

The shadow of the sacro-iliac joints also is mis- 
leading. The sacrum is a double wedge placed between the two iliac bones; the narrow end of the wedge in one direction is directed backwards and upward, and in the other direction backwards and downwards. This gives rise to a very complicated shadow, the misleading factor in which is the double, and sometimes at parts treble, outline of the joint. This is due to the penetration of the rays, which cast a shadow of the anterior, middle, and posterior portions of the joint, which lies at an obtuse angle to the $\mathrm{X}$-ray plate. In the normal pelvis one or other of these double lines is uncommonly like a fracture, and unless one is accustomed to this appearance a fracture may be diagnosed in error.

Screen Examination.-This part of an X-ray examination is not so often taken advantage of as it might be. It is useful in determining what anatomically corresponds with the point of maximum tenderness. If the examination is conducted on a couch with the X-ray tube underneath, it is possible to localise any damage, and to so focus the tube that the best view of the region is obtained.

In the ordinary radiograph of the lumbo-sacral region one or other of the transverse processes of the fifth lumbar vertebra is frequently seen to be apparently crushed down on to the crest of the ilium, and from the radiograph alone it is impos- 
sible to state definitely that this is a fixed or permanent deformity. A screen examination will definitely determine the temporary or permanent character of the deformity. It is so common, that the term deformity should not be applied to it. As a faet, the transverse process in question is in a different plane from the crest of the ilium, and eannot be crushed against it, and on screen examination the transverse process can be seen moving "past" the crest of the ilium.

While making a sereen examination of the spine, it is well to extend the observation to the heart and lungs. It is well known how frequently these baek injuries resolve in Court into a question of dilatation of the heart from strain. The size of the heart cannot be aceurately estimated by any other means than by X-rays. It is useful, therefore, to be able to give accurate information regarding the actual appearance of the heart.

It is surprising how often an unsuspected aneurysm is discovered in the course of such an examination.

\section{Electrical Testing}

Muscle Testing.-In the ordinary clinical examination of a strained muscle, little information ean be obtained which is of any value in estimating the degree of damage which exists, or the pro- 
gress towards recovery which is being made. It has hitherto only been measured by the amount of pain produced when the musele has been thrown into action. This is a very variable quantity, depending as it does upon the man's own description and estimate of his pain.

For several years the writer tried all sorts of variations in the application of the older methods of electrical testing: viz. by means of the galvanic and faradic currents. This invariably gave negative results, unless the injury was of such severity as to be easily demonstrated by ordinary methods of examination. If some method of actually measuring the degree of deviation from normal could be devised, a great boon would be conferred on those of us who are frequently called upon to examine cases of minor baek injuries.

In January 1913, Dr. Jones ${ }^{1}$ gave a description of the use of condenser discharges in electrical testing, and as this method appeared to offer very great advantages over the older method of musele testing, I personally made a convenient apparatus out of twenty-four telephone condensers (giving a gradation from 0.018 to 2 microfarads). Since then I have used it in testing every available case of strained back in hospital and in private practice, and, in order to control

${ }^{1}$ Dr. Lewis Jones, Royal Metlical Society Transactions, vol. vi., No. 6. 
the results, have examined about a hundred backs where there was no question of injury.

The following conclusions have been come to, but are given with all reserve, as the observations only extend over a period of two and a half years, and only about 200 cases in all have been thus examined. In normal backs there is a considerable variation in the minimum discharge which will produce a response in different individuals. This is probably due to the varying resistance of skin and subcutaneous tissue of these individuals. 'There is no difference, however, in the behaviour of the corresponding muscles of the two sides of the body.

There may be some difficulty in getting the patient into a suitable position. The erector spinie muscles are usually in action to a much greater degree than the other muscles of the back. They may accordingly take a little larger discharge to produce a response. I cannot speak to the electrical condition of the muscle immediately after it has sustained a strain, because the cases which I have examined have been sent, not because the workman has strained his back, but because he has not returned to work within a reasonable time-thrce or four weeks to as many years.

The conclusions arrived at as the result of examination of such cases are-(1) 'That a muscle 
which is still suffering from the effects of strain has its electrical cxcitability altered; (2) that if no difference exists in the electrical exeitability, the muscle has recovered from any strain which it may have sustained. These are conclusions of importance to the medical examiner, even in the absence of definite information as to the nature of the change. Sometimes a strained muscle is found to be hyperexcitable, sometimes hypoexcitable, but the fact remains that there is an alteration from the normal.

With other workers in this field of investigation, we will have ere long more data to go upon, but even from the limited number of cases already examined, it would appear that strain produces an increased electrical excitability; that this diminishes in degree; that it swings past the normal excitability and gives place to less exeitability than normal (hypoexcitability), and then eventually returns to normal. I cannot say that this always oecurs, because it is not often that one has the opportunity of following up the afterhistory of these minor back injuries, but I have found it on several occasions where, this opportunity has presented itself. The following case is illustrative :

W. S., a miner, aged twenty, towards the end of a shift strained his back in May 1914, while lifting a derailed hutch. Clinically the left erector spinæe 
muscle was apparently strained. He had not returned to work by August 1914, and on examination then, the electrical reactions were as follows: left erector, $\cdot 025$; right, $\cdot 062$. It should be noted that he had never been confined to bed, that he had just gone about doing no work, and probably lounging about street corners. He had been having some sort of massage daily.

When examined in December 1914, his reactions were-left erector, 125 ; right, $\cdot 062$. It will be seen here that the injured muscle is hypoexcitable -that it took, in fact, double the stimulus to produce a response as compared with the normal muscle. $\mathrm{He}$ started work after this examination, and only suffered inconvenience in performing certain movements. He worked on till April 1915, when he again strained his back, and on examination now the reactions were as follows: April 1915, left erector, $\cdot 016$; right, $\cdot 06$. It will be seen that now he was apparently worse off than he was originally. With the view of giving the injured muscle absolute rest, I overstepped my province as medical examiner, and acted as adviser, because his original doctor had left the district; I told him to lie on his back for four weeks, and advised him as to gradual exercises. In June 1915 (six weeks later) his reactions were: left erector, 062 ; right, 062 . After another fortnight of gradually increased exercises he returned to work, and I believe is now doing his ordinary full work.

This case is illustrative of several things. It shows how the strained muscle exhibited de- 
finite deviation from the normal, being sometimes hyper- and sometimes hypo-excitable to electrical stimulation. It shows that after a strain the muscle became hyperexcitable. This is what is found in the very great majority of strained backs, and it appears that when hypoexeitability is present the muscle is just approaching the normal condition. It would further seem to show that absolute rest in bed is the most rapid road to recovery when the muscle is hyperexcitable.

The fact of there being insufficient data to establish a direct relationship between the degree of strain and the degree of deviation from the normal excitability, does not detract from the value of the fact that there is a deviation in strained muscle, and that there is no deviation in normal muscle. It may be possible in the future to assign a definite numerical value to a definite degree of strain, and for those interested in this method the following technical points may be of value.

'The principle on which the testing of muscle by condenser discharge is based, is quite simple. Condensers of known capacity are charged with electrieity, and discharged through the muscle to be tested: All that is looked for is a contraction of the muscle. We start off by discharging the smallest condenser through the muscle-say 018 
of a microfarad (Mf.). Then the next-sized condenser, 02 Mf. There may be no responsive contraction. As the condensers of gradually increasing capacity are brought into play, a response is suddenly obtained by one of them.

The response is all that is noted, and it.is useless to describe it as sluggish or of any other character, because the larger capacities will still produce the same height of contraction. That is to say, when once a response is obtained, the larger capacities will not increase the height of the contraction, although the length of the contraction will be increased.

This will be more clearly understood by a glance at the following diagram taken from Dr. Lewis Jones's paper :

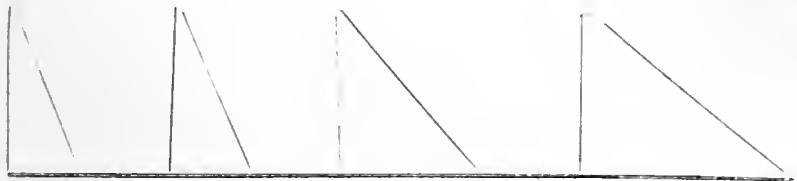

HIG. 13.-Discharge Curves of Condensers when their capacities are in the ratios of $1,2,3$, and 4 , with constant voltage and constant resistances.

Our electric mains are of practically constant voltage, and the resistance of the patient's skin is constant within limits. Our condensers are charged direct from the mains, so it is possible to record in actual figures the degree of excitability 
of a damaged muscle. This may not seem a very great advantage, but if we compare it with the older method, it will be seen that the latter is inadequate to demonstrate the slighter degrees of muscular damage which we have to deal with in back injuries. In addition to this, we eliminate at once the great variations which exist in all ordinary medical coils.

The response to electrical stimulation practically resolves itself into a question of the wave-length of the current applied to the muscle. The faradic current, as obtained from a medical coil, gives a very variable wave-length according to the make of coil. Roughly speaking, $\frac{1}{400}$ to $\frac{1}{800}$ of a second represents the duration of the wave in an average medical coil. In testing with the galvanic current with the closing and opening contraction, the wave-length is enormously longer. The discharge from a condenser of 018 of a microfarad capacity has a wave duration of about $\frac{1}{20000}$ of a second, and that from a condenser of two microfarads, a wave duration of about $\frac{1}{200}$ of a second.

Now, normal muscle reacts to a wave duration of somewhere in the region between $\frac{1}{2000}$ and $\frac{1}{15000}$ of a second, and the ordinary coil gives somewhere in region of $\frac{1}{400}$ to $\frac{1}{800}$ of a second. It will be seen, therefore, that the older method cannot possibly be used to detect the minor 
deviations of muscle from its normal condition, its wave duration being far too long. With the condenser method we have a range of wave durations from $\frac{1}{20000}$ to $\frac{1}{200}$ of a second, and by its use, which is comparatively painless, we can detect the slighter variations in the muscle, which, according to the older method, reacts normally. On the other hand, the condenser discharge method can demonstrate the existence of contractile tissue in a muscle which gives a complete R.D. by the older method.

To sum up, the older method gave us no information regarding the minor variations of the muscle from normal. The results we grouped into normal-partial R.D.-and complete R.D. The newer method gives us definite information about the minor deviations from normal; it gives us a series of numerical values (according to the number of condensers in our apparatus, 12 to 24) which we can assign to the degree of deviation, and, at the other end of the scale, we can demonstrate the presence of contractile tissue in muscle, which to the older method showed a complete R.D. It will be seen that it is possible to write down a whole series of facts which have been elicited during the examination.

There are several observations which may with advantage in some cases be written down. These apply to the man's demeanour before, during, and 
after the examination. If the case is likely to go into Court, it may be advisable to overhaul the man generally in case a question is asked regarding some trivial detail which has no connection with the injury. 


\section{PHYSICS OF BACK INJURIES}

Is dealing with the physics of any injury, the architecture and the mechanical arrangement of the parts must be taken into consideration, because the effects of violence applied will depend to a great extent upon these two factors.

The architecture of the spine has been somewhat fully discussed already (pp. 1 et seq.), and before going on to a consideration of the different effects produced by different kinds of violence, we must study the spinal column from the mechanical point of view. In order to save time and space, we will only consider what constitutes a mechanical disadvantage.

A weakness exists at the junction of curves.The word "curve" is here used in its widest sense, i.e. an alteration in the direction of the longitudinal axis of any structure. The more angular the junction, the weaker the mechanical arrangement "in general." "In general" is said advisedly, because the production of an angle or bend results in strength against one direction of force at the expense of strength in all other directions.

The spinal column presents several curves. 133 
These curves run into one another in a more or less gradual manner, and so the mechanical weakness is mitigated. The weakness, however, is always present. It should be noted that such weakness only represents a diminished ability to withstand what, for want of a better term, we call "indirect" violence, such as a "shearing" stress. This will be better appreciated when we come to analyse what really constitutes violence (page 139 et seq.).

The curves of the spine are not useless, for what is lost in strength is gained in comfort. The curves enormously diminish the minor jars which are transmitted through the spine to the head. Even in the simple act of walking, the shock of each step is transmitted through the spine to the head; we are made painfully aware of this fact when suffering from an ordinary headache.

\section{A mechanical weakness exists at the junction} of a flexible with a less flexible structure.-In the spinal column, such a weakness exists at the junctions between each vertebra and the adjoining intervertebral dises, and not only so, but also between the different segments of the spinal eolumn. The cervical region is flexible. The dorsal is almost inflexible, while the lumbar is again flexible. A weakness exists at each of these junctions. 
As an illustration of this fact the development of an aneurysm might be given. The bulge does not take place "through" the inelastic atheromatous patch, but at its junction with the elastic vessel wall. Again, the weak spot in an ordinary driving whip is at the junction of the thong with the shaft.

A weakness exists at the junction of two movements.-There are several examples of this afforded in the spinal column, but these need not be elaborated, as the junction of two movements presupposes inflexibility in other directions. Where a junction of two movements exists, thereforc, there is the junction of a flexible with an inflexible segment.

In a long structure a weakness exists at its middle.-This might be expressed in other words by saying that the strain in a long structure is greatest at its middle. It is for this reason that the connecting rod of a locomotive is made thicker in the middle than elsewhere, and for the same reason that the spokes of a wheel, which has to stand a great strain, are made thicker in the middle.

'The long bones of our body furnish a very conclusive proof of this fact, if we accept the postulate that the structure of a bone is subservient to its function. If we cxamine the distribution of the compact bone, we will find it greatest in the 
middle of the shaft, gradually tapering off towards the extremities. If we examine the spinal column from this point of view, we find that it becomes actually thimer towards its middle. This brings us to the consideration of another mechanical factor.

Constrictions constitute mechanical weaknesses.-This is so self-evident that it calls for no elaboration. It will be of interest and importance for us, however, to examine the constrictions which exist in the spinal column. The spinal column is not of equal thickness in its entire extent, nor does it gradually diminish as it approaches the head. From Fig. 3 it will be seen that its width increases from the coccyx to the top of the sacrum, diminishes till it reaches about the fourth dorsal vertebra, again inereases till it reaches the seventh cervical, and then diminishes till it reaches the first cervieal vertebra. In order to emphasize this, an exaggerated diagrammatic representation is given on the same page, showing the column to be made up of four pyramids joined together (Fig. 4). It will be noted that the most marked constriction oecurs in the region of the fourth dorsal vertebra. It should be remembered, however, that the spinal column in this region is extrinsieally strengthened by the walls of the thoracic cavity.

Adjacent mobility gives a relative increase 
in strength.-The spinal column furnishes many examples of this. Even the mobility of the scalp on the skull gives protection to the skull against direct injury. If the violence fall in any other direction than normal (i.e. at right angles to the tangent), the scalp slides upon the skull, and the direction of the force is altered. The skull is further protected from injury by its free movement on the spinal column.

The eervical region is protected by its own mobility, further by the mobility of the lumbar region, and still further by the mobility of the feet on the ground. The spinal column as a whole is protected by the free mobility of the adjacent hip joints. The position of the man at the time of the aecident is therefore of the utmost importance. If the feet are fixed, or if the hip joints are flexed to their fullest extent, the spine will be caught at a time of its greatest mechanical disadvantage.

We have seen, then, that the spinal column exhibits constrictions, junctions of curves, of various movements, and of flexible with less flexible segments: and that these constitute mechanical weaknesses. It must not be imagined, however, that the spinal column is a poorly eonstrueted mechanical contrivance. It is what nature has made it, and has been developed in accordanee with the use to which 
it has been put. In our upright posture it is of the greatest possible strength compatible with lightness and flexibility.

Certain sites are, however, at a mechanieal disadvantage when the physiological limits of function are exceeded.

Fig. 14 illustrates the relative frequency of fractures in the various regions of the spine. It is of importance to note again the relative immunity of the fifth lumbar vertebra from

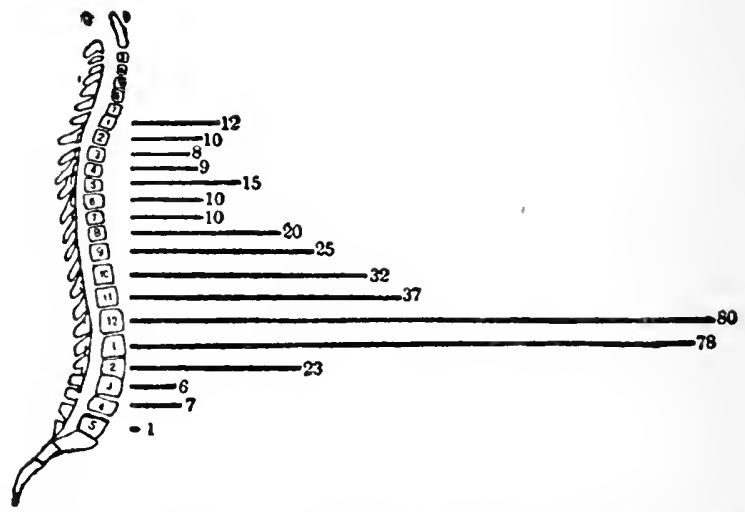

FIG. 14.-Frequency of fractures in regions of the spine (384 cases) after Ménard (Murphy).

injury. This is not surprising, for, in spite of its situation at the junction of two curves and at that, of a flexible with an inflexible segment, the spine is stronger here than elsewhere. It is the most massive and strongest region of the 
spine mechanically. It has the freely movable hip joints in the immediate vicinity, and is strengthened accordingly.

\section{DYNAMICS}

Having considered the architecture of the spine and its mechanical abilities and disabilities, we are now in a position to study the different kinds of violence to which it may be subjected, and the resistance which it can offer to such violence.

We must at the outset, however, clearly distinguish two totally different kinds of violence so far as the spine is concerned, viz., intrinsic and extrinsic.

Intrinsic Violence refers to violent or excessive movements of the spine produced by forcible contraction of the muscles acting upon it. This form of violence, bearing as it does upon a physiological factor, will be dealt with later.

Extrinsic Yiolence.-At present we will confine our attention to extrinsic violence, or force applied to the spine from without. This may be of the nature of direct or indirect violence. It should be stated that this classification of violence into direct and indirect is retained because it is the time-honoured classification fol- 
lowed in all surgical teaching. It has much to recommend it, although it is necessary to explain the meaning of the terms and to qualify them.

Surgically speaking, the qualifying adjectives "direct" and "indirect" do not apply to the violence itself, but to the site of the damage. That is to say, they refer to the relationship between the part struck and the site of the damage. They are therefore purely relative terms. If violence is applied to the body, and the damage is produced at the site of impact, the violence is said to be "direct." If the same violence is applied to the same part of the body, and the resulting damage occurs at a distance from the site of impact, the violenee is said to be "indirect." So long as this is distinetly understood, we may employ the terms in accordance with surgical usage. It will be seen that, although clinically deseriptive, the terms in no way describe the violence, and do not help us therefore in the appreciation of the how and the why a certain injury has resulted therefrom. Violence may be defined as that which produces injury, and, as such, must be composed of two or more forees acting at one and the same time. The surgical term violence practically corresponds with the mechanical term "stress."

Stress is that which produces strain, and strain 
is the deformation produced by stress. The term "stress" is used, therefore, to denote a combination of forces acting together upon a body. The term "strain" is used to indicate the fact that the body has been deformed thereby, or that a tendency to alteration in shape has been set up in a body. The direction or nature of the strain will, of course, depend upon the direction of the various forces which are at work upon the body. Flexion, compression, shearing, or torsion may be produced, but before going on to a consideration of these, it is essential that we have a clear understanding of the component parts of a single force.

Every force las three principal qualities: (1) point of application; (2) direction; and (3) intensity. These qualities are so definite that it is possible to represent any force graphically by means of a straight line. One end of the line may be taken to represent the point of application, the direction of the line to indicate the direction of the force, and the length of the line its intensity.

The point of application of a force is only of importance in its relationship to the point of application of the other force or forces, which may be acting upon the body at the same time (p.144).

The same may be said of the direction of a force. It only develops its importance when considered along with the other forces.

We can pass then to a consideration of the 
third quality of a force, namely, its intensity. The intensity of a force is a measure of its momentum. We know that the momentum of a body is equal to its velocity multiplied by its weight. We have, therefore, two factors to take into consideration. In dealing with injuries, it is the individual factors of the intensity, and not the intensity as a whole, which determines the nature of an injury.

The same intensity of violence will produce different effects according as the relationship between its component parts is altered. This is of prime importance in the study of the physics of injury, and resolves itself into the fact that the transmission of force through an elastic solid takes an appreciable time, and that in the process of transmission it is being gradually dissipated throughout the solid. A sharp blow will produce deformation in the immediate vicinity, whereas the same amount of force (intensity), applied more slowly, will have time to be transmitted and will produce strain throughout the whole structure. This can be described in terms of elasticity. When a blow is struck with a hammer on the end of a rod, there is compression produced in the immediate vicinity. This passes along the rod as a wave of condensation, followed by a wave of rarefaction (due to elasticity), exactly analogous to 
a wave of sound. If the counter force is insufficient, the rod will, of course, be projected in a line with the force applied; but as we are considering "injury," we must take it that the counter force is as great or greater in degree than the impressed force of the blow from the hammer. A short sharp blow allows of recoil, but if the compression is produced at a greater speed than the wave of compression can travel along the solid, deformation or injury will result at the site of impact. This is described surgically as "direct" violence. If, instead of a short sharp shock, the head of the hammer is allowed to follow on, or if it is of a sufficient weight to overcome the recoil, the condensation will travel throughout the length of the rod, and the whole of it will be in a condition of "compression strain." 'The rod will then give way at its weakest point. This is described surgically as "indirect" violence.

In spinal injuries these two factors, comprising the intensity of a force, are continually coming into play-the short sharp shock and the prolonged force. The former produces fracture in many cases where the intensity of the violence is apparently surprisingly small.

Two or more forces are necessury for the production of injury-an impressed force and a counter force. The combination of these two or 
more forces is what we call "violence." We are accustomed to consider the impressed force alone as the violence. This is far from correct, because of the two the counter force determines, even more than the impressed force, what the site and the nature of the injury will be. It should be pointed out that there are often two counter forces in action, and that the points of application of these counter forces determines the site of the lesion.

Flexion.-To produce bending in a straight structure, an impressed force and at least two counter forces are necessary. In the case of the spine, which normally presents several curves, an exaggeration of these curves may be produced by a single impressed force and a single counter force, if these are applied at either end of the spine.

Conpression.-Compression is produced when the counter force and the impressed force are in the same straight line and in opposite directions.

Shearing.- Shearing stress is set up in a body when the counter force and the impressed force are in opposite directions, but not quite in the same straight line. That is to say, when one part of the body tends to be "driven past" the other part.

Tonsion.-For the production of a torsion stress at least four forces are necessary, in order to establish the two couples which are essential.

In spinal injuries it is difficult to separate these 
varions stresses from one another, or to describe the strain produced as of onc single character. This is on account of the complex structural nature of the spinal columm.

Fall on the buttocks.-If this injury is analysed, it will be found that the impressed force and the counter force are equal and opposite, and therefore interchangeable. The travelling body is brought to an absolute stop when the buttocks strike the ground, but the whole body does not come to rest at the same moment. The head continues to travel downwards after the buttocks have come to rest. A wave of condensation is set up in the base of the spinal column. This wave is transmitted upwards through the spine, and meets the down-coming head. Several things may happen, and these will be determined by, (1) the elasticity of the spine, and (2) the momentum of the travelling body. The elasticity of the spine varies with age. A young man's spine is to an old man's something as a cane is to a carrot. The momentum of the travelling body depends upon the height from which it has fallen, and upon its weight.

Now let us take a simpler illustration, and see what happens as we gradually increase the speed of the travelling body. If a curved rod is held a short distance from the ground and dropped end on, it will rebound a short distance. If it is dropped from a greater height, it will rebound a 
greater distance. This relationship between the height dropped and the extent of the rebound does not go on indefinitely. A point is reached when the rod will break instead of performing a rebound, and this is not all, for if the distance dropped is still farther increased, the break will be of a different nature. The spine does not possess anything like the elasticity of the rod. In fact, it is built so as to dissipate any violence applied to it. It possesses nevertheless a certain degree of elasticity, and the transmission of violence through it is practically analogous to the transmission through a curved rod.

What has happened in the above experiment? As the rod was dropped from a short distance, the end which struek the ground was compressed. The elasticity of the rod determines its powers of recovery. The recovery is as sudden as the compression. This recovery or rarefaction spreads up and down the rod. The down-going wave reaches the ground, and expends its energy in making the rod rebound off the ground. The up-going wave, preceded by a wave of condensation, meets the down-coming upper end of the rod, and so the compression is augmented. Recovery is correspondingly augmented, and so it comes about that the greater the height dropped, the greater in degree are the waves of condensation and rarefaction, and consequently the greater the rebound. The 
fracture point is reached when the speed of the travelling body is greater than the speed of the transmission of the waves of condensation and rarefaction. That is to say, there is a summation or a crushing together of these waves to such an extent that the whole rod, or the whole spinal column, as the case may be, is in a state of compression strain.

The incidence of this strain is, of course, most marked in the concavity of the curves, and accordingly might be looked upon as a fracture due to flexion beyond the anatomical limits. It is, however, a fracture due to compression, and usually occurs in the upper lumbar region towards the anterior aspect of the body of a vertebra (first or second). This is in the line of the violence, or, in other words, in the line of the centre of gravity. $^{1}$ (See Fig. 2.)

If the height from which the body dropped were sufficiently great, it is possible that a shearing strain might be set up, and the fracture occur as the result of one part of the spine being driven "past" the other part.

Fall of a weight on the back. - This is a much more complicated study than the foregoing. It is taken as being a common type of spinal injury. The exact attitude of the man at the time of the

${ }^{1}$ It should be noted here that the ligaments of the spine are not necessarily strained in this form of spinal injury. 
accident is the most important determining factor of the lesion, or, in other words, the counter force determines the nature of the injury.

The man may be standing erect, and if his feet are free and the road clear, he may merely be knocked forwards and thus escape a gross spinal injury. He may be standing with his legs apart, and his back bent forwards to its fullest extent. A weight falling upon his back might then easily carry with it the upper portion of his spine, the upper part of his back being "driven past" the lower half. Usually the ligaments in front of, as well as behind, the spine are torn in this lesion, before the dislocation can occur. This is an example of shearing stress, and produces the worst of all spinal injuries-a fracture dislocation. The spinal cord gets nipped between the lower edge of the neural arch of the upper vertebra, and the upper edge of the posterior part of the body of the lower vertebra.

If the man happened to be in the sitting posture at the time of the accident, it is evident that his hip joints and spine, being already nearly fully flexed, could not be further flexed, and that a weight falling now upon his back would tend to flex his spine beyond its anatomical limits. The posterior ligaments are overstretched, and may or may not give way. His spine would be liable therefore to fracture from excessive flexion. 
It is important to note the difference between this and the fracture dislocation, because the prognosis is so totally different. Here the spinal cord is not as a rule grossly injured, and, accordingly, permanent paralysis is not produced. In fracture dislocation the paralysis is: (1) absolute; (2) annular; (3) immediate. That is to say, the paralysis is motor and sensory, and is complete. The anæsthesia and hyperæsthesia go horizontally round the trunk. All the signs and symptoms are present immediately after receipt of injury.

In fracture from compression or over-flexion there may be none of these symptoms or signs. If there is paralysis, it is not absolute; it may be sensory or only motor; or it may be that localised areas are anæsthetic or hyperæsthetic. The sensory paralysis, instead of being annular, follows the course and distribution of the intercostal nerves. The signs and symptoms vary in their time of onset after the accident.

It might be pointed out here that where the injury is below the level of the twelfth dorsal vertebra, the treatment and prognosis are entirely altered. The cauda equina, which begins here, is made up of structure analogous to that of peripheral nerves, and not to spinal cord fasciculi. Regeneration is therefore possible after accurate suture.

Localised blow on the back.-In the case of a 
weight falling on the back, and similarly in a fall from a height, the force continues to act after the impact. In a localised blow on the back we may have to deal either with a force which continues to act after impact, or a force which is of the nature of a short sharp shock.

As the prolonged form of violence has already been discussed, we will confine our attention to the sudden blow.

This is a comparatively uncommon cause of spinal injury, and when it does occur the site of the lesion corresponds with the site of impact; commonly called injury from "direct" violence. The spinal column is particularly well protected from such forms of violence, and if a lesion of bone does result, it usually only amounts to fracture of one or more of the long spinous processes. It may happen that a neural arch gives way, but this is comparatively rare.

\section{Intrinsic Violence}

By excessive or violent muscular action it is possible, and even common, to have an injury produced in the region of the back. The incidence of the lesion is commonest in muscle, uncommon in ligament, and rare in bone.

Muscle Injury.-The physics of muscle injury is a complicated problem, bcaring as it does on 
anatomical as well as on pysiological factors. Why is it that the muscles of the back are more liable to strain than the muscles elsewhere in the body? Why is it that some strains are associated with immediate pain, while others are not? Why does a strained back take so long to recover? These are questions which can only be answered by a thorough understanding of the physics of muscular structure and muscular action, combined with a knowledge of the anatomy and physiology of muscle.

The voluntary muscles of the limbs extend between two or more bones, like pieces of elastic. When they are in action they become shorter, thicker, and firmer, and thus the two points of attachment are approximated. Generally speaking, the attachment of the muscle to the more or less fixed bone is called its origin, while its attachment to the movable bone is called its insertion. The origin of a muscle is usually fairly extensive. This gives a greater strength of attachment. The insertion is usually small, and to make up for lack of area, this attachment is usually accomplished through a tendon. This is an inelastic structure composed of strong strands of fibrous tissue running longitudinally. These fibres appear almost to run right through the surface of the bone. If a section of bone is cut where a tendon of a strong muscle is inserted, the lamellæ of bone appear to be 
a direct continuation onwards of the fibres of the tendon. Here again we must recall what has been said on p. 134, that a weakness exists at the junction of an elastic with a non-elastic structure. The junction of muscle with fibrous tissue is always weak, and it is found that when a muscle ruptures it usually does so at the junction of the muscle with its tendon.

In the muscles of the limbs the junction of tendon and muscle is not abrupt. The fibres of the tendon continue onwards through the muscle, and gradually become lost in its substance. This gives great strength to the junction, and accounts for the relative infrequency of strain of any of the limb muscles. The physical arrangement of the attachment of the back muscles is different. Here there is no actual tendon. The muscles are not simple-acting only between two bones. The erector spina, for example, may be looked upon as a contractile mass of tissue attached to numerous bony processes and to numerous fascia (fibrous tissue). When it is thrown into action, all its numerous attachments tend to be approximated to one another.

The multiplicity of attachment niakes it unnecessary that each individual attachment be as strong as that required in the muscles of the limbs. The muscle seems to be "tacked on" or to grow out in little tufts from the bony points and fibrous 
tissue to which it is attached. In rising from the stooping posture, the approximation of all the points of attachment is gradual, and so the movement is carried out harmoniously.

In lifting weights, on the other hand, a certain portion of the muscle (lumbar) has a greater strain put upon it than the remainder of the muscle. The little tufts are called upon to withstand a greater strain than is their due. They accordingly may give way, and the lesion constitutes one of the forms of "strained back." This form of strain is almost invariably associated with immediate pain. It will thus be seen that there is a very definite physical reason why the back muscles are particularly liable to suffer from excessive strain.

We will now consider the physiological disabilities to which the back is liable, and which very markedly predispose to strain. There are several physiological factors which predispose all voluntary muscle to strain.

Prolonged use of a muscle produces physiological tiredness of the muscle, and renders it more easily strained. It is for this reason that a miner usually sustains this form of injury towards the end of his shift. Deficiency in the quantity or quality of the blood supplied to a muscle renders it more easily tired and more readily strained. 
There is another physiological fuetor which predisposes the back to strain, and which seldom exists in any other group of voluntary nuseles, viz. prolonged overstretehing of the muscles. Everyone is familiar with the difficulty in straightening the back after prolonged work in a stooping posture. The erecting museles have been overstretehed for such a time, that they have temporarily lost a considerable portion of their normal range of contractility. This loss in extent is associated with a corresponding loss in degree or power. This factor seems to aceount for the relatively high proportion of strained backs oceurring in coal miners, who have to work, often for hours at a stretch, in the bent position.

'There are two distinct types of intrinsic muscle injury. The ordinary sudden strain is the one we are particularly concerned with. This might be called the physical strain, produeing an actual tearing of some of the muscle fibres or associated structures.

The other type is the physiological strain, in which there is no real accident, but rather an over-use of the muscle so far as tissue is concerned. This may go so far as to produce petechial hæmorrhages in the region of the muscles so overused.

Most of us have experienced this type of muscle injury. A hard day's tennis after long absence 
from the game is not associated with pain, and not even usually associated with a feeling of tiredness in the muscles. Next day, however, or perhaps the day affter that again, there is pain on movement, stiffness and discomfort, and even discolouration over the deltoid and half of the upper arm, characteristic of effusion of blood in the subcutaneous tissues.

Recovery from this is usually so rapid that we may leave it out of consideration in dealing with back injuries as met with by the medical examiner.

Relative to any action there are two sets of muscles employed-an active group, and an opposing group. Either of these may be strained, but the method of production of the strain is widely different in the two cases. A simple experiment has been already referred to on page 14 which demonstrates the complex phenomena associated with a simple muscular action involving the operation of two opposing groups of muscles. If the one set of muscles is suddenly called into action it may give way, or if the opposing group of muscles is suddenly and unexpectedly called upon to stop that action, such opposing muscles or one of them may give way.

This is the same all over the voluntary musculature of the body, and may account for the varying descriptions given by different writers on 
the subject of loss of equilibrium in certain brain lesions. The possessor of a cerebellar tumour is said by some to fall to the side of the lesion, by others to the side away from the lesion. It seems reasonable to suppose that he does actually tend to fall to the side of the lesion, and that an overcorrection may make him actually fall towards the other side.

We are dealing with strains, however, and for us the fact that nature usually overdoes it when attempting to stop a sudden movement is sufficient.

We have seen how, even when the volition is prepared for such sudden stoppage, the opposing muscles are overtaxed. When the stoppage has to be done, and the volition is unprepared, the overtaxing of the opposing group is much greater.

If anyone is lifting a heavy weight, it may be quite within his power to do so without straining the acting group of muscles, but if the rope breaks, or the grip suddenly slips, the opposing group will almost certainly be overtaxed, and will be very liable to be strained. The strains which we have to deal with are usually caused by lifting heavy weights. If the strain occurs during the performance of the lift, it is the "acting" muscles which are situated behind the spinal column which will be strained. If the grip gives way, and there is thus a sudden and unexpected calling into play of the "oppos- 
ing" group of muscles, this opposing group (in front of the spinal column) may be strained.

Liganent InJuRy.-CThere are two kinds of ligaments met with in the spinal column.

(1) The ligamentu subflava, which are possessed of elastic fibres. These extend between the neural arches of the vertebre, and so complete the tumnel for the transmission of the spinal cord. They allow of bending of the spine and straightening, without any slack such as must exist in the case of ordinary ligaments. They possess no inherent power of contractility, and cannot, therefore, be subjected to intrinsic strain, whilst their elasticity protects them from extrinsic strain. They are therefore never strained per se.

(2) The ordinary ligaments about the spinal joints are composed of non-elastic fibrous tissue. They are accordingly never the seat of an intrinsic strain. They may be subjected to extrinsic strain, but this is not common. On account of their inelasticity, they possess an amount of slack corresponding with the range of movement available in the joints which they surround.

When a joint is flexed to its fullest extent, the ligaments on the flexor aspect have a considerable slack which is thrown into concertina-like folds. The ligaments on the extensor aspect are stretched to their fullest, and in fact it is usually these ligaments which limit further flexion. When a 
joint is extended to its fullest degree, the extensor ligaments are crumpled up and the flexor ligaments stretched.

It will be seen, then, that the ligaments about a joint are never in a state of tension or strain, except when the limit of movement is reached. Strain of ligament can therefore only occur when the normal range of movement has been exceeded. The ligament strained is situated on the convexity of the point of flexion, and pain is produced whenever it is put upon the stretch or otherwise pressed upon. A characteristic attitude is accordingly adopted in which the strained ligament is relaxed.

Strain of ligament is met with in the cervical and lumbar segments of the spine (the movable regions). From the nature of its production it almost invariably extends over several intervertebral articulations. If the bending is sudden, the ligaments on the convexity usually resist, and if the violence is sufficiently great, its incidence is on the bodies of the vertebrse in the concavity of the curve, and a "compression" fracture may be produced. The history in a case of strained ligaments of the spine is, therefore, usually one of a comparatively slow but excessive bending.

Bone InJury.-It is possible for bone or joint injury to occur from intrinsic violence, but in such cases the violence is always of the nature of a jerk. That is to say, muscular violence as 
caused by the lifting of a weight cannot possibly produce a fracture or a dislocation. The incidence of such strain is of necessity on the muscle itself. It is even inconceivable, also, that from a calculated muscular exertion, injury to ligaments can result.

It is different, however, in the case of a sudden and unexpected jerk. This may produce, (1) injury to the opposing group of muscles, (2) to the ligaments either on the acting or opposing side of the joint, (3) to bone or joint at the junction of a fixed with a movable portion of the spine-usually the cervico-dorsal junction. This is the region of the spine which corresponds with the junction of the thong with the shaft of a whip, and which is strong enough where moderately fast movement is concerned, but mechanically weak to resist sudden or jerky movement.

Attention has already been called to the arrangement of the articular facets in the cervical region (page 9).

In the normal position these facets are opposed to one another, just as two coins might lie one on the top of the other. The ligaments surrounding the joints are attached to the edges of the facets, and are of course sufficiently loose to allow of the facets gliding past one another. As the neck is bent, the facets slide over one another, so that there is less of their surfaces in contact. 
A point is reached where the capsular ligaments are overstretched, and if the forced bending continues to act, they may give way and allow of a dislocation. So loose are some of these ligaments, that it is conceivable that the facets might actually slide past one another without actual rupture.

It should be noted that when the neek is moved in any but the absolutely antero-posterior plane, the articular surfaces slide upon one another in an oblique fashion. The upper facet on one side of the vertebra goes upwards and forwards, while its fellow on the other side goes

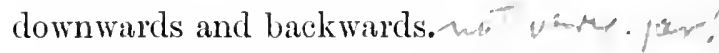

Although the cervico-dorsal junction is the most likely site of injury where the violence is intrinsic, it is not the only possible site. The case of the man who suddenly turned his head to speak to a friend (page 10) and dislocated his third eervical joint, may be recalled. 


\section{A P PEN DIX}

Concussion of Cord-

Temporary retention of urine; transient loss of power; numbness; recovery gradual.

\section{Railway Spine-}

Usually no actual mechanical damage; days or weeks between receipt of injury and onset of symptoms; general character of symptoms, irritability, defective memory, general weakness; no changes in deep reflexes; no clinical signs to be elicited; if litigation long, patient develops such signs as loss of weight, anxious facies, \&c.; recovery rapid after litigation finished.

Hematorrachis (Extra-medullary Hamorriage)- Some time between receipt of injury and onset of symptoms; cramps, jerking of muscles, and racliating pains while hæmorrhage is increasing (irritation); gradual onset of paralysis as pressure from hæmorrhage rises; recovery gradual.

Hematomyelia (Intra-medullary Hemorrhage)Symptoms immediate and dependent upon site and extent of hemorrhage; motor and sensory paralysis; if hæmorrhage slight, recovery rapid, sensation restored before motion ; if hæmorrhage 161 
extensive, paralysis more or less permanent corresponding with the site of the lesion; paralysis of distant parts may be transient if due to pressure on tracts; paralysis corresponding with site of lesion may be permanent, due to damage to nerve cells.

\section{Spinal Spraix-}

Due only to bending of spine beyond anatomical limits; symptoms immediate and same as sprain elsewhere; at first, pain on all movements, later, pain on active and passive movements which cause stretching of the injured ligament; tenderness almost absent.

\section{Fracture (Simple) -}

May give rise to almost no symptom beyond pain and stiffness in the back.

\section{Fracture, with Contusion of Cord-}

If there is contusion of the cord as the result of a fracture, there will be motor and sensory paralysis; paralysis is rarely immediate, never complete and annular of motion and sensation; recovery gradual and often complete.

Fracture-Dislocation, witi Cuttixg of CordSymptoms and signs immediate; sensory and motor paralysis complete and annular ; recovery is practically impossible if lesion is in cervical or dorsal region; if below 12 th dorsal prognosis is different, because cauda equina, which begins here, is made up of essentially peripheral nerve and not of spinal cord fasciculi. 


\section{Fracture Dislocations (complete)}

Sensory and motor paralysis immediate, annular, and complete below level of lesion. Later symptoms, tendon reflexes lost, painful jerking of limbs, muscles become rigid, cystitis and trophic sores develop.

Above 4th Cervicat-

Rapidly fatal; phrenics damaged.

4tin Cervical to 1st Dorsal-

All limbs paralysed. Sensation lost below level of second rib, hiccough, priapism, slow pulse, glycosuria, small pupil, and anidrosis (sympathetic).

6th Cervical-

Chäracteristic attitude, upper arm abducted and rotated out, elbow sharply flexed, fingers flexed, sensation retained on radial side of forearm.

\section{1st Dorsal-}

Same as above, but arms lie across belly instead of chest.

\section{All Dorsal-}

Anæsthesia runs horizontally round, and does not follow intercostals; zone of hyperesthesia with girdle pain; patient unable to cough, so mucus gathers in throat, unable to pass flatus, so meteorism results; micturition performed without patient being aware of the act if arc is intact, but when arc is not intact there is dribbling from overflow of the over-distended and paralysed bladder. 
LuMBO-SACRAL-

Incontinence of freces; the caula equina is below level of first lumbar, so that anterior crural, obturator and superior gluteal escape; paralysis of all other muscles below lesion.

\section{Reflexes}

It is a common experience in Court to have considerable controversy as to the state of certain reflexes. A consideration of the nature of a reflex, and how it is elicited, may therefore, however brief, be of some value.

A reflex act is a movement which is performed as the result of the application of some external stinulus, and without the intervention of the patient's will. The purest form of reflex is seen in the case of reflex micturition in certain spinal injuries, where the bladder fills normally, and when full sends a message up to the centre for micturition. The act of emptying the blarkler occurs withont the patient being even aware of the performance.

The ordinary reflex arc comprises the afferent nerve, the anterior horn of the cord, the efferent nerve, and the muxcle. When the function of any of these is lost, the chain is broken and any attempt to elicit the reflex will fail.

Besides this complicated internal mechanism, which is not fully understood, there are two factor's which have a very decided infuence on the nature of the reflex if present. The intervention of the patient's will power has a marked influence on the result, and it is of ten necessary to distract his attention from the performance. The condition of the muscle as to its 
state of relaxation is the other factor which modifies the result.

Bearing these in mind, it will be evident how the result of the test may vary according to the method by which the reflex is elicited, the state of the patient's mind, and the degree of relaxation of his muscles at the time of examination. Notwithstanding these fairly wide discrepancies in the "degree" of any reflex response, we can learn a great deal from the presence or absence of any reflex, and can even, in however wide terms, say if the response is diminished or exaggerated.

Superficial Reflexes.-In these, stimulation of skin produces muscular reaction.

Plantar Reflex.-In order to elicit this reflex properly, the patient's attention should be distracted, and his leg muscles fully relaxed. This may be attained by getting him to perform some movement with his hand which engages his attention. He should be lying on his back with the hip semi-flexed and the knee rotated outwards and resting on some support. The foot should be warm and dry. The plantar region is stimulated by scratching with the finger-nail. Ordinarily, the reflex response is a plantar flexing of the toes.

Babinski has pointed out that in lesions of the pyramidal system there is an alteration in the response whereby the toes are dorsi-flexed, especially the great toe. Babinski's toe reflex is normal in childhood, and may be frequently elicited in healthy persons during unconsciousness (sleep and anæsthesia). It may also be elicited in cases of acute alcoholism.

A table of the superficial reflexes with the corresponding levels of the cord concerned is on next page. 


\section{Superficial Reflexes}

\begin{tabular}{|c|c|c|c|}
\hline REFLEX. & METHOD. & RESULT. & $\begin{array}{c}\text { CORD } \\
\text { SEGMENT. }\end{array}$ \\
\hline PLANTAR & $\begin{array}{l}\text { Stroking sole } \\
\text { of foot with } \\
\text { finger nail. }\end{array}$ & $\begin{array}{c}\text { Flexion of } \\
\text { toes (dorsal } \\
\text { or plantar). }\end{array}$ & $\begin{array}{l}\text { Lower part of } \\
\text { lumbar en- } \\
\text { largement } \\
\text { (dorso-lum- } \\
\text { bar region). }\end{array}$ \\
\hline GLUTEAL & $\begin{array}{l}\text { Vertical strok- } \\
\text { ing of but- } \\
\text { tock. }\end{array}$ & $\begin{array}{c}\text { Contraction } \\
\text { of glutei } \\
\text { muscles. }\end{array}$ & $\begin{array}{l}\text { 4th and 5th } \\
\text { lumbar } \\
\text { nerves. }\end{array}$ \\
\hline CREMASTERIC & $\begin{array}{l}\text { Stroking up- } \\
\text { per in ner } \\
\text { part of thigh. }\end{array}$ & $\begin{array}{l}\text { Retraction of } \\
\text { testicle. }\end{array}$ & $\begin{array}{l}\text { 1st and 2nd } \\
\text { lumbar } \\
\text { nerves. }\end{array}$ \\
\hline ABDONINAL & $\begin{array}{l}\text { Stroking side } \\
\text { of abdomen. }\end{array}$ & $\begin{array}{c}\text { Contraction } \\
\text { of rectus. }\end{array}$ & $\begin{array}{l}\text { Sth to } 12 \text { th } \\
\text { dorsal. }\end{array}$ \\
\hline SCAPULAR & $\begin{array}{c}\text { Stroking the } \\
\text { interscapu- } \\
\text { lar region. }\end{array}$ & $\begin{array}{l}\text { Contraction } \\
\text { of posterior } \\
\text { fold of axilla. }\end{array}$ & $\begin{array}{l}\text { 5th cervical } \\
\text { to } 1 \text { st } \\
\text { dorsal. }\end{array}$ \\
\hline EPIGASTRIC & $\begin{array}{l}\text { Stroking side } \\
\text { of chest } \\
\text { downwards } \\
\text { from nipple. }\end{array}$ & $\begin{array}{l}\text { Drawing in of } \\
\text { epigastrium. }\end{array}$ & $\begin{array}{l}\text { 4th to } 7 \text { th } \\
\text { dorsal. }\end{array}$ \\
\hline
\end{tabular}

Deep or Tendon Reflexes.-In these a muscular contraction is produced by suddenly striking a sharp blow upon the tendon of the muscle. The responsive contraction (of which the knee-jerk is the most familiar example) occur's so instantaneously, that it is questionable if it is really of the nature of a reflex act. 
Whether or not it is due to the tonicity of the muscle, the fact remains that the degree of responsive contraction depends to a large extent upon the condition of the upper (cranial) motor neuron, and of the lower (spinal) motor neuron.

Roughly speaking, the tendon reflexes are exaggerated where the restraining influence of the upper motor neuron on the lower motor neuron is disturbed, or where there is some factor at work producing irritation of the lower motor neuron. The reflexes are diminished or lost where the lower motor neuron is totally or partially destroyed, or where its influence is otherwise in abeyance.

The degree of exaggeration or diminution in the responsive contraction is always a matter of opinion, because so many factors have to be taken into consideration during its elicitation. A more vigorous response is always obtained when (1) the patient's attention is distracted, (2) the patient is performing some work with some distant muscles, (3) the muscle itself is put upon the stretch. This is known as reinforcement.

A diminution in the response is observed when the converse of any or all of these conditions obtains.

ANkle Clovus. - When a patient's knee is slightly bent, and a sudden, firm, and continued pressure is applied to the fore part of the sole of the foot, a series of clonic contractions at the ankle joint, occurring about six to nine times per second, may result. This is known as ankle clonus. A similar series of contractions may be produced in the quadriceps by dragging the patella lownwards ; this is known as knee or patellar clonus.

In general, it may be said that ankle clonus may be present where the knee-jerk is exaggerated. It is 
most marked in disseminated sclerosis. It may be present during excitement or when the limb is tired. It is often present even in functional paralysis, but it should be noted that, where the paralysis is organic, the clonus is not obtained until the ankle joint is bent to or beyond a right angle, whereas in other conditions it may commence before the right angle is reached.

\section{Deep or Tendon Reflexes}

\begin{tabular}{|c|c|c|c|}
\hline REFLEX. & METHOD. & RESULT. & $\begin{array}{c}\text { CORD } \\
\text { SEGMENT. }\end{array}$ \\
\hline KNEL-JERK & $\begin{array}{l}\text { Tapping lig- } \\
\text { amentum } \\
\text { patellax. }\end{array}$ & $\begin{array}{l}\text { Sudden ex- } \\
\text { tension of } \\
\text { leg. }\end{array}$ & $\begin{array}{l}\text { 2nd and } 3 r d \\
\text { lumbar. }\end{array}$ \\
\hline $\begin{array}{l}\text { AYKLE } \\
\text { CLONUS }\end{array}$ & $\begin{array}{l}\text { Sudden pro- } \\
\text { longed pres- } \\
\text { sure on sole } \\
\text { of foot. }\end{array}$ & $\begin{array}{l}\text { Rhythmic con- } \\
\text { tractions of } \\
\text { calf muscles. }\end{array}$ & $\begin{array}{l}\text { 1st and } 2 \text { nd } \\
\text { sacral. }\end{array}$ \\
\hline ELBOW-JEIR & $\begin{array}{l}\text { Tapping in- } \\
\text { sertion of } \\
\text { triceps or } \\
\text { biceps. }\end{array}$ & $\begin{array}{l}\text { Cuntraction of } \\
\text { triceps or } \\
\text { biceps. }\end{array}$ & $\begin{array}{l}\text { 5th to } 7 \text { th } \\
\text { cervical. }\end{array}$ \\
\hline
\end{tabular}

Organic Reflexes.-So far as we are concerned, these refer to the bowel and bladder sphincters which are so often paralysed in lesions of the cord. 


\section{N D E X}

A

Abdominal reflex, 166

Acting $v$. opposing muscles, $14,38,155$

Adhesions in back injuries, 80

Alimentary toxins, 81

Anæsthesia in fractures, 149

Ankle-clonus, 167

Appendix, 161

Articular facets, 8-11, 159; processes, $4,9,116$

Asymmetry, 93, 111

Atrophy of bone, 90, 91

Attitude in accidents, $54,95-$ 97,158

B

Babinski's sign, 165

Bacterial infection, $73,80,81$

Blood pressure in pain, 69,70

Blue flannel belt, 77, 83

Boarding of muscles, 96, 101, 102

Bodies of vertebræ, 2

Bone, injuly to, $158-160$; pain in, 87

Buttocks, fall on, 60, 145

\section{C}

Capsular ligaments, 8, 10, 160

Canda equina, 149

Cervical dislocation, 10, 160 ; region, $9,12,118,159$; vertebræ, $9,10,44,113$

Cervical region-movements, 9 ,
11 ; strength of, 137 ; X-ray examination of, 113

Cervico-dorsal region, strength of, 12,160 ; X-ray of, 114

Cesspool, septic, 76

Complaint, 58

Compression, force, 142 ; fracture, $6,147,149,158$; strain, 143 ; stress, 144,147

Concomitants of pain, 69

Concussion of cord, 161

Condensation wave (force), $142,145,146$

Condensers, electrical testing, 60,128

Constrictions, wcakness of, 136

Contraction remainder, 40

Contributory negligence, $5 \tilde{5}$

Contusion of muscles, 41

Cord, spinal, 1, 53, 148, 149

Counter force, 143,145

Cremasteric reflex, 166

Curves of spine, $5,93,133$; children, $\tilde{5}, 98$; disappearance of, 98; dorsal, 104 ; exaggeration of, 99 ; hysterical, 94 ; lumbar, 99 ; postural, 94 ; senile, 98 ; weakness at junction of, 133

\section{D}

Deep reflexes, 166

Deformity of spine, 97,98 , 192,111

Demeanour of claimants, 48

Devitalisation of muscle, 74 
Dietetic errors in pain, 81

Direct violence, 140, 143

Discs, intervertebral, $2,3,16$, 114,117

Dislocation, cervical, 10, 160 ; fracture, 148, 162, 163

Dorsal region, dises, 5 ; movements, 104,105, 109 ; strength of, 7,136 ; X-ray examination, 11 j

Dorso-lumbar region, movements, 108 ; strength, 12

Dynamics of spine, $139 \mathrm{ct}$ seq.

\section{$\mathrm{E}$}

Effusion in muscle injury, 78 , 82,85

Elasticity, force, 142, 145

Elbow jerk, 168

Electrical testing, 60, 83, 123 et seq.

Endomysium, 31

Epigastric reflex, 166

Epinysium, 32

Epiphyses of fifth lumbar, 120

Equilibrium, loss of, 156

Erector spina (sacro-spinalis), $19,30,93,125$

Examination, 48

Extensors of spine, 13, 18 et seq., 99

Extrinsic violence, 139 et seq.

\section{li}

Facts on examination, 92

Fæcal masses and X-rays, 116

Fall of weight on back, $14 i$

Fall on buttocks, 60,145

Faradic current, 124, 130

Fascia of back, $27 \mathrm{et} s \mathrm{~s}$.

Fasciculus of muscle, 32

Fibrillary twitchings, 41

Fibrous nodules, 101

Fifth lumbar vertebra, 49 et seq. ; 118, 120-138

Flexion of spine, 16, 105 et scq.; lateral, 109, 111 ; stress, 144
Flexors of spine, 13, 15 et seq., 26

Force, qualities of, 141,142

Fracture, compression, 6, 112, $14 \pi, 149,158$; dislocation, $148,149,162,163$; frequency of, 138 ; marching, 36 ; pain of, 87 ; simple, 162 ; with contusion of cord, 162

\section{G}

Galvanic current, 124, 130

Gluteal reflex, 166

Guy-rope and muscle action, 32

\section{$\mathrm{H}$}

Hæmatomyelia (intra-medullary), 161

Hæmatorrachis (extra-medullary), 161

Hæmorrhage, petechial, 154

Hamstring muscles, 17

Healing of muscle, 42,78

Heart and $\mathrm{X}$-ray examination, 115. 123

History of injury, 53

$\mathrm{H}$ yoid bone and $\mathrm{X}$-rays, 114

Hyperesthesia in fracture, 149 Hyperexcitability in muscle, 126,128

Hypoexcitability 126, 128

Hysterical boarding of muscle, 102 ; curvature, 94

I

1 liocostalis cervicis, 21 ; dorsi, 21 ; lumborum, 20

Impressed force, 9, 143, 145

Indirect violence, 140, 143

Insertion of muscle, 31, 151

Inspection, 93 et seq.

Intercostal muscles, 24

Interlaminous spaces, 117

Interspinalis, 24

Intertransversarii, 25 
Intervertebral discs, 2, 3, 16, 114,117

Intrinsic violence, 150 et seq.

\section{J}

Jarring of spine, $3,6,87$

Jones, Dr., on electric testing, 124,129

Junctions, weakness of, 133 et seq.

\section{K}

Knee-jerk, 168

Knees, in lumbar flexion, 17, 105

\section{L}

Laminæ of vertebra, 4, 9,1]4, 121

Lateral curvature, 93, 94, 103, 109 ; flexors, 24, 25

Latissimus dorsi, 25, 47

Ligaments of spine, $4,8,147$, 157 ; capsular, 8,157 ; injury of, 148,157 ; pain in, 83,84 ; strain of, $35,147,158$; subflava, 4,157

Lipomata after injury, 103

Longissimus capitis, 22 ; cervicis, 22 ; dorsi, 21

Lordosis, 99

Lumbago, 72

Lumbar curve, 99 ; fifth vertebra, $49,57,117,119$; region. $12,15,18,19,45,109,116$

Lumbo-dorsal fascia, 28 ; sacral region, 118

\section{MI}

Malignant disease and rigidity, 102

Massage, in back injuries, 82

Measurements, $106 \mathrm{et} \mathrm{seq.}$

Momentum of force, 142, 145

Movements of spine, 18,86 , 104 et seq.
Multifidus muscle, 23

Muscle, contusion of, 41 ; devitalisation of, 74 ; healing of, 42 ; fibres, 31 ; fibre bundle, 32 ; injury, 150 ; rupture, 37,152 ; strain, 13 , 15 , 34,39 ; stress, 34,39 ; tiredness, $40,54,153,155$

Muscles, acting, 14, 38, 155 ; extensors, 13, 18 et seq.; flexors, $13,15,26$; opposing, $14,38,155$; rotators, 25

Muscular tissue in general, 31

Myosilis ossificans, 42, 102

$$
\text { N }
$$

Nerve receptors in muscle, 71 Neural arches, 1, 2, 3, 114, 121, 148,150

Neurasthenia, boarding in, 102 ; sexual, 90 ; weakness in, 89

\section{O}

Opposing groups of muscles, $14,38,155,159$

Origin of muscle, 31,151

Osteo-arthritis, 102

Osteo-porosis, !1

Overstretching of muscle, 154

\section{$\mathrm{P}$}

Pain, 63 et seq., 82; concomitants of, 64,69 ; bone, 87 ; girdle, 67; ligament, 83; local, 66,68 ; muscle, 52,71 ; pressure, 68,69 ; referred, 66 et seq. ; varieties, 65

Palpation, 100 et seq.

Paralysis in backinjurics, 149 , 162,163

Pedestal, sacral, 7, 121

Pedicles of vertebræ, 4

Pelvis line in measurements, 17, 104 et se\%.

Perspiration from pain, 70

Photographs of back, 17, 104 
Physics of back injuries, 133 et ser.

Physiological factors, 153

Plantar reflex, 165

Posture in accident, 54, 117, 148,153

Pressure, effects of, 68, 69

Processes of spine, 4, 5, 8

Protective gestures, 70, 95

Psoas muscle, 16, 116

Pulse, in pain, 69, 71

Pupil dilatation in pain, 69, 71

Q

Quadratus lumborum, 23, 47

$\mathrm{R}$

Railway spine, 161

Rarefaction wave, 142

Reaction of degeneration (R.D.), 60, 61, 131

Rectus abdominis, 16

Reflexes, 164 ct seq. ; deep, 166 ; organic, 168 ; superficial, 165

Report, written, 53, 64, 92

Rest in back injuries, 76,79 , 82

Rheumatoid affections oî spine, 6,98

Ribs, 45

Rib-hump, 93

Right angular position, 18, 104, 105

Rigidity of spinal muscles, $96,9 \overline{7}, 102$

Rotation of spine, 11, 12, 93, $100,109,110$

Rotators of spine, $\mathbf{2 3 ,} 25$

Rupture of muscle, $37,39,152$

\section{$\mathrm{S}$}

Sacro-iliac joints and $\mathrm{X}$-rays, 121

Sacro-spinalis (erector spinæ), 10 et seq., 47
Sacrum, 35

Sarcolemma, 31

Scapula, winged, 95

Scapular reflex, 166

Scar in muscle wound, 78

Scoliosis, 93

Screen examination, 122

Semispinalis, 23

Sepsis in back injuries, 73 ct seq.; 80, 81

Serrati josteriores, 24

Serratus magnus, 95

Shearing stress, 144, 148

Shift, weakness at end of, 40 , 54,153

Skin, in muscle injury, 71,94

Smallpox, back pain in, $\pi 2$

Spinal column, 1 et seq.; cord, $1,53,148,149,163,166$, 168 ; joints, 85 ; sprain, 162

Spinalis cervicis, $\mathbf{2 3}$; dorsi, 22

Spinous processes, $2,5,44,114$, 117,150

Sprain, 35 ; spinal, 162

Stiffness in back injuries, 89

Strain of muscle, $13,15,30,34$, et ser., $72,76,77,140$; ligament, 35 ; mechanical hindrance in, 78 ; toxic factors in, 80

Strained or racked back, 49, 153

Strength of spinal column, 8, 134 ; of adjacent mobility, 136

Stress of muscle, 15, 30, 34, 39,140

Stretching, effects on pain, 68 Subflava, ligamenta, 4,157

Surface anatomy, 43

Syphilitic pain, 87

\section{$\mathrm{T}$}

Tenderness, $63,70,72,831$

Tendon, 30, 31, 151 ; reflexes, $166^{\circ}$

Tiredness of muscle, 36,40 , 153 
Tone of muscle, 14, 33

Torsion stress, 144

Toxins in back injuries, 73,80 , 81

Transvorse processes, 8, 94, 115

Trapezius muscle, 46,95

Trauma $v$ toxins, 75

Treatment of back injuries, 82

Troplic cbanges in pain, 69

'Tubercular disease, 87, 102

\section{V}

Vaso-motor changes in pain, 69

Velocity in force, 142

Vertebræ, body, 1, 2; intervertebral discs, 2, 3; neural arches, 4 ; processes, 5

Violence, direct, 140,143 ; effects of, $62,142,143$; extrinsic, 139 et seq. ; indirect,
140, 143 ; intrinsic, $150 c t$ scq.; varieties, $7,40,54$, 139

\section{W}

Weather, effects on pain, 77

Weight-lifting, 27, 99, 153,156 Workmon's Compensation Act, 52

Weakness, 89 ; at junctions of curves, 133,134 ; constrictions, 136 ; elastic and nonelastic structures, 12, 30, 31, 135; two movements, 12, 135 ; middle of long bones, 135

\section{$\mathrm{X}$}

$\mathrm{X}$-ray examination, $10,37,50$, $58,62,91,108,112$; of cervical region, 113 ; cervicodorsal, 114; dorsal, 115 ; dorso-lumbar, 115 ; lumbar, 116; lumbo-dorsal, 118 


\section{Crozen Bio, Cloth, 96 Pages, 1s. 6d. net, inland postage, $4 d$.}

\section{A L I N G E R I N G AND ITS DETECIION}

UNDER TIE

WORKMEN'S COMPEASATION AND O'THER ACIS

BY

ARCHIBALI) McKENDRICK, F.R.C.S.E., \&c. SLRGEON IN CHARGE OF SURGICAL X-RAY DEPARTMENT, ROYAL INFIRMARY, EINEBURGH

\section{EXTRACTS FROM REVIEWS}

\section{BRITISH MEDICAL JOURNAL}

"This book is a valuable contribution to a difficult subject, and it may be recommended to those to whom it specially appeals, namely, judges and magistrates, members of the legal profession, and insurance societies. Medical men will also find it helpful in dealing with a class of cases which frequently presents many difficulties. We can cordially recommend this book."

\section{EDINBURGH}

E. \& S. LIVINGS'IONE, 15-17 'I'eniot Place 


\section{EXTRACTS FROM REVIEWS-continued}

\section{THE REVIEW (Insurance)}

"This we believe is the first separate volume to be devoted to this highly interesting subject, and we feel sure it will be welcomed by all who are struggling with the many problems surrounding the malingerer."

\section{$\operatorname{SCOTSMAN}$}

"The subject is treated in a thoroughly practical manner, and the book ought to be very helpful, particularly to judges, lawyers, insurance companies, medical men, and others who may be called upon to deal with compensation claims."

\section{NATIONAL INSURANCE GAZETTE}

"It is likely to be of service to approved societies and sick visitors in connection with the menace of malingering under the National Insurance Act."

\section{THE SCOTS LAW TIMES}

"The book is a model of clearness and lucidity, and will be of great service to those for whose use it is intended."

\section{LAW STUDENTS' JOURNAI,}

"It treats of the subject in a most interesting and satisfactory manner. The chapter on the electric testing of muscles and nerves is particularly well dealt with. We are sure that a careful perusal of its pages will be of great benefit to those for whom the work is intended."

\section{EDINBURGH}

E. \& S. LIVINGS'TONE, 15-17 'T'eviot Place 



\section{Date Due}

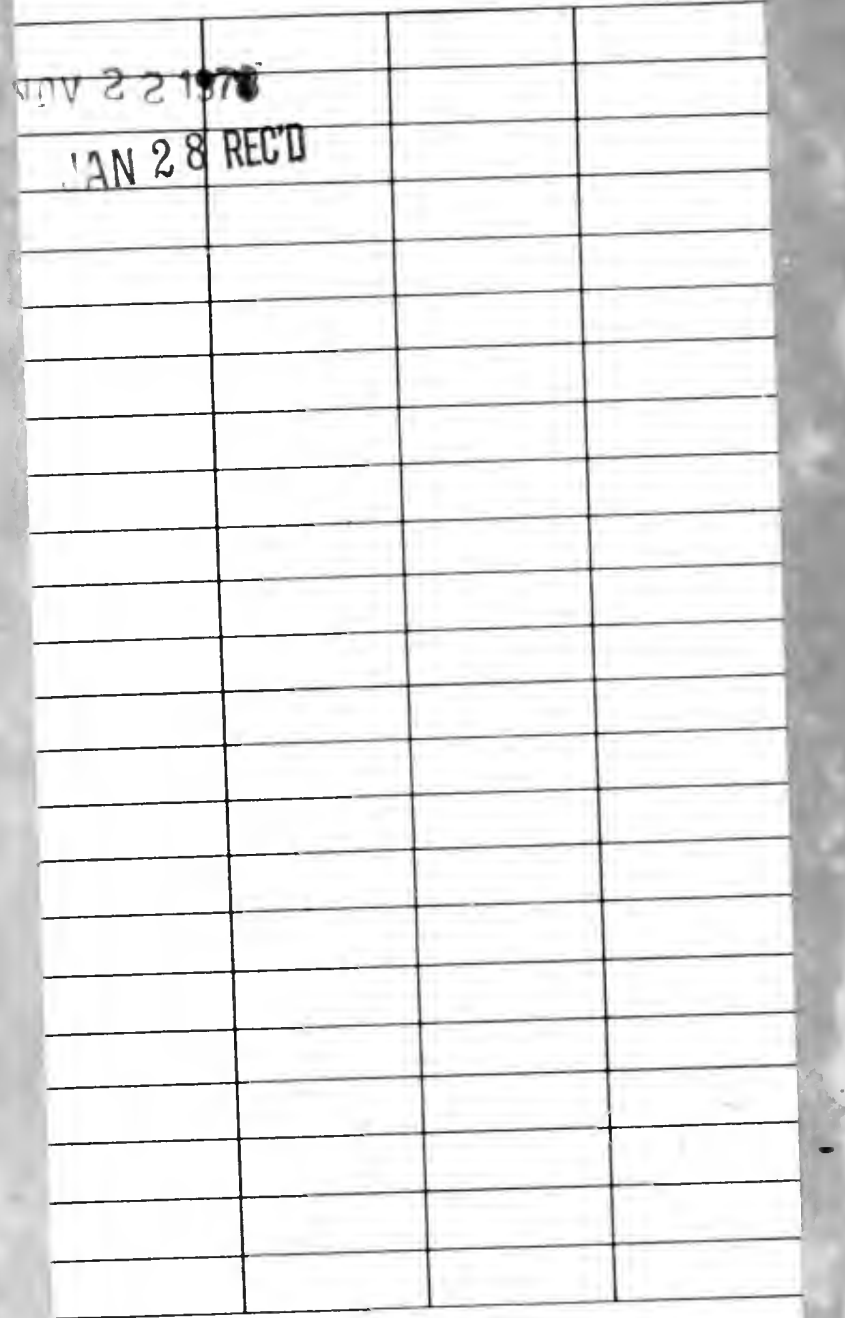

PRINTED IN U.s.A. CAT. NO. 24161 PAP 
UC SOUTHERN REGIONAL LIBRARY FACILITY

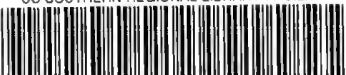

A $000421790 \quad 7$

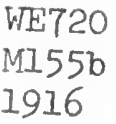

McKendrick, Archibald.

Back injuries...

\section{MEDICAL SCIENCES LIBRARY UNIVERSITY OF CALIFORNIA, IRVINE IRVINE, CALIFORNIA 92664}




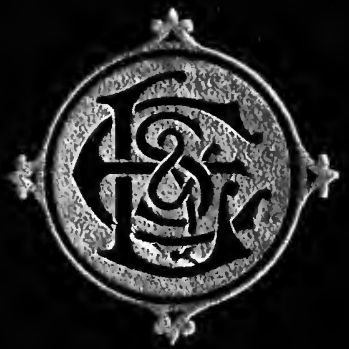

